\author{
UNIVERSIDADE DE SÃO PAULO \\ FACULDADE DE CIÊNCIAS FARMACÊUTICAS \\ Programa de Pós-Graduação em Fármaco e Medicamentos \\ Área de Produção e Controle Farmacêuticos
}

\title{
Estudos de biodisponibilidade e bioequivalência de medicamentos com alimentação: fundamentos \\ e critérios de execução
}

Pedro de Lima Filho

Dissertação para obtenção do grau de MESTRE

Orientadora:

Profa. Dra. Sílvia Storpirtis

São Paulo

2005 


\section{UNIVERSIDADE DE SÃO PAULO \\ FACULDADE DE CIÊNCIAS FARMACÊUTICAS \\ Programa de Pós-Graduação em Fármaco e Medicamentos Área de Produção e Controle Farmacêuticos}

\section{Estudos de biodisponibilidade e bioequivalência de medicamentos com alimentação: fundamentos e critérios de execução}

Pedro de Lima Filho

Dissertação para obtenção do grau de MESTRE

Orientadora:

Profa. Dra. Sílvia Storpirtis 


\section{DEDALUS - Acervo - CQ

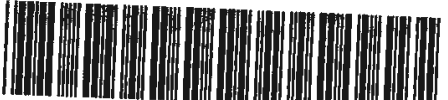 \\ 30100011094}

Ficha Catalográ fica

Elaborada pela Divisão de Biblioteca e

Documentação do Conjunto das Químicas da USP.

\footnotetext{
Lima Filho, Pedro de

L732e Estudos de biodisponibilidade e bioequivalência de medicamentos com alimentação: fundamentos e critérios de execução / Pedro de Lima Filho. -- São Paulo, 2005.

$125 \mathrm{p}$.

Dissertação (mestrado) - Faculdade de Ciências Farmacêuticas da Universidade de São Paulo. Departamento de Farmácia.

Orientador: Storpirtis, Silvia

1. Bioequivalência : Farmacocinética 2. Biofarmacotécnica 3. Biodisponibilidade : Farmacocinética 4. Medicamento genérico I. T. II. Storpirtis, Silvia, orientador
} 


\title{
PEDRO DE LIMA FILHO
}

Estudos de biodisponibilidade e bioequivalência de medicamentos com alimentação: fundamentos e critérios de execução

\author{
Comissão Julgadora \\ da
}

Dissertação para obtenção do grau de Mestre

Profa. Dra. Sílvia Storpirtis

orientadora/presidente

\author{
Prof. Dr. François Germain Noël \\ $1^{\circ}$. examinador
}

Prof. Dr. Humberto Gomes Ferraz

$2^{\circ}$. examinador

São Paulo, 16 de setembro de 2005. 
Aos meus pais,

Aldenora

e Pedro in memorian 


\section{AGRADECIMENTOS}

À vida.

À Profa. Dra. Sílvia Storpirtis, pela oportunidade concedida e pela orientação profissional e acadêmica sempre atenciosa, elegantemente severa e muitíssimo amiga.

Aos professores(as) da Faculdade de Ciências Farmacêuticas da USP, pelos valiosos conhecimentos transmitidos.

Aos colegas acadêmicos, pela harmoniosa convivência, troca de informações, ajuda e amizade.

Aos amigos da Unidade de Avaliação de Estudos de Bioequivalência da ANVISA [Angélica, Chang, Daniel, Edvaldo, Fabiano, Kyung, Isarita, Jéferson, Mônica, Nelson, Paula, Paulo Rogério, Paulo Vinícius, Patrícia, Regiane, Roberto e Solange], pela compreensão, companheirismo e colaboração para realização deste trabalho.

Às bibliotecárias Leila e Maria Luiza, pela revisão das referências bibliográficas e elaboração da ficha catalográfica e aos demais funcionários da Biblioteca do Conjunto das Químicas, pelo atendimento prestativo e atencioso.

Aos funcionários da Faculdade de Ciências Farmacêuticas da USP: Bete, Celi, Elaine, Jorge e Susy, pelo atendimento atencioso e de notável competência.

À amiga e colega Márcia Bueno, pelo companheirismo, colaboração com material de estudo e estímulo, úteis para a conclusão deste trabalho.

Aos meus irmãos, irmãs e demais familiares, pela confiança e imensa torcida.

Especialmente a Edmilson Lima (in memorian) e Antônio Lima, pela inesquecível e tão essencial ajuda inicial.

De forma muito especial e carinhosa, à minha mãe, Aldenora, por suportar a ausência e rezar pelo meu sucesso.

Aos amigos e amigas que me acompanharam, apoiaram, confiaram e, de variadas formas e em diversos momentos, ajudaram-me na realização deste trabalho. 


\section{RESUMO}

LIMA FILHO, P. Estudos de biodisponibilidade e bioequivalência de medicamentos com alimentação: fundamentos e critérios de execução. 2005. 125p. Dissertação de Mestrado - Faculdade de Ciências Farmacêuticas, Universidade de São Paulo, São Paulo, 2005.

A biodisponibilidade é definida pelos parâmetros de velocidade e extensão com que o fármaco atinge a circulação sistêmica a partir da forma farmacêutica, sendo uma propriedade não somente do fármaco, mas também da formulação, representando o desempenho in vivo da qualidade do medicamento. $\mathrm{O}$ medicamento genérico, para ser intercambiável com sua referência (geralmente o inovador registrado após comprovação de eficácia e segurança), deve ser considerado pelas autoridades regulatórias como seu equivalente terapêutico. A bioequivalência é o estudo comparativo das biodisponibilidades entre medicamentos, empregado para comprovação de equivalência terapêutica, baseada no princípio de que a similaridade dos perfis sanguíneos de concentração-tempo proporciona similares resultados quanto à eficácia e segurança. $\mathrm{O}$ presente trabalho compreendeu uma abordagem sobre os estudos de biodisponibilidade e bioequivalência com alimentação, com objetivo de sistematização dos fundamentos científicos e critérios normativos nacionais e internacionais, avaliação da necessidade e elaboração de diretrizes para condução destes estudos. Foi pesquisada a literatura científica sobre o tema, com ênfase nas publicações dos últimos dez anos, e também as diretrizes regulatórias nacionais e internacionais vigentes. Foram avaliados os efeitos do alimento na absorção gastrintestinal de fármacos, os fatores envolvidos na interação fármaco-alimento e os mecanismos físico-químicos e fisiológicos envolvidos. $\mathrm{O}$ alimento pode influenciar a absorção dos fármacos e promover aumento, retardo ou redução de absorção, devido a diferentes efeitos, por exemplo: prolongamento do tempo de esvaziamento gástrico, interação direta do fármaco com constituintes do alimento, aumento da viscosidade do conteúdo intestinal, alteração do $\mathrm{pH}$, aumento do fluxo sanguíneo esplâncnico e interação com transportadores. A interação fármaco-alimento pode resultar em alterações farmacocinéticas e farmacodinâmicas. $O$ efeito do alimento é mais significativo nas fases de absorção e metabolismo do fármaco, podendo resultar em perda de eficácia ou toxicidade. As interações fármaco-alimento são influenciadas pela natureza do alimento, constituição e quantidade da refeição, tempo entre alimentação e medicação e pela formulação. A refeição altamente gordurosa tem maior potencial de alteração da fisiologia gastrintestinal, principalmente aumentando o tempo de esvaziamento gástrico, o fluxo sanguíneo e a secreção biliar. Esses efeitos podem afetar significativamente a absorção de fármacos, sendo especialmente críticos para as formulações de liberação modificada. O efeito total do alimento na farmacocinética é resultante da interação de múltiplos efeitos relacionados ao fármaco, à formulação, à fisiologia gastrintestinal e à refeição. Devido à variabilidade e difícil previsibilidade dos efeitos do alimento sobre a velocidade e extensão de absorção dos fármacos, devem ser conduzidos estudos 
de efeito do alimento para novos fármacos e novas formulações. A pesquisa resultou na compilação das diretrizes para avaliação do efeito do alimento na biodisponibilidade, incluindo-se os desenhos dos estudos. É apresentado um esquema para avaliação da necessidade dos estudos de biodisponibilidade e bioequivalência, com base nas características do fármaco e nos tipos de formulações. As diretrizes para requerimento e condução dos estudos foram sistematizadas em uma proposta de guia para estudos de biodisponibilidade e bioequivalência com alimentação a ser empregado no caso de registro e alterações pós-registro para medicamentos novos, genéricos e similares no Brasil.

Palavras-chave: Biodisponibilidade. Bioequivalência. Biofarmacotécnica. Interação Fármaco-Alimento. Medicamentos Genéricos e Similares. 


\section{ABSTRACT}

LIMA FILHO, P. Bioavailability and bioequivalence studies of medicines with feeding: fundaments and execution criteria. 2005. 125p. Master's Degree Dissertation - Faculty of Pharmaceutical Sciences, São Paulo University, São Paulo, 2005.

Bioavailability is defined by rate and extension parameters with which the drug reaches the systemic circulation from its dosage form, being not only a property of such drug, but also of the formulation, representing the in vivo quality of the medicine. In order to be interchangeable with its reference drug (usually the innovative drug registered after efficacy and safety proof), the generic drug must be considered as its therapeutic equivalent. Bioequivalence is the comparative study between drugs' bioavailabilities, used for the proving of therapeutic equivalence, based on the principle that the similarity between blood concentration-time profiles generates similar efficacy and safety results. This work is a discussion about the food-effect bioavailability and fed bioequivalence studies, aiming at systematizing the scientific fundaments and national and international regulatory criteria, necessity evaluation and elaboration of de guidelines for studies execution. Research was done on scientific literature on the subject, with emphasis on publications over the last ten years, and also on current regulatory guidelines. The effects of food on the gastrointestinal absorption of the drugs, the factors related to the food-drug interaction and the physicalchemical and physiological mechanisms involved were evaluated. Food may influence the drug absorption and cause drug absorption increase, delay or reduction due to different factors, for example: gastric emptying time increase, direct drug interaction with food constituents, intestinal content viscosity increase, $\mathrm{pH}$ alterations, spleen blood flow increase and transporter interaction. The food-drug interaction may cause pharmacokinectic and pharmacodynamic alterations. Food's effect is most significant during the absorption and metabolic phases of the drug and may result in efficacy loss or toxicity. The food-drug interaction is influenced by the nature of the food, meal constitution and quantity, feeding and medication interval time and formulation. A high-fat meal has greater gastrointestinal physiology alteration potential, especially increasing the gastric emptying time, the blood flow and bile secretion. These effects may significantly impact the drugs' absorption being especially critical for the modified-release formulations. The total food effect on pharmacokinectic is the result of the interaction of multiple effects related to the drug, the formulation, the gastrointestinal physiology and the meal. Due to its variability and the difficulty to predict the effects of food on the rate and extension of drugs' absorption effect studies must be carried out for new drugs and new formulations. The research resulted in the compilation of the guidelines for the evaluation of food effects on bioavailability, including the studies' designs. A scheme is presented for the evaluation of the necessity of bioavailability and bioequivalence studies based on the drug's characteristics and the types of 
formulations. The guidelines for the requirement and conduction of the studies were systematized in a guide proposal for bioavailability and bioequivalence studies of medicines with feeding to be used in the case of registration, and postregistration changes for new, generic and similar drugs in Brazil.

Keywords: Bioavailability. Bioequivalence. Biopharmaceutics. Generic and Similar Medicines. Food-Drug Interaction. 


\section{LISTA DE FIGURAS}

Figura 1 - Exigência de estudo de bioequivalência com alimentação, segundo norma da ANVISA.

Figura 2 - Decisão para exigência de estudo de bioequivalência em jejum e/ou com alimentação, para composição da Lista-1 da ANVISA com formulações de liberação imediata...................................... 


\section{LISTA DE TABELAS}

Tabela 1 - Efeitos da interação da refeição na absorção de fármacos....... 51

Tabela 2 - Classificação dos fármacos pelo Sistema de Classificação Biofarmacêutica (SCB)

Tabela 3 - Interações fármaco-alimento conforme a classificação biofarmacêutica em formulações de liberação imediata

Tabela 4 - Efeitos na absorção do fármaco em função das alterações nas propriedades fisico-químicas.

Tabela 5 - Efeitos potenciais na absorção de fármacos em função de alterações na fisiologia gastrintestinal.

Tabela 6 - Interações fármaco-alimento de natureza físico-química e seus efeitos na absorção de fármacos.

Tabela 7 - Interações fármaco-alimento de natureza fisiológica e seus efeitos na absorção de fármacos.

Tabela 8 - Enzimas e transportadores envolvidos na disposição de fármacos em humanos.

Tabela 9 - Interações fármaco-alimento envolvendo enzimas e transportadores

Tabela 10 - Estudo comparativo sobre requerimento para estudos de bioequivalência sob efeito de alimento e/ou jejum, para medicamento genérico em diversos países

Tabela 11 - Dados de interação fármaco - alimento e forma de administração, disponíveis em literatura, incluindo sugestão do tipo de estudo de bioequivalência a ser realizado.

Tabela 12 - Modelo para informação do conteúdo calórico da refeição padronizada no estudo. 


\section{LISTA DE ABREVIATURAS E SIGLAS}
ANDA - Abbreviated New Drug Application
ANVISA - Agência Nacional de Vigilância Sanitária
ASC - Área sob a curva de concentração plasmática versus tempo
$\mathrm{ASC}_{0 \text {-inf }} \quad$ - Área sob a curva de concentração plasmática versus tempo, do tempo zero ao infinito
$\mathrm{ASC}_{0-\mathrm{t}} \quad$ - Área sob a curva de concentração plasmática versus tempo, do tempo zero ao tempo $t$
BD - Biodisponibilidade
$\mathrm{BE} \quad-$ Bioequivalência
BR - Biodisponibilidade relativa
$\mathrm{C}_{\max } \quad-$ Concentração plasmática máxima
$\mathrm{C}_{\min } \quad$ - Concentração plasmática mínima
CV - Coeficiente de variação
CYP - Cytochrome P450
DEF - Dicionário de especialidades farmacêuticas
EMEA - The European Agency for the Evaluation of Medicinal Products
FDA - Food and Drug Administration
FFOLI - Forma farmacêutica oral de liberação imediata
FFOLM - Forma farmacêutica oral de liberação modificada
GST - Glutathione S-transferase
IND - Investigational New Drug Application
NDA - New Drug Application
OATP - Organic anion transporting polypeptide
PDR - Physicians' desk reference
SCB - Sistema de classificação biofarmacêutica
$\mathrm{t}_{1 / 2} \quad-\quad$ Meia vida
$t_{\text {lag }} \quad-\quad$ Tempo para atingir concentrações plasmáticas mensuráveis
$\mathrm{t}_{\max } \quad-$ Tempo da concentração plasmática máxima
UGT - Uridine diphosphate glucuronosyltransferase 


\section{SUMÁRIO}

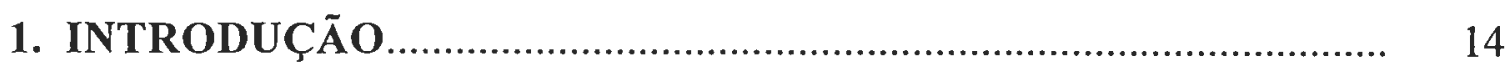

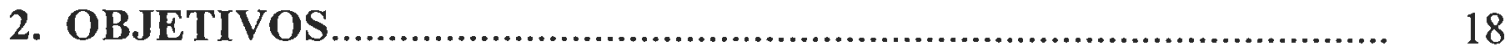

3. MATERIAL E MÉTODOS................................................................ 19

3.1 PLANEJAMENTO ................................................................... 19

4 REVISÃO BIBLIGRÁFICA............................................................... 20

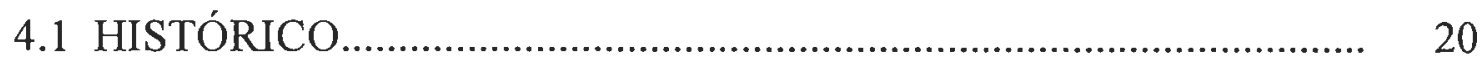

4.1.1 O início dos estudos.................................................................. 20

4.1.2 O desenvolvimento da regulamentação........................................ 21

4.2 CONCEITOS E DEFINIÇÕES......................................................... 24

4.3 ABSORÇÃO GASTRINTESTINAL DE FÁRMACOS........................ 27

4.3.1 O estômago........................................................................... 28

4.3.1.1 Anatomia, digestão e absorção.................................................. 28

4.3.1.2 pH gástrico............................................................................. $\quad 30$

4.3.1.3 Motilidade e esvaziamento gástrico.......................................... 31

4.3.1.4 Efeito do volume e composição da refeição sobre o esvaziamento gástrico.............................................................. 33

4.3.1.5 O trânsito da forma farmacêutica no estômago.......................... 34

4.3.2 Absorção de fármacos no intestino................................................ 36

4.4 INTERAÇÃO FÁRMACO-ALIMENTO.............................................. 38

4.4.1 Efeitos do alimento na absorção de fármacos................................. 43

4.4.1.1 Diminuição da velocidade (retardamento) da absorção............. 44

4.4.1.2 Diminuição da absorção.......................................................... 44

4.4.1.3 Aumento da absorção........................................................... 45

4.4.1.4 Ausência de efeito do alimento na absorção de fármacos......... 47

4.4.2 Fatores envolvidos na interação fármaco-alimento...................... 48

4.4.2.1 Fatores relacionados à refeição................................................. 48

4.4.2.2 As propriedades do fármaco e a classificação biofarmacêutica 51

4.4.2.3 Mecanismos físico-químicos e fisiológicos............................... 55

4.4.2.4 Influência da formulação......................................................... 60

4.4.3 Efeitos do alimento no metabolismo de fármacos........................ 61

4.5 REQUERIMENTOS DOS ESTUDOS DE BIODISPONIBILIDADE SOB EFEITO DO ALIMENTO......................................................... 67

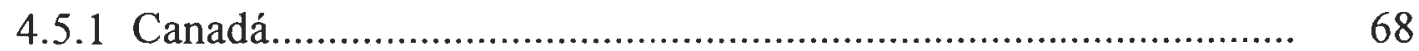

4.5.2 Estados Unidos................................................................... 72

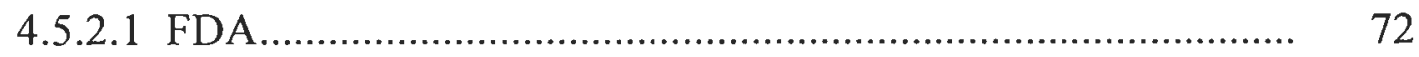

4.5.2.2 Farmacopéia dos Estados Unidos............................................ 73 

ALIMENTAÇÃO E/OU JEJUM EM DIVERSOS PAÍSES.

5. RESULTADOS E DISCUSSÃO.

5.1 DECISÃO PARA ESTUDO EM JEJUM E/OU ALIMENTO...............

\subsection{PROPOSTA DE GUIA PARA ESTUDOS DE} BIODISPONIBILIDADE E BIOEQUIVALÊNCIA COM ALIMENTAÇÃO

5.2.1 Introdução

5.2.2 Recomendações dos estudos de biodisponibilidade e bioequivalência sob efeito de alimento.

5.2.2.1 Para medicamento novo.

5.2.2.1.1 Formas farmacêuticas orais de liberação imediata................. 107

5.2.2.1.2 Formas farmacêuticas orais de liberação modificada............. 107

5.2.2.2 Para medicamento genérico ou similar..................................... 108

5.2.2.2.1 Formas farmacêuticas orais de liberação imediata.................. 108

5.2.2.2.2 Formas farmacêuticas orais de liberação modificada............. 108

5.2.3 Condução dos estudos........................................................... 109

5.2.3.1 Desenho do estudo................................................................. 109

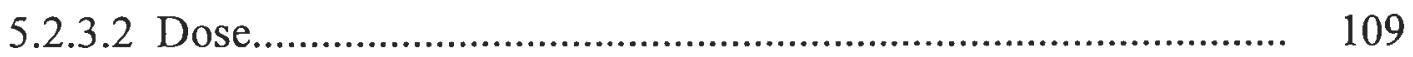

5.2.3.3 Refeição padrão................................................................... 109

5.2.3.4 Tratamentos................................................................. 110

5.2.3.5 Coleta das amostras.............................................................. 111

5.2.3.6 Quantificação do fármaco....................................................... 111

5.2.3.7 Análise dos dados.............................................................. 111

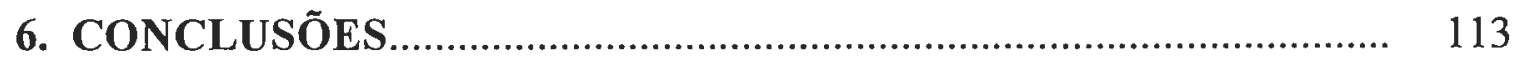

REFERÊNCIAS BIBLIOGRÁFICAS................................................ 115 


\section{INTRODUÇÃO}

Está muito bem estabelecido, no meio profissional farmacêutico, o conceito de que medicamentos contendo o mesmo fármaco, na mesma dose molar, não produzem, necessariamente, os mesmos resultados quanto à eficácia $\mathrm{e}$ segurança. No começo dos anos sessenta foi constatado que diferentes formulações administradas oralmente, de importantes agentes terapêuticos (difenilhidantoína, fenilbutazona, prednisona, hormônio tireoidiano, varfarina, aspirina, digoxina, cloranfenicol, oxitetraciclina e tetraciclina) variavam significativamente em suas biodisponibilidades (GLEITER et al., 1998).

Biodisponibilidade e bioequivalência é um tema que tem gerado crescentes discussões, o que tem promovido a conscientização dos problemas clínicos relacionados à bioinequivalência e, por intervenção do corpo regulador, a melhoria da qualidade dos estudos de biodisponibilidade. A definição de biodisponibilidade inclui os parâmetros velocidade e extensão com que a substância ativa (fármaco ou metabólito) atinge a circulação sistêmica a partir da forma farmacêutica. A extensão é representada pela área sob a curva (ASC) do gráfico em que se relacionam as concentrações plasmáticas (soro ou sangue) e os tempos, enquanto que a velocidade é representada pela concentração máxima $\left(\mathrm{C}_{\max }\right)$ e tempo da concentração máxima $\left(\mathrm{t}_{\max }\right)$. É importante notar que a biodisponibilidade não é uma propriedade somente do fármaco, mas também da forma farmacêutica da qual o fármaco é liberado, sendo, portanto, a manisfetação in vivo da qualidade de um produto farmacêutico (GLEITER et al, 1998).

No contexto do medicamento genérico, um produto farmacêutico deve ser terapeuticamente equivalente ao produto inovador, o qual teve sua eficácia e segurança muito bem comprovadas através dos estudos clínicos. A comprovação da equivalência terapêutica, base para a intercambialidade, é a demonstração de que o medicamento genérico possui o mesmo perfil de eficácia e segurança que o produto inovador, sendo que, pelo método convencional, seria necessária a realização dos extensos estudos clínicos. Isto implica tempo e dinheiro, além do aspecto ético, pois seriam envolvidos grandes grupos de pacientes nesses ensaios. 
A bioequivalência substitui a comparação direta (ensaios clínicos) pela comparação indireta (farmacocinética), baseada no princípio de que a similaridade dos perfis de concentração-tempo no sangue (ou soro, ou plasma) proporciona similares resultados quanto à eficácia e segurança (GLEITER et al., 1998). Essencialmente, a bioequivalência é o estudo comparativo das biodisponibilidades entre produtos farmacêuticos. Na prática, o estudo de bioequivalência é conduzido sob critérios muito bem padronizados e a conclusão é obtida através de análise estatística (STORPIRTIS, 1999; STORPIRTIS; CONSIGLIERI, 2000).

Alguns casos representam grandes desafios para comprovação da bioequivalência, como exemplo, os fármacos de alta variabilidade na absorção ou muito pouco absorvidos, substâncias endógenas, fármacos com metabólitos ativos, ausência de metodologia analítica confiável, fármacos de meia-vida longa, fármacos desenhados para aplicação tópica, fármacos quirais, fármacos com polimorfismo genético em seus metabolismos e fármacos de elevada toxicidade (MARZO, 1999).

Os sistemas de liberação de fármaco são fontes de variabilidade do desempenho in vivo entre as formulações. Em geral, muitos dos produtos listados no Orange Book (relação dos medicamentos aprovados nos Estados Unidos com avaliação de equivalência terapêutica) (UNITED STATES, 2005) de comprovados ou potenciais problemas de bioequivalência são formulações de liberação modificada (WELAGE et al., 2001). Estas são situações ainda não bem definidas nos guias vigentes ou que têm gerado questionamentos no meio científico.

A influência da alimentação na absorção de fármacos tem merecido atenção e vem sendo estudada mais recentemente. A interação fármaco-alimento é de difícil previsão e ocorre por uma variedade de razões, tais como alterações fisiológicas (motilidade intestinal, fluxo sanguíneo, etc.) e/ou físico-químicas (quelação, adsorção, etc.), podendo aumentar, retardar ou diminuir, ou mesmo não afetar a absorção de fármacos (WELLING et al., 1991). Na Conferência 
Internacional da Federação Farmacêutica Internacional, realizada na Alemanha em 1992, foi estimulada a realização de estudos pilotos para determinação da interação fármaco-alimento no desenvolvimento de formulações (JACKSON, 1994).

Os estudos do efeito da alimentação na absorção de fármacos são realizados, geralmente, no período de desenvolvimento de novos medicamentos. No entanto, sabe-se que o alimento pode alterar a biodisponibilidade, por interação com o fármaco ou com a formulação. Em alguns casos, as interações dos excipientes com os alimentos induzem alterações fisiológicas no trato gastrintestinal, podendo influenciar na demonstração da bioequivalência. Para todas as formulações de liberação modificada, cuja dissolução in vivo e absorção do fármaco está sujeita à presença de alimento, a magnitude dos efeitos da alimentação na biodisponibilidade e na demonstração da bioequivalência dos medicamentos é difícil, senão impossível, de prever sem a realização de estudo de bioequivalência com alimentação (UNITED STATES, 2002).

A regulamentação técnica no Brasil, seguindo a tendência das práticas regulatórias internacionais, preconiza a condução de estudos de bioequivalência com alimentação para o registro e comercialização do medicamento genérico, notadamente para formulações de liberação modificada. A Resolução - RE $n^{\circ}$ 896 de 29/05/03 da ANVISA (BRASIL, 2003f) preconizava a realização de dois estudos de bioequivalência, um em jejum e outro com alimentação, para as formas farmacêuticas de liberação modificada; para as formas farmacêuticas de liberação imediata, o estudo com alimentação era exigido nos casos de conhecida interação com alimentos. Posteriormente, a Resolução - RE no 397 (BRASIL, 2004) forneceu um melhor detalhamento sobre a exigência de estudos de bioequivalência com alimento para as formas farmacêuticas de revestimento gastro-resistentes e as de liberação imediata. No entanto, muitas questões estão abertas, especialmente quanto às diretrizes para condução desses estudos.

Este trabalho compreende uma abordagem sobre os estudos do efeito do alimento na biodisponibilidade dos fármacos e sobre os casos em que a 
bioequivalência deve ser demonstrada em presença de alimentos. Está focado na elaboração dos critérios técnicos, fundamentados em bases científicas e de necessidade urgente no contexto atual, referentes ao requerimento e condução dos estudos de biodisponibilidade e bioequivalência de medicamentos com alimentação.

Considerando-se que o Brasil é o primeiro país da América do Sul que apresenta regulamentação técnica para registro de medicamentos genéricos, com base na comprovação de sua bioequivalência com os respectivos medicamentos de referência, e que está no período de implementação da adequação dos medicamentos similares do mercado a essas novas exigências, o presente trabalho constitui-se em contribuição técnico-científica para o aprimoramento da regulamentação vigente, podendo servir de base às discussões sobre o tema no plano da harmonização de critérios para estudos de biodisponibilidade e bioequivalência na região das Américas. 


\section{OBJETIVOS}

Os objetivos do presente trabalho foram:

1. Sistematizar os aspectos técnico-científicos relativos aos estudos de biodisponibilidade e biequivalência de medicamentos sob efeito de alimentos.

2. Avaliar a importância e necessidade da realização desses estudos para formas farmacêuticas de liberação imediata e modificada, considerando as interações fármaco-alimento e formulação-alimento.

3. Elaborar proposta para o "Guia para a realização de estudos de BD e BE de medicamentos sob efeito de alimentos aplicável a medicamentos novos, genéricos e similares no Brasil". 


\section{MATERIAL E MÉTODOS}

Este trabalho foi realizado por meio de levantamento bibliográfico e análise das diretrizes reguladoras internacionais e nacionais em vigor e da literatura técnico-científica. A pesquisa teve ênfase nos trabalhos publicados nos últimos dez anos, período em que se intensificou o debate sobre a definição de critérios para os estudos de bioequivalência com alimentação.

\subsection{PLANEJAMENTO}

O desenvolvimento do trabalho compreendeu:

> classificação dos fármacos quanto à interação com alimentos;

> elaboração da árvore de decisão, para exigência dos estudos de bioequivalência (jejum ou alimento; jejum e alimento);

$>$ elaboração da relação de fármacos quanto à necessidade de estudos (jejum ou alimento; jejum e alimento);

elaboração da proposta do guia (desenhos, cardápios etc.). 


\section{REVISÃO BIBLIGRÁFICA}

\subsection{HISTÓRICO}

\subsubsection{O início dos estudos}

O estudo de absorção de composto exógeno tem registro já em 1912 com iodeto de sódio (WAGNER, 1971). Na década de 30 foram realizados trabalhos de avaliação da absorção de fármacos a partir de formas farmacêuticas através de medidas de excreção urinária de salicilato, após administração de comprimidos de salicilato de sódio com revestimento entérico (PORTA, 1999). Porém, destaca-se o artigo de Oser et al. (1945), que introduz um novo conceito ao denominar a absorção de vitaminas a partir de produtos farmacêuticos como disponibilidade fisiológica.

Dennis (1990) considera que o estudo científico de absorção de fármacos começou seriamente com Shoie, Brodie e Hogben (1957), e depois foi estimulado por dois casos de problemas terapêuticos, resultantes de reformulações dos produtos, a saber: a substituição do sulfato de cálcio por lactose em comprimidos de fenitoína (TYRER et al., 1970) e a redução do tamanho de partículas do fármaco em comprimidos de digoxina (JOHNSON et al., 1973). Nos dois casos houve aumento da biodisponibilidade dos fármacos e conseqüente toxicidade aos pacientes.

As primeiras observações sobre problemas de irregularidade na absorção ocorreram no início dos anos 1960, a partir das conseqüências clínicas de bioinequivalência ou falta de biodisponibilidade de formulações orais de importantes agentes terapêuticos, por exemplo: difenilhidantoína, fenilbutazona, prednisona, hormônio tireoidiano, varfarina, aspirina, digoxina, cloranfenicol, oxitetraciclina e tetracilina (GLEITER et al., 1998). A preocupação aumentou no meio dos anos sessenta com a demonstração de falta de equivalência terapêutica entre preparações de digoxina (LINDENBAUM et al., 1971). 
Gleiter e Gundert-Remy (1994) documentam casos identificados de falta de equivalência terapêutica com: amitriptilina, em 1978; carbamazepina, em 1987 e 1989; diazepam, em 1977; digoxina, em 1974 e 1977; diltiazem, em 1990; glibenclamida, em 1983; oxitetraciclina, em 1969 e fenitoína, em 1971.

Com o crescimento da capacidade bioanalítica a partir da década de 1950, a performance dos medicamentos passou a ser facilmente detectada e expressada como medida de biodisponibilidade. A disponibilidade de métodos sensíveis o suficiente para permitir quantificar o fármaco (ou metabólitos) na urina ou no sangue (plasma) possibilitou, na década de sessenta, a comparação de formulações em voluntários. Em consequiência, muitos trabalhos foram publicados. Essas investigações demonstraram claramente grandes diferenças na biodisponibilidade entre diferentes formulações do mesmo fármaco (McGILVERAY, 1994).

\subsubsection{O desenvolvimento da regulamentação}

No Canadá, a lei de licenciamento compulsório em 1969 facilitou a entrada de medicamento genérico no mercado e o Drugs Directorate, órgão do Departamento Federal Canadense de Saúde e Bem-estar, começou a utilizar a bioequivalência como medida para aprovação de medicamento em 1970 (McGILVERAY, 1991). O programa canadense foi examinado e aprimorado nos Estados Unidos e, em 1977, a FDA regulamenta a exigência de estudos de biodisponibilidade e de bioequivalência para o registro de medicamentos novos (New Drug Application - NDA), tornando-se a primeira agência regulatória a decretar normas para bioequivalência (UNITED STATES, 1977).

Em 1962, nos Estados Unidos, o conselho de pesquisa da Academia Nacional de Ciências iniciou uma avaliação de todos os medicamentos aprovados pela FDA até esse ano, abrangendo mais de 3.000 produtos, os quais foram classificados como provavelmente efetivos, possivelmente efetivos e inefetivos. Essa avaliação estimulou o início da fabricação de medicamentos genéricos, 
porque as empresas podiam agora aprovar seus produtos sem a necessidade de testes de eficácia (BENSON, 2001).

Em 1970, a FDA estabeleceu o processo abreviado denominado "Abbreviated New Drug Application (ANDA)" para aprovação das versões genéricas dos produtos registrados entre 1938 e 1962 (ANDERSON, 1992). Para os produtos aprovados após 1962, os fabricantes de produtos genéricos tinham que submeter os dados completos de segurança e eficácia. Em 1978 passou a ser requerida a citação de estudos publicados para documentação de segurança e eficácia. Nenhuma dessas estratégias foram consideradas satisfatórias, uma vez que a realização dos estudos era de elevado custo e os dados de literatura científica não estavam disponíveis, pois não tinham sido publicados (WELAGE et al., 2001). No entanto, o grande marco no desenvolvimento da fabricação de produtos equivalentes terapêuticos veio com a Lei Hatch-Waxman (Lei de competição de preços e restauração das patentes) em 1984 (BENSON, 2001). Essa Lei modificou e acelerou o procedimento abreviado (ANDA), possibilitando aprovação de versões genéricas de produtos inovadores aprovados após 1962, que não mais estivessem sob proteção patentária, dispensando a apresentação dos dados de eficácia e segurança e considerando o produto genérico como equivalente terapêutico ao inovador com base na equivalência farmacêutica e bioequivalência (WELAGE et al., 2001).

A definição e a determinação dos procedimentos apropriados para avaliação de biodisponibilidade e bioequivalência tem sido objeto de esforços internacionais. Posteriormente, a comprovação de equivalência farmacêutica e bioequivalência tornou-se importante nas alterações pós-registro (CHEN et al., 2001).

Nos anos oitenta algumas agências regulatórias publicaram guias, por exemplo Inglaterra (1983), Holanda (1985) e Suécia (1987) (McGILVERAY, 1994).

A discussão continuada sobre bioinequivalência elevou a consciência quanto aos problemas clínicos associados, melhorou a qualidade dos estudos de 
biodisponibilidade e influenciou os procedimentos de tomada de decisão dos órgãos reguladores. Um bom exemplo disso é a maneira como a autoridade reguladora da Alemanha (Bundesinstitut für Arzneimittel und Medizinprodukte BfArM) tem tratado desse assunto, criando em 1989 a Comissão de Biodisponibilidade, um órgão independente, formado por especialistas externos (farmacologistas clínicos e farmacêuticos da academia e da indústria farmacêutica), para aconselhar o BfArM sobre as circunstâncias e os fármacos para os quais os estudos de biodisponibilidade devem ser legalmente requeridos para concessão de autorização de comercialização (GLEITER et al., 1998).

O consenso sobre os aspectos científicos relacionados à Bioequivalência tem promovido a harmonização internacional dos padrões regulatórios. Em 1991, a Comissão da Comunidade Européia emitiu um guia para investigação de biodisponibilidade e bioequivalência (INVESTIGATION..., 1991). O ministério da saúde do Japão emitiu, em 1997, o guia para estudos de bioequivalência de produtos genéricos, como parte das medidas regulatórias para garantir a qualidade dos produtos genéricos no mercado (JAPAN, 1997). Em 1994, a OMS elaborou o guia para estudos de bioequivalência, um padrão comum internacional aplicável para a avaliação, autorização de comercialização e controle de qualidade dos medicamentos genéricos, de forma que a autoridade reguladora em cada país pode garantir a qualidade, efetividade e segurança dos mesmos (NAKAI; FUJITA; OGATA, 2000). 


\subsection{CONCEITOS E DEFINIÇÕES}

Absorção - a absorção descreve a velocidade com a qual os fármacos deixam seus locais de administração e a magnitude com que isto ocorre (GOODMAN et al., 2003).

Biodisponibilidade - indica a velocidade e a extensão de absorção de um princípio ativo em uma forma de dosagem, a partir de sua curva concentração/tempo na circulação sistêmica ou sua excreção na urina (BRASIL, 1999).

Biodisponibilidade absoluta - porcentagem do fármaco contido em um produto farmacêutico que entra na circulação sistêmica na forma não transformada após administração do produto (KOCH-WESER, 1974).

Biodisponibilidade relativa - porcentagem absorvida de um produto farmacêutico teste relativa à preparação padrão (WAGNER, 1971). Os estudos de biodisponibilidade relativa são úteis para comparação de perfis de exposição sistêmica de diferentes formas farmacêuticas e vias de administração (CHEN et al., 2001). Quociente da quantidade e velocidade de princípio ativo que chega à circulação sistêmica, a partir da administração extravascular de um preparado, e a quantidade e velocidade de princípio ativo que chega à circulação sistêmica, a partir da administração extravascular de um produto de referência que contenha o mesmo princípio ativo (BRASIL, 2003a)

Bioequivalência - consiste na demonstração de equivalência farmacêutica entre produtos apresentados sob a mesma forma farmacêutica, contendo idêntica composição qualitativa e quantitativa de princípio (s) ativo (s), e que tenham comparável biodisponibilidade, quando estudados sob um mesmo desenho experimental (BRASIL, 1999).

Medicamentos bioequivalentes - são equivalentes farmacêuticos que, ao serem administrados na mesma dose molar, nas mesmas condições experimentais, não apresentam diferenças estatisticamente significativas em relação à biodisponibilidade (BRASIL, 2003c). 
Produto farmacêutico intercambiável - equivalente terapêutico de um medicamento de referência, comprovados, essencialmente, os mesmos efeitos de eficácia e segurança (BRASIL, 1999).

Medicamento de referência - produto inovador registrado no órgão federal responsável pela vigilância sanitária e comercializado no País, cuja eficácia, segurança e qualidade foram comprovadas cientificamente junto ao órgão federal competente, por ocasião do registro (BRASIL, 1999).

Equivalência terapêutica - dois medicamentos são considerados terapeuticamente equivalentes se eles são farmaceuticamente equivalentes e, após administração na mesma dose molar, seus efeitos em relação à eficácia e segurança são essencialmente os mesmos, o que se avalia por meio de estudos de bioequivalência apropriados, ensaios farmacodinâmicos, ensaios clínicos ou estudos in vitro (BRASIL, 2003c).

Equivalentes farmacêuticos - são medicamentos que contêm o mesmo fármaco, isto é, mesmo sal ou éster da mesma molécula terapeuticamente ativa, na mesma quantidade e forma farmacêutica, podendo ou não conter excipientes idênticos. Devem cumprir com as mesmas especificações atualizadas da Farmacopéia Brasileira e, na ausência destas, com as de outros códigos autorizados pela legislação vigente ou, ainda, com outros padrões aplicáveis de qualidade, relacionados à identidade, dosagem, pureza, potência, uniformidade de conteúdo, tempo de desintegração e velocidade de dissolução, quando for o caso (BRASIL, 2003c).

Forma farmacêutica - estado final de apresentação que os princípios ativos farmacêuticos possuem após uma ou mais operações farmacêuticas executadas com a adição de excipientes apropriados ou sem a adição de excipientes, a fim de facilitar a sua utilização e obter o efeito terapêutico desejado, com características apropriadas a uma determinada via de administração (BRASIL, 2003a).

Fórmula - relação quantitativa dos farmoquímicos que compõem um medicamento (BRASIL, 2003a). 
Medicamento - produto farmacêutico, tecnicamente obtido ou elaborado, com finalidade profilática, curativa, paliativa ou para fins de diagnóstico (BRASIL, 1973).

Liberação imediata ou convencional - permite a dissolução do fármaco no conteúdo gastrintestinal, sem função de retardamento ou prolongamento da dissolução ou absorção do fármaco (UNITED STATES, 1997).

Liberação Retardada - liberação do fármaco em um tempo outro que não o imediatamente seguinte à administração oral da forma farmacêutica (UNITED STATES, 1997).

Revestimento gastro-resistente - tem a função de retardar a liberação do fármaco até que a forma farmacêutica tenha passado através do estômago (UNITED STATES, 1997).

Forma farmacêutica de liberação modificada - forma farmacêutica cujas características de liberação do fármaco, quanto ao curso de tempo e/ou local, são selecionadas para cumprir com objetivos terapêuticos, ou de conveniências, não possibilitados pelas formulações de liberação convencional. Engloba as formulações de liberação retardada e estendida (UNITED STATES, 1997).

Liberação estendida - produtos de liberação estendida são formulados para disponibilizar o fármaco por um período estendido após a administração (UNITED STATES, 1997). 


\subsection{ABSORÇÃO GASTRINTESTINAL DE FÁRMACOS}

A absorção de fármacos a partir do trato gastrintestinal (TGI) não é um processo simples, sendo influenciado por diversos fatores. Tanto a fisiologia em si do TGI, como as características químicas do seu conteúdo, são de importância fundamental. A estrutura da molécula do fármaco, seu grau de ionização, solubilidade e lipofilia irão influenciar a velocidade de absorção de uma molécula em particular. Outros importantes fatores que influenciam a velocidade de dissolução do fármaco são sua estrutura cristalina, forma polimórfica e tamanho de partícula. A própria formulação pode também impedir ou atrasar a absorção do fármaco por não liberá-lo de maneira rápida o suficiente. Muitos outros fatores fisiológicos, tais como ingestão de alimento, estresse ou repouso podem afetar a absorção. A co-administração de outros fármacos pode tanto reduzir como aumentar a absorção (DENNIS, 1990).

Os métodos de estudo da absorção de fármacos são classificados em métodos diretos e métodos indiretos. Pelo método direto mede-se a concentração remanescente do fármaco no estômago ou na corrente sanguínea da veia portal. Muitos modelos de absorção de fármacos empregam membranas sintéticas ou segmentos de intestino de animais. Como os métodos diretos são geralmente mais difíceis de serem realizados em humanos, são freqüentemente utilizados os métodos indiretos, que geralmente envolve a comparação do perfil de concentração sanguínea de uma formulação, cuja absorção é conhecida (injeção em bolus ou infusão à velocidade constante), com a formulação cujo perfil de absorção é desconhecido e, através de cálculos matemáticos, são determinadas a velocidade e a extensão da absorção (DENNIS, 1990). 


\subsubsection{O estômago}

\subsubsection{Anatomia, digestão e absorção}

O estômago tem diversas funções: serve de reservatório para os alimentos; processa os alimentos em quimo fluido, o qual facilita a absorção dos nutrientes no intestino delgado; regula a liberação dos alimentos para o intestino delgado; produz ácido, que tem ação bacteriostática e também produz o $\mathrm{pH}$ adequado para o funcionamento da pepsina. O estômago é divido em três regiões anatômicas: a parte superior, denominada fundo, contém os gases após a refeição, produz contrações lentas e demoradas, exercendo pressão sobre o conteúdo gástrico, empurrando-o gradualmente na direção aboral; a parte mais vasta do estômago, denominada corpo, atua como reservatório de alimento e líquidos ingeridos; o antro, que é a parte inferior do estômago, tem forma afunilada, com sua região mais larga junto à parte inferior do corpo do estômago e sua terminação mais estreita conectando-se ao canal pilórico. A porção pilórica, formada pelo antro mais o canal pilórico, curva-se para a direita e ligeiramente para cima e para trás, dando ao estômago sua aparente forma de J. O estômago adapta-se aos volumes aumentados de alimento através do relaxamento, que permite expansões com pequenas variações na pressão intragástrica. A porção distal (antro) do estômago tem uma parede composta de músculo espesso, com função de regulação do esvaziamento de sólidos pela contração e também atua como homogeneizador e moedor. O antro e o corpo atuam coordenadamente na propulsão do conteúdo gástrico em direção ao piloro. O esfíncter pilórico tem duas funções: peneira o quimo, evitando a passagem de grandes partículas sólidas e também evita o refluxo de material duodenal contendo bile e enzimas pancreáticas que podem danificar a mucosa gástrica (WASHINGTON; WASHINGTON; WILSON, 2001).

O estômago secreta entre 1,0 e 1,5 litros de suco gástrico por dia. $O$ suco gástrico é altamente ácido devido ao conteúdo de ácido clorídrico, é rico em 
enzimas, prover as condições para dissolução das partículas do alimento e inicia a digestão, principalmente das proteínas. A amilase salivar atua sobre o amido dos alimentos enquanto a acidez da mistura é baixa, em torno do $\mathrm{pH} 6$, mas cessa quando a acidez da mistura aumenta com o aumento da secreção ácida. As pepsinas gástricas realizam apenas de 10 a 15 por cento da digestão de proteínas e são mais ativas na primeira hora da digestão. O estômago é primariamente um órgão de processamento e não de absorção, não sendo essencialmente vital. É possível, por exemplo, após gastrectomia total (remoção completa do estômago), uma pessoa permanecer ou se tornar obesa, porque a maioria da digestão e absorção dos alimentos ocorre no intestino. O estômago pode absorver algumas substâncias, incluindo glicose e outros açúcares simples, aminoácidos e algumas substâncias lipossolúveis. Alguns álcoois, como o etanol, são facilmente absorvidos no estômago. $\mathrm{O} \mathrm{pH}$ do conteúdo gástrico controla a absorção de certos compostos ionizáveis, como a aspirina, que é facilmente absorvida na sua forma não ionizada quando o estômago está ácido, porém mais lentamente quando o conteúdo gástrico está neutro. A absorção de água e álcool é diminuída quando o estômago contém alimento, especialmente gordura, provavelmente porque o esvaziamento gástrico é retardado e a maior parte da água, em qualquer situação, é absorvida no jejuno. A água desloca-se livremente, atravessa a mucosa gástrica e entra no sangue. Em experimentos com óxido de deutério, aproximadamente $60 \%$ da água localizada no estômago é absorvida para o sangue em 30 minutos. No entanto, a absorção resultante de água no estômago é pequena, porque ela desloca-se facilmente do sangue para o lúmen do estômago (WASHINGTON; WASHINGTON; WILSON, 2001). 


\subsubsection{2 pH gástrico}

O conteúdo do estômago humano normalmente está na faixa de $\mathrm{pH}$ de 1,0 a 3,5, sendo que é mais comum o $\mathrm{pH} 1,0-2,5$. O pH gástrico é influenciado basicamente por dois fatores: secreção ácida e conteúdo gástrico. Num período de 24 horas, o pH diurno mediano de oito voluntários foi 2,7 no corpo e 1,9 no antro do estômago (McLAUGHLAN et al., 1989). O alimento tampona e neutraliza o ácido gástrico, produzindo uma elevação no $\mathrm{pH}$. $\mathrm{O}$ pH não é uniforme no estômago devido a diferenças na distribuição das células parietais e aos diferentes padrões de motilidade em várias regiões do estômago. No corpo do estômago, a maior concentração de células parietais causa rápida produção ácida, mas a agitação nessa região é fraca, assim um grande efeito de tamponamento do alimento é observado. A medida que o alimento move-se para o antro, a agitação vigorosa não só reduz o tamanho de partículas do alimento, como também mistura-o com o ácido gástrico que foi produzido. $\mathrm{O} \mathrm{pH}$ no antro permanece baixo, embora não existam células parietais nesta região, porque o alimento foi neutralizado no corpo do estômago (WASHINGTON; WASHINGTON; WILSON, 2001).

A secreção ácida é aumentada após refeições quentes ou frias, embora a temperatura por si não altere o esvaziamento gástrico (McARTHUR; HOGAN; ISENBERG, 1982). Uma refeição de carboidratos não tem efeito detectável sobre a acidez gástrica (BUMM; BLUM, 1987), enquanto uma refeição protéica de caloria similar tem efeito tamponante significativo (RICHARDSON et al., 1976). 


\subsubsection{Motilidade e esvaziamento gástrico}

Após uma refeição, o alimento digerível será transformado em quimo e passado para o intestino delgado deixando um resíduo de muco e sólidos não digeridos. Esses permanecem no estômago até o intestino delgado terminar a absorção dos nutrientes contidos no quimo, o que demora aproximadamente duas horas após a última porção de alimento digerivel ter deixado o estômago. Neste ponto cessa a fase digestiva de atividade, que é substituída pela fase interdigestiva, a condição normal de repouso do estômago e intestino delgado. Todos os resíduos gástricos resultantes da formação do quimo são removidos na fase interdigestiva, através de fortes contrações contra um piloro aberto. $\mathrm{O}$ esvaziamento gástrico da secreção gástrica basal ocorre mesmo durante o jejum para evitar acumulação de fluido, assim é muito pequena a absorção através da mucosa gástrica (WASHINGTON; WASHINGTON; WILSON, 2001).

A capacidade do estômago de um adulto é aproximadamente $1500 \mathrm{~mL}$. A ingestão média diária ocidental de alimento e bebida é de 3 a $4 \mathrm{Kg}$, e estima-se que outros cinco litros de fluidos, como saliva, suco gástrico, suco pancreático e outros líquidos corporais sejam adicionados. A maior atividade secretora ocorre no estômago dentro da primeira hora da ingestão e o volume de suco gástrico produzido pode ser de até duas vezes o volume da refeição. O terço superior do estômago, ou fundo, adapta-se ao volume variável de alimento ingerido através do relaxamento da parece muscular, mantendo o alimento enquanto ocorrem as primeiras etapas da digestão. Esta adaptação permite a acomodação do alimento ingerido sem aumento da pressão intragástrica. A mistura, moagem e esvaziamento do alimento ocorrem ao mesmo tempo. A dispersão do alimento é mais um processo mecânico do que enzimático. A mistura e moagem são realizadas por uma série de ondas peristálticas cuja intensidade e frequêencia aumentam gradualmente no sentido do duodeno. A ação de moagem, combinada com as forças de corte produzidas durante a retropulsão, reduzem o tamanho das partículas e misturam as partículas com o suco gástrico. A movimentação e a 
digestão ácida-pepsínica são responsáveis pela quebra física do alimento sólido nesta região. A velocidade de esvaziamento do estômago humano diminui se o alimento sólido ingerido compõe a maior massa. Os sólidos são esvaziados somente após serem moídos em partículas pequenas de aproximadamente $1 \mathrm{~mm}$, as partículas maiores e pesadas demoram para alcançar este tamanho. A atividade motora e tônica do estômago reduz o tamanho do lúmen, uma vez que todas as partes da parede se contraem quase ao mesmo tempo. Isto faz com que o estômago se ajuste ao volume do conteúdo. As contrações ocorrem numa velocidade constante de três por minuto no antro. Esta velocidade é denominada de ritmo básico e pode ser abolida ou estimulada por alguns fármacos. A distensão do corpo do estômago pelo alimento ativa um reflexo neural que inicia a atividade do músculo do antro (WASHINGTON; WASHINGTON; WILSON, 2001).

Aproximadamente a cada duas vezes por minuto, 1 a $5 \mathrm{~mL}$ de conteúdo antral escapa para o duodeno e diminui o $\mathrm{pH}$ duodenal, isto ocorre em episódios discretos de apenas 2 a 5 segundos (KING et al., 1984). O piloro parece estar amplamente aberto, com uma abertura maior que $5 \mathrm{~mm}$, por aproximadamente 15-20\% do tempo (HAUSKEN; ODEGAARD; BERSTAD, 1991). O período de tempo em que o piloro permanece aberto não determina completamente a velocidade de esvaziamento de líquidos, porque o duodeno também parece aplicar um mecanismo de freio. A abertura periódica do piloro durante a fase alimentada de motilidade pode explicar como algumas grandes partículas, incluindo fragmentos intactos de comprimidos, podem ser esvaziados do estômago. Sólidos e líquidos não são esvaziados do estômago ao mesmo tempo, como uma massa homogênea. Os líquidos são esvaziados de acordo com o gradiente de pressão entre o estômago e o duodeno, sendo que refeições líquidas isotônicas são esvaziadas mais rapidamente que misturas hipo ou hipertônicas. O componente líquido da refeição esvazia-se exponencialmente, enquanto que o esvaziamento de sólidos é linear e possui um lag time. Este lag 
time é proporcional ao tamanho das partículas (WASHINGTON; WASHINGTON; WILSON, 2001).

4.3.1.4 Efeito do volume e composição da refeição sobre o esvaziamento gástrico

O estômago vazio tem um volume de aproximadamente $50 \mathrm{~mL}$ e aumenta para mais de 1 litro quando cheio. O estômago esvazia os três diferentes componentes da refeição, líquido, sólido digerível e sólido não digerível, em diferentes velocidades. Geralmente, quanto maior a quantidade de alimento ingerido, mais longo será o período de atividade. Grandes refeições tendem a esvaziar-se mais lentamente na primeira hora que as refeições pequenas. A velocidade de esvaziamento é igualmente reduzida na proporção do teor calórico. O esvaziamento dos aminoácidos parecem depender somente da osmolaridade, exceto o L-triptofano, que retarda o esvaziamento. Ácidos graxos, mono e triglicerídios retardam o esvaziamento gástrico, com maior efeito os ácidos graxos com 10-14 carbonos na cadeia. A presença de gorduras causa relaxamento do fundo do estômago, o que aumenta o lag time. Interessantemente, o esvaziamento dos óleos segue o padrão linear, em vez do esvaziamento monoexponencial típido dos líquidos (WASHINGTON; WASHINGTON; WILSON, 2001).

A gordura da dieta pode ser ingerida em três formas: sólida, emulsão aquosa e óleo não emulsificado. A residência gástrica de uma refeição de composição idêntica pode ser prolongada se o conteúdo de gordura for usado para fritar o alimento, em vez de ser ingerido como óleo frio (BENINI et al., 1994). A ingestão de refeição altamente gordurosa aumenta a sensação de saciedade por um período maior que uma refeição de baixo teor de gordura e idêntico teor energético (SEPPLE; READ, 1990). A gordura também prolonga o tempo em que a refeição eleva o pH gástrico (KONTUREK et al., 1995). 


\subsubsection{O trânsito da forma farmacêutica no estômago}

Presume-se que comprimidos desintegrarão rapidamente in vivo devido ao emprego de superdesintegrantes e às evidências dos testes de dissolução in vitro, embora isto muitas vezes não seja o caso. Isso é um problema com formulações que causam irritação da mucosa gástrica que, devido à falta de dispersão, o fármaco agride uma pequena área da mucosa por um longo período de tempo. A velocidade de desintegração de cápsulas é afetada pela natureza hidrofóbica ou hidrofílica do conteúdo. A dispersão do conteúdo das cápsulas é limitada no estado de jejum e aumentada quando ingerida com refeição, particularmente com refeição de elevado conteúdo líquido. A cápsula de gelatina ingerida com 100 $\mathrm{mL}$ de água irá, inicialmente, flutuar sobre as dobras gástricas; quando a gelatina se torna aderente, a cápsula pode grudar na parede do estômago, o que prejudica a dispersão do conteúdo (GRAHAM; SMITH; BOUVET, 1990).

Os padrões de ingestão de alimento, atividade e postura são grandes contribuidores para a variação inter e intra-sujeito nos estudos clínicos de determinação de perfis plasmáticos de concentração-tempo de fármacos administrados via oral. A ingestão de alimento não é específica somente para raça e localização geográfica, mas é única para cada pessoa, além de variar a cada dia. Este fator provavelmente produz a maior variação fisiológica no comportamento da formulação oral. A velocidade de esvaziamento gástrico, a presença de alimento ou outros fármacos, características da formulação (tamanho, forma e velocidade de desintegração) e veículo influenciam na absorção do fármaco. Quando a formulação chega no estômago, encontra um ambiente altamente variável em termos de conteúdo alimentar e pH. O * esvaziamento gástrico de comprimidos, pellets e líquidos é altamente dependente da presença e quantidade de alimento no estômago. Comprimidos grandes podem desintegrar-se no estômago e serem esvaziados com a fase digerível do alimento, ou se foram desenhados para permanecerem intactos, serão tratados como material não digerível. Cápsulas grandes não desintegradas serão esvaziadas na 
fase III do ciclo de atividade do estômago em estado não alimentado; nesta fase são esvaziadas as grandes partículas sólidas não digeridas da refeição. Como a ingestão não é sincronizada com nenhuma fase do ciclo, o esvaziamento será errático, ocorrendo a qualquer tempo, entre poucos minutos a até três horas após a administração (WASHINGTON; WASHINGTON; WILSON, 2001).

$\checkmark$ Quando se administra a formulação após uma refeição leve (1500 kJ), o esvaziamento é mais previsível, em torno de 2 a 3 horas. A refeição induz o início do ciclo de atividade em estado alimentado, que durará até o completo esvaziamento de todos os componentes digeríveis da refeição, quando o estômago passa para o ciclo não alimentado. Aproximadamente após duas horas do término da atividade em estado alimentado, inicia-se a fase de contrações para esvaziamento das partículas sólidas não digeridas, ocasião em que a formulação não desintegrada sairá do estômago. Freqüentemente são administradas formas farmacêuticas aos voluntários em jejum nos estudos farmacocinéticos para reduzir a variabilidade, mas o efeito de esvaziamento errático pode afetar o tempo de aparecimento do fármaco no plasma. Todavia, se a formulação é administrada com alimento para sincronizar a motilidade, a absorção do fármaco pode ser influenciada pelo alimento. Uma alternativa possível é administrar o medicamento com suco de maçã, que é um líquido claro, mas tem calorias suficientes para sincronizar a motilidade gástrica. Se uma forma farmacêutica de grandes dimensões for ingerida com uma refeição pesada $(3600 \mathrm{~kJ})$ e o indivíduo alimentar-se em intervalos regulares, a formulação pode permanecer no estômago por até 8 horas devido à supressão prolongada do ciclo de esvaziamento gástrico de partículas não digeridas (WASHINGTON; WASHINGTON; WILSON, 2001).

O efeito do volume da refeição sobre o tempo de esvaziamento gástrico da formulação é extremamente importante, especialmente para preparações de revestimento entérico, sendo o principal fator de influência no início da liberação do fármaco (HARDY et al., 1987). A velocidade de esvaziamento gástrico de formulação multiparticuladas não é severamente afetada pela presença ou 
ausência de alimento. Quando pellets são administrados com uma refeição eles tendem a esvaziar-se de forma similar aos componentes digeriveis (HUNTER et al., 1983).

\subsubsection{Absorção de Fármacos no Intestino}

A forma farmacêutica desloca-se rapidamente pelo intestino delgado em estado de jejum, através de uma ação de natureza propulsiva e não de mistura. Uma cápsula contendo pellets ingerida com o estômago vazio pode chegar ao intestino como um bolus de dispersão mínima, pois o aumento da dispersão no intestino ocorre mediante a administração de uma refeição, na qual as partículas são dispersas no estômago. No caso de comprimidos, dependendo de sua dimensão, o esvaziamento será errático após a alimentação. O trânsito no intestino delgado é de aproximadamente 4 horas para soluções, pellets e formulações de unidade única. O trânsito no intestino delgado de uma formulação não é afetado pelo seu estado físico, dimensão ou ainda presença ou ausência de alimento, mas elevadas cargas calóricas podem retardá-lo ligeiramente, embora o maior efeito seja sobre o esvaziamento gástrico. Grandes quantidades de carboidratos não absorvíveis ou elevado volume de fluido aceleram o transito através do intestino delgado, podendo reduzir o grau de absorção de uma formulação de liberação controlada administrada com uma refeição. Aumentando-se a viscosidade do conteúdo luminal, aumenta-se o grau de absorção de fármacos de liberação ou absorção lentas, por exemplo: a absorção da riboflavina é aumentada quando misturada a uma solução viscosa de alginato de sódio. A absorção de fármacos também é aumentada no intestino delgado com o prolongamento do trânsito causado pelo alimento (WASHINGTON; WASHINGTON; WILSON, 2001).

A permeabilidade do epitélio para pequenos íons e moléculas orgânicas hidrossolúveis é maior no duodeno que no íleo, indicando que existem maiores e mais numerosos canais no intestino delgado. A variação na capacidade absortiva 
pode também ser explicada pela maior área superficial no intestino superior comparado com a parte inferior. Embora exista excelente absorção no duodeno, o transito nessa área é extremamente rápido, na ordem de segundos e dessa forma a real quantidade de fármaco absorvida nessa região será pequena (WASHINGTON; WASHINGTON; WILSON, 2001). Em geral, macromoléculas, como proteínas do alimento, atravessam o epitélio do intestino delgado em pequenas quantidades e alcançam a circulação sistêmica. O potencial de liberação para fármacos macromoleculares administrados por via oral, incluindo proteínas, está sendo largamente estudado (PUSZTAI, 1989).

Um fármaco administrado em uma forma farmacêutica sólida deve dissolver-se no conteúdo gastrintestinal e passar do estômago para o intestino delgado, ganhando acesso ao epitélio. Finalmente, deve atravessar o epitélio por partição na membrana lipídica ou por passagem por canais ou ainda por combinação com carreadores específicos. A residência da formulação no intestino delgado deve ser longa o suficiente para a completa absorção. A principal barreira de permeabilidade é representada pela superfície luminal de borda de escova. A maioria dos fármacos é absorvida pela difusão passiva de suas formas não ionizadas. $\mathrm{O} p H$ do intestino delgado determina o grau de ionização, controlando a eficiência de absorção. $\mathrm{O}$ pH do jejuno proximal normalmente está entre 5,0 a 6,5 , crescendo lentamente ao longo do intestino delgado para alcançar $\mathrm{pH} 6,0-7,0$, embora valores altos na faixa de 7,0 a 9,0 têm sido encontrados ocasionalmente. Medições utilizando microeletrodos demonstraram que o $\mathrm{pH}$ do fluido mucosal adjacente ao epitélio intestinal está entre 4,5 e 6,0, dependendo da concentração luminal de glicose. Este microambiente ácido imediatamente adjacente ao epitélio intestinal contribui para a absorção de fármacos ácidos, como o ácido acetilsalicílico. A maioria dos fármacos está ionizada no $\mathrm{pH}$ do conteúdo intestinal, mas a molécula ácida está menos ionizada imediatamente adjacente ao epitélio intestinal, tornando rápida a sua absorção (WASHINGTON; WASHINGTON; WILSON, 2001). 


\subsection{INTERAÇÃO FÁRMACO-ALIMENTO}

No estudo das interações farmacológicas, deve ser dada especial importância às interações fármaco-alimento, uma vez que as ingestões diárias de alimentos e medicamentos podem estar associadas, sendo já bem conhecido que ocorrem numerosas interações, algumas clinicamente insignificantes, enquanto outras podem ser fatais. As interações fármaco-alimento são geralmente discutidas somente nos casos em que os efeitos de um fármaco são alterados de forma clinicamente significativa pela presença do alimento (DAKOVICSVAJCER, 2002). É crucial que o médico tenha conhecimento dessas interações e comunique-as aos seus pacientes, para o melhor proveito dos efeitos terapêuticos, evitar as falhas na terapia e minimizar as reações adversas aos fármacos (MAKA; MURPHY, 2000).

A literatura registra as primeiras observações de interação fármacoalimento com significância clínica em 1927, quando Burrows e Fair demonstraram que os óleos minerais utilizados como laxantes diminuem a absorção de vitaminas lipossolúveis. Nos anos cinqüenta, uma interação historicamente importante foi o déficit de vitamina B6 com a utilização do tuberculostático isoniazida, uma reação adversa metabólica. Nos primeiros anos da década de sessenta, Blackvell e Asatoon publicaram casos de crises hipertensivas graves envolvendo fármacos inibidores da monoamino-oxidase $\mathrm{e}$ aminas biogênicas (tiramina e histamina) encontradas em diferentes alimentos e bebidas submetidas à fermentação (CARDONA PERA, 1999), incluindo-se mortes por acidentes cérebro-vascular (DAKOVIC-SVAJCER, 2002). Nos anos setenta foi descoberto que o cálcio dos produtos lácteos afetava a absorção das tetraciclinas e, a partir dessa década, passou-se a estudar a interação dos alimentos na farmacocinética. Nos anos oitenta, foram registrados casos letais de arritmias ventriculares em pacientes tratados com terfenadina que costumavam tomar suco de toronja (grapefruit) (DAKOVIC-SVAJCER, 2002). 
O estudo dos efeitos do alimento na absorção de fármacos passou a ter interesse no meio científico e regulatório a partir de 1977, quando foi publicada a primeira grande revisão sobre o assunto (WELLING, 1977). Desde então, tem crescido o número de estudos examinando os vários aspectos das interações fármaco-alimento e extensas revisões têm sido publicadas, abordando as interações dos fármacos individualmente ou por categorias, além de relacionar as conseqüências clínicas dessas interações (WELLING, 1996). Quanto à significância clínica das interações fármaco-alimentos, Cardona Pera (1999) e Dakovic-Svajcer (2002) destacam os fármacos de estreita faixa terapêutica, em que problemas de absorção ou metabolização podem alterar os níveis plasmáticos para níveis tóxicos ou de ineficácia terapêutica (digoxina, teofilina, ciclosporina) e os fármacos, no caso de muitos antibióticos, que devido ao mecanismo de ação, a variação dos níveis plasmáticos afeta criticamente a eficácia.

A co-administração de fármaco com alimento pode resultar em alterações nos perfis farmacocinético e farmacodinâmico. $\mathrm{O}$ alimento pode interagir nas fases: anterior e durante a absorção, durante a distribuição, metabolismo ou eliminação. A absorção e metabolismo são as fases onde o alimento tem os maiores efeitos, com conseqüência de perda de eficácia ou toxicidade.

A absorção dos fármacos pode ser diminuída, retardada, aumentada ou acelerada em presença de alimento. As interações fármaco-alimento são influenciadas tanto pela natureza do alimento como também pela formulação que contém o fármaco. O tipo e tamanho da refeição exercem grande influência, uma vez que refeições líquidas podem ter um efeito totalmente diferente na absorção do fármaco, comparada com refeições sólidas, de maior relevância clínica. O intervalo de tempo entre a alimentação e a medicação também afetará a natureza e extensão da interação fármaco-alimento. Estudos têm demonstrado que formulações mais dispersas são menos suscetíveis aos efeitos do alimento, ou seja, fármacos administrados em soluções são menos afetados pelo alimento do que na forma de comprimidos (WELLING, 1996). Administrar o fármaco com suco de fruta ou bebidas ácidas pode afetar a absorção pela alteração no $\mathrm{pH}$ 
gástrico. Geralmente, a presença de alimento no trato gastrintestinal (especialmente gorduras) reduz a velocidade de esvaziamento gástrico e retarda a absorção do fármaco.

Muitos fármacos têm uma baixa biodisponibilidade oral, mesmo com uma absorção gastrintestinal completa. Isto é devido ao extenso metabolismo présistêmico, durante a primeira passagem do fármaco pelo fígado. Em muitos casos o alimento inibe a depuração pré-sistêmica, aumentando a biodisponibilidade desses fármacos (propranolol, metoprolol, labetalol, dixirazina e hidralazina), quando administrados em comprimidos convencionais de liberação rápida, mas não quando administrados em formulações de liberação lenta. A ingestão prolongada de nutrientes específicos (proteínas) e contaminantes alimentares (benzopirenos) pode aumentar o metabolismo pré-sistêmico de fármacos pela indução enzimática (DAKOVIC-SVAJCER, 2002).

Os resultados dos estudos do efeito do alimento na absorção dos fármacos demonstram que muitos dos fármacos, cuja absorção foi reduzida ou aumentada, também exibiram absorção retardada em variadas intensidades. Os resultados indicam também que a natureza da interação fármaco-alimento pode ser, ao menos parcialmente, previsível, a partir da perspectiva físico-química, porém uma previsibilidade acurada é dificultada pelas muitas exceções que envolvem os processos naturais. O impacto clínico da interação fármaco-alimento depende da natureza e extensão da alteração dos níveis circulantes do fármaco, da margem de segurança e da inclinação da curva de concentração-resposta do fármaco. Uma pequena alteração dos níveis circulantes de um fármaco, cuja curva dose-resposta seja relativamente plana, pode ter uma significância clínica pequena. No entanto, uma grande alteração dos níveis circulantes de um fármaco com uma curva doseresposta altamente inclinada, e uma estreita margem de segurança, pode ter sérias conseqüências clínicas (WELLING, 1996).

As variações na absorção dos fármacos podem ser devido a uma série de diferentes efeitos. Em primeiro lugar, o efeito do alimento sobre o esvaziamento gástrico é considerável, sendo que variações na velocidade com que o alimento 
chega ao intestino delgado afetará a cinética dos fármacos. Em segundo lugar, o fármaco pode interagir com o alimento no lúmen intestinal, adsorvendo ou sendo adsorvido pelo alimento. A quelação de fármacos por íons metais presentes no alimento, como leite, ou ligação às proteínas da dieta alteram a biodisponibilidade. A presença de quimo viscoso pode atuar como barreira física, reduzindo o acesso do fármaco à superfície de absorção. Finalmente, o alimento pode influenciar o processo de absorção pela interferência direta na bioquímica intestinal; por exemplo, a absorção do fármaco estimulada pelo sistema de transporte de carboidratos pode ser desacelerada na presença de uma refeição rica de carboidratos, devido à competição pelos transportadores. $\mathrm{Na}$ prática, é extremamente difícil desembaraçar esses fatores, assim a maioria dos estudos simplesmente relata o efeito total. Alguns componentes do alimento têm um efeito particularmente importante na absorção dos fármacos. As fibras inibem a absorção da digoxina e capturam os esteróides; os alimentos derivados do leite, os quais têm alto conteúdo de metais polivalentes, como cálcio, magnésio, ferro, alumínio e zinco, inibem a absorção da tetraciclina. A biodisponibilidade de muitos fármacos é determinada pela solubilidade no $\mathrm{pH}$ local. No estômago, o pH é altamente variável, dependendo da presença de alimento, mas no intestino delgado é relativamente constante, em torno de 7,0. A absorção de fármacos pode ser modulada pela presença do alimento, que altera o $\mathrm{pH}$ gástrico, a viscosidade $\mathrm{e}$ o tempo de trânsito pelas várias seções do intestino (WASHINGTON; WASHINGTON; WILSON, 2001).

Suco de toronja (grapefruit) aumenta intensamente a biodisponibilidade de alguns fármacos, por exemplo lovastatina e sinvastatina, mas não pravastatina. O aumento na biodisponibilidade provavelmente resulta de inibição da CYP3A4 no intestino delgado. O efeito parece ser específico para o suco de grapefruit, não sendo reproduzido com outros sucos cítricos, como suco de laranja. Tem sido sugerido que o efeito inibidor do suco de grapefruit pode ser parcialmente neutralizado uma vez que ele também ativa o efluxo pela P-glicoproteína para alguns fármacos. A absorção de muitos fármacos de baixa solubilidade em água é 
aumentada quando administrados junto com uma refeição gordurosa. Sugere-se que o retardo do esvaziamento gástrico juntamente com a presença de lipídios aumentam a quantidade de fármaco dissolvido e assim, aumento da absorção. Foi demonstrado aumento de absorção para nitrofurantoína, diftalona e griseofulvina. A absorção de outros fármacos, como hidroclorotiazida e riboflavina, é aumentada na presença de alimento, possivelmente devido à saturação do mecanismo de absorção no estado de jejum, que não está saturado com o trânsito gastrintestinal mais lento na presença de alimento. Estudos mostraram que o volume de fluido pode influenciar a absorção de fármacos. Em muitos casos, os fármacos são mais completamente absorvidos com grandes volumes de fluido $(200 \mathrm{~mL})$ do que com pequenos volumes $(20 \mathrm{~mL})$. Isso parece ser devido, em parte, à maior velocidade de esvaziamento gástrico e em parte ao aumento do fluxo de fluido mucosal para o serosal (DENNIS, 1990).

Geralmente, o efeito do alimento é de retardamento da velocidade de absorção dos fármacos administrados oralmente, mas sem redução da fração absorvida da dose. A diminuição da velocidade de absorção ocorre principalmente, porque o alimento prolonga o tempo de esvaziamento gástrico. As características da refeição têm influência nos efeitos, por exemplo: refeições sólidas chegam a duplicar o tempo de esvaziamento em comparação com refeições líquidas. $\mathrm{O}$ alimento também estimula a motilidade intestinal, podendo diminuir a difusão de fármacos através da mucosa em função do movimento acelerado ao longo do intestino. A absorção pode ser aumentada em conseqüência do aumento do tempo de residência no estômago, permitindo um tempo maior para a dissolução das partículas de fármacos pouco solúveis. $\mathrm{O}$ aumento da motilidade intestinal pode também acelerar a dissolução. As gorduras do conteúdo alimentar estimulam o fluxo de bile, que contém agentes surfactantes e aumenta a dissolução de fármacos pouco solúveis, embora possa também formar sais insolúveis com alguns fármacos e reduzir a absorção destes. $\mathrm{O}$ alimento estimula um aumento no fluxo sanguíneo esplâncnico e isto tem um profundo efeito para fármacos de alta extração hepática. Lidocaína e propranolol 
têm uma maior biodisponibilidade quando ingeridos com alimento do que em jejum. Isto seria explicado pela passagem rápida pelo fígado quando administrado com alimento, reduzindo assim a extração hepática do fármaco (HANSCH, 1990).

\subsubsection{Efeitos do alimento na absorção de fármacos}

A ingestão de alimento desacelera o esvaziamento gástrico, eleva o $\mathrm{pH}$ do intestino delgado proximal, aumenta o fluxo sanguíneo hepático e prolonga o tempo de trânsito gastrintestinal em relação às condições no estado de jejum. Como resultado, o alimento pode afetar a biodisponibilidade sistêmica dos fármacos pela alteração da velocidade ou extensão (ou ambas) da absorção a partir do lúmen intestinal, ou por afetar a extração hepática. Os efeitos do alimento podem variar em função da quantidade e composição da refeição. Welling (1996) classificou as interações fármaco-alimento em cinco categorias, de acordo com as possíveis conseqüências na absorção do fármaco: as que reduzem, retardam, aumentam, aceleram e as que não afetam a absorção //Os efeitos na velocidade de absorção são refletidos em alterações na concentração plasmática máxima $\left(\mathrm{C}_{\max }\right)$ e os efeitos na extensão de absorção são refletidos em alterações na área sob a curva de concentração-tempo (ASC), bem como também na $\mathrm{C}_{\max }$. A ocorrência de efeitos de intensidade semelhantes em $\mathrm{C}_{\max }$ e ASC, com $\mathrm{t}_{\max }$ não sendo afetado, é indicativo de efeito do alimento somente na extensão de absorção. Se somente a velocidade de absorção é afetada pelo alimento, $\mathrm{t}_{\max }$ é atrasado, $\mathrm{C}_{\max }$ é reduzido, mas a ASC pode não ser afetada. No entanto, a velocidade e extensão de absorção são afetadas quando o efeito sobre a $\mathrm{C}_{\max }$ excede o efeito sobre a ASC e o $t_{\max }$ é atrasado (SINGH; MALHOTRA, 2004). 
4.4.1.1 Diminuição da velocidade (retardamento) da absorção

A diminuição da velocidade de absorção pela presença do alimento pode ocorrer especialmente com os fármacos de alta solubilidade/alta permeabilidade e rápida absorção oral. O principal mecanismo responsável é a diminuição da velocidade de esvaziamento gástrico, com diminuição da velocidade de apresentação do fármaco nos locais de absorção, ou seja, o intestino delgado. A presença do alimento no estômago atrasa o início do processo de absorção intestinal, o que é manifestado como diminuição da $C_{\max }$, aumento do $t_{\max } \mathrm{e}$ aumento do tempo para atingir concentrações plasmáticas mensuráveis ( $\left.\mathrm{t}_{\mathrm{lag}}\right)$. Uma absorção retardada ou com velocidade reduzida freqüentemente pode não afetar a ASC, enquanto a estabilidade do fármaco não seja afetada pela aumentada residência gástrica e a absorção na porção distal do intestino delgado seja boa. No entanto, pode atrasar o início da atividade terapêutica aguda. Para os fármacos administrados por longo período, esse efeito pode não ser clinicamente relevante, como demonstrado em estudos com atorvastatina (redutor de colesterol) e domitrobam (inibidor da agregação plaquetária). Uma absorção mais lenta em presença de alimento pode ser vantajosa em alguns casos, para evitar efeitos adversos e diminuir a toxicidade aguda. Um exemplo é a tansulosina, que tem rápida absorção gastrintestinal, o rápido aumento da concentração plasmática está associado a algumas reações adversas, tais como hipotensão ortostática e vertigem (SINGH; MALHOTRA, 2004; SINGH, 1999).

\subsubsection{Diminuição da absorção}

Na diminuição da absorção, o parâmetro farmacocinético relacionado com a extensão da absorção (ASC) é significativamente reduzido, com reflexos também na $\mathrm{C}_{\max }$. $\mathrm{O}$ efeito de diminuição da biodisponibilidade sistêmica pelo alimento ocorre particularmente com fármacos instáveis nos fluidos gástricos, fármacos que interagem irreversivelmente com os componentes da dieta ou que 
interagem de forma reversível, mas possuem janela de absorção na porção proximal do intestino delgado. Outro mecanismo possível é o aumento do metabolismo de primeira passagem ou aumento da depuração sistêmica, induzidos pela ingestão repetida de dietas específicas, por exemplo, refeições altamente protéicas e vegetais crucíferos (couve de Bruxelas e repolho).

A absorção do fármaco pode ser reduzida pelo aumento da viscosidade do conteúdo gastrintestinal, resultante da administração de formas farmacêuticas em suspensões contendo agentes indutores de viscosidade, da ingestão de alimentos contendo polímeros solúveis ou administração de suplementos de polímeros solúveis, geralmente com o objetivo de regular o movimento intestinal ou a absorção de glicose. A presença de quimo viscoso gerado por uma refeição sólida pode atuar como uma barreira física, reduzindo o acesso do fármaco à superfície de absorção do trato gastrintestinal. Os dados da literatura demonstram que o efeito da elevada viscosidade luminal na absorção gastrintestinal parece ser maior para os fármacos mais solúveis e resulta de uma combinação da diminuição das velocidades de dissolução e de esvaziamento gástrico (SINGH, 1999).

\subsubsection{Aumento da absorção}

O aumento da absorção ocorre quando a ASC é aumentada significativamente, geralmente associada com aumento de $\mathrm{C}_{\max }$. Os possíveis mecanismos envolvidos incluem: aumento de solubilização; diminuição do metabolismo de primeira passagem; alteração transitória da permeabilidade da membrana epitelial, causada por certos ácidos graxos presentes no alimento; aumento da ligação com lipoproteínas, no caso de fármacos lipofílicos e; aumento do transporte de íons, no caso de fármacos hidrofílicos, que tendem a formar íons com sais biliares. Estudos demonstram que, para fármacos pouco hidrossolúveis, a refeição altamente gordurosa tem maior capacidade de elevação da biodisponibilidade, em comparação com a refeição padrão ou com refeição 
altamente protéica, uma indicação de que o mecanismo comum para o aumento da absorção, nesses casos, seria o aumento da velocidade de solubilidade e dissolução (SINGH; MALHOTRA, 2004).

Singh (1999) esclarece que o alimento aumenta a absorção intestinal dos fármacos que têm uma absorção incompleta em conseqüência da pouca solubilidade nos fluidos gastrintestinais. $\mathrm{O}$ aumento da absorção intestinal resulta do demorado esvaziamento gástrico (aumentado tempo de residência gástrica) e secreção aumentada de sais biliares, causados pela ingestão de alimento e que podem aumentar a velocidade de dissolução. São exemplos clássicos de fármacos cuja absorção é favorecida pelos sais biliares: ciclosporina, halofantrina, griseofulvina e danazol. Também o maior volume de fluido gástrico induzido pela ingestão de alimento pode aumentar a solubilidade e dissolução do fármaco. O saquinavir tem aumento de biodisponibilidade atribuído ao aumento de solubilização, induzido pelo aumento do $\mathrm{pH}$ gástrico. Portanto, a absorção gastrintestinal do fármaco em presença de alimento é regida por uma combinação de dois ou mais fatores. Por exemplo, a rufinamida, um antiepilético de solubilidade moderada em $\mathrm{HCl} 0,1 \mathrm{~mol} / \mathrm{L}$ e em fluido intestinal simulado e de comportamento lipofílico, tem sua solubilidade modificada em presença de alimento possivelmente causada pelo aumento do fluido gástrico e pela estimulada secreção biliar. No caso da bropirimina, o aumento da dissolução, que aumenta a biodisponibilidade, seria resultado do maior tempo de residência gástrica a maior volume de fluido gástrico. $\mathrm{O}$ itraconazol, uma base fraca $(\mathrm{pKa}=$ 3,7), altamente lipofílico e quase insolúvel em água e em ácidos diluídos, tem sua absorção facilitada em presença de alimento por contribuição do baixo $\mathrm{pH}$ gástrico, longo tempo de residência no estômago e conteúdo gorduroso elevado da refeição.

A biodisponibilidade oral de fármacos altamente extraídos pelo fígado é aumentada quando administrados com alimento. O mecanismo envolvido é a diminuição do metabolismo de primeira passagem, baseado na relação entre fluxo sanguíneo hepático e depuração hepática. Esta interação está bem 
documentada para fármacos básicos e lipofilicos, o propranolol é um exemplo clássico. Durante o processo de absorção, as moléculas do fármaco atravessam o epitélio gastrintestinal e entram na rede capilar adjacente, pertencente à circulação esplâncnica, que conduz à circulação portal. A velocidade do fluxo sanguíneo através da rede capilar esplâncnica exerce um efeito significativo na absorção de fármacos. A ingestão de alimento aumenta o fluxo sanguíneo esplâncnico e, assim, aumenta a absorção do fármaco, como também aumenta a fração do fármaco que desvia o fígado durante a absorção. Assim, o aumento pós-prandial do fluxo sanguíneo esplâncnico pode está relacionado com o aumento da biodisponibilidade dos fármacos sujeitos a um extenso metabolismo de primeira passagem e depuração hepática saturável (SINGH, 1999).

A ingestão concomitante de alimento com medicamento pode afetar a liberação do fármaco a partir de algumas formulações. Isto tem grande relevância clínica para formulações de liberação estendida, em que o perfil de absorçãotempo do fármaco e o efeito clínico é controlado pela liberação do fármaco da formulação. As formulações com revestimento gastro-resistente podem liberar parcialmente o fármaco no estômago, quando tomadas com refeição. Nestes casos, o alimento pode ser um determinante significativo na eficácia e segurança de produtos orais de liberação controlada que exibem um padrão de liberação sensível ao $\mathrm{pH}$ (SINGH, 1999).

\subsubsection{Ausência de efeito do alimento na absorção de fármacos}

Em alguns casos não há alteração significativa na velocidade ou extensão da absorção. Os fármacos não afetados pelo alimento são aqueles com as seguintes características: são relativamente insensíveis às alterações que ocorrem no trato gastrintestinal após a entrada do alimento; são rápida e completamente absorvidos a partir do trato gastrintestinal e são bem absorvidos tanto no intestino delgado como no intestino grosso. Quando a biodisponibilidade do fármaco não é afetada pelo alimento, o mesmo pode ser administrado com ou sem alimento, não 
sendo necessária uma coordenação especial entre a administração e as refeições. Isto possibilita uma flexibilidade e viabiliza opções de administração, por exemplo, em situações em que a administração pode ser facilitada pela abertura das cápsulas (ou quebra do comprimido) e mistura do conteúdo com alimento ou suco de frutas, sem alteração do efeito terapêutico, uma característica importante para promover a adesão do paciente ao tratamento (SINGH; MALHOTRA, 2004).

\subsubsection{Fatores envolvidos na interação fármaco-alimento}

A velocidade e extensão da absorção de um fármaco a partir do intestino delgado dependem da liberação do fármaco da forma farmacêutica oral, da solubilidade e estabilidade do fármaco liberado na fase líquida do conteúdo gastrintestinal, do trânsito do fármaco ou da forma farmacêutica do estômago para o intestino, da permeabilidade do fármaco e da área superficial do(s) local(is) de absorção no trato gastrintestinal. O efeito total do alimento na farmacocinética é resultante da interação de múltiplos efeitos relacionados aos quatro elementos principais envolvidos na liberação do fármaco administrado oralmente: fármaco, formulação, fisiologia gastrintestinal e refeição (SINGH; MALHOTRA, 2004).

\subsubsection{Fatores relacionados à refeição}

Os estudos demonstram aumento significativo da biodisponibilidade de fármacos na presença de refeições altamente gordurosas, em comparação com refeições de conteúdos elevados em proteínas ou carboidratos. Também observase absorção de fármacos prejudicada em indivíduos vegetarianos.

O tempo de administração do fármaco em relação à refeição também é um fator de influência na biodisponibilidade. A administração do fármaco ao mesmo tempo da refeição, ou imediatamente antes, ou imediatamente após, pode 
diminuir a velocidade da absorção em função da diminuição da velocidade de esvaziamento gástrico. O volume da refeição, que também afeta o tempo de esvaziamento gástrico, pode ser um fator significativo nos efeitos do alimento sobre a biodisponibilidade de fármacos.

a) Refeição altamente gordurosa

Uma refeição altamente gordurosa pode aumentar significativamente a absorção gastrintestinal dos fármacos lipofílicos em particular, como os retinóides acitretina, etretinato, fenretinida, temaroteno, isotretinoína e tretinoína. O aumento da absorção pode ser resultado da combinação de mecanismos físicoquímicos e fisiológicos. Os mecanismos físico-químicos incluem o aumento da solubilidade e dissolução do fármaco nos componentes da refeição e um possível aumento do poder de penetração do fármaco na membrana intestinal, em função de uma maior lipossolubilidade na presença da refeição gordurosa.

Os principais mecanismos fisiológicos em resposta à refeição gordurosa são: aumento da secreção biliar, diminuição da velocidade de esvaziamento gástrico, aumento da motilidade intestinal e aumento da absorção linfática.

$\mathrm{O}$ aumento do transporte de fármacos via sistema linfático pode minimizar o metabolismo de primeira passagem, por não conduzir o fármaco diretamente para o fígado. A dissolução dos fármacos pode ser aumentada pelos sais biliares, pelo maior tempo de residência gástrica e pelo aumento do volume de fluidos, constituídos pelos líquidos ingeridos e pelas secreções induzidas pelo alimento.

b) Refeição altamente protéica

Estudos em humanos têm demonstrado que o fluxo sanguíneo esplâncnico aumenta durante as primeiras horas após uma refeição altamente protéica, enquanto com uma refeição de alto teor de carboidratos este efeito é pequeno ou não é observado. A este efeito atribui-se o aumento da biodisponibilidade, como 
observado com fenretinida, quando administrada com refeição altamente protéica, comparada com refeição de alto teor de carboidratos ou em jejum. O aumento do fluxo sanguíneo esplâncnico reduz a fração do metabolismo de primeira passagem no fígado, uma vez que é diminuído o tempo de trânsito do fármaco neste órgão.

Um importante aspecto relacionado à refeição altamente protéica é o mecanismo da indução enzimática, que pode diminuir a biodisponibilidade oral de alguns fármacos. Aminoácidos da dieta, particularmente $l$-leucina e $l$ glutamina, são implicados na redução significativa da biodisponibilidade por interferirem na absorção intestinal dos fármacos, como observado com melfalana, em pacientes portadores câncer. Investigações sugerem o mecanismo de inibição competitiva do transporte de melfalana no local de absorção por aminoácidos estruturalmente relacionados. Para gabapentina, foram observados aumento na $\mathrm{C}_{\max }$ e $\mathrm{ASC}$ com refeição protéica, tal aumento foi atribuído ao efeito de trans-estimulação, em que a elevada concentração de aminoácidos no lúmen intestinal resulta numa regulação para cima, com aumento da atividade do transportador de L-aminoácido (SINGH; MALHOTRA, 2004; SINGH, 1999).

c) Refeições ricas em carboidratos e fibras

A biodisponibilidade da metformina mostrou-se reduzida quando administrada com desjejum de baixo teor de gorduras e alto teor de carboidratos. O efeito da morfina é elevado em indivíduos que consomem continuadamente alimentos ricos em carboidratos (DAKOVIC-SVAJCER, 2002).

Alguns trabalhos relatam a diminuição da absorção da lovastatina com dietas ricas em fibras, como farinha de aveia e fibra cereal solúvel; diminuição da biodisponibilidade da tiroxina com ingestão de farelo de trigo, pelo mecanismo de adsorção do fármaco às fibras da dieta.

$\mathrm{Na}$ Tabela 1 estão indicados os possíveis mecanismos de interação de fármacos de acordo com a composição da refeição. 
Tabela 1 - Efeitos da interação da refeição na absorção de fármacos.

\begin{tabular}{lll}
\hline Composição da refeição & $\begin{array}{l}\text { Possível mecanismo de } \\
\text { interação }\end{array}$ & Exemplos \\
\hline Carboidrato & $\begin{array}{l}\text { Diminuição da } \\
\text { velocidade de } \\
\text { esvaziamento gástrico. }\end{array}$ & $\begin{array}{l}\text { Aumento da absorção: } \\
\text { fenitoína. }\end{array}$ \\
Proteína & $\begin{array}{l}\text { Aumento do pH gástrico; } \\
\text { ligações. }\end{array}$ & $\begin{array}{l}\text { Diminuição da absorção: } \\
\text { indinavir. }\end{array}$ \\
Gordura & $\begin{array}{l}\text { Aumento de volume do } \\
\text { fluido luminal; } \\
\text { estimulação da secreção } \\
\text { pancreática e biliar; } \\
\text { solubilização de fármaco } \\
\text { lipofilico com sais }\end{array}$ & $\begin{array}{l}\text { Aumento da absorção: } \\
\text { fenitoína. }\end{array}$ \\
& $\begin{array}{l}\text { biliares. } \\
\text { Ligaçães; diminuição da } \\
\text { velocidade de } \\
\text { esvaziamento gástrico; } \\
\text { diminuição da } \\
\text { velocidade de difusão. }\end{array}$ & Diminuição da absorção: \\
& metformina. \\
\hline
\end{tabular}

(Adaptado de FLEISHER et al., 1999)

4.4.2.2 As propriedades do fármaco e a classificação biofarmacêutica

Em geral, o alimento influencia os fármacos cuja absorção ocorre principalmente nas regiões superiores do trato gastrintestinal. Se um fármaco apresenta solubilidade e perfil de dissolução independente de $\mathrm{pH}$ (um composto neutro), deverá, em teoria, apresentar uma maior biodisponibilidade na presença de alimento, desde que a estabilidade não esteja comprometida em $\mathrm{pH}$ mais elevado. Isto é consistente com os efeitos da presença do alimento: prolongamento do tempo de retenção da formulação e favorecimento da dissolução e absorção. Estes benefícios são mais importantes para fármacos que 
apresentam boa permeabilidade. Para a clorambucila, que sofre hidrólise rápida em meio aquoso, a prolongada retenção gástrica com alimento causa diminuição da biodisponibilidade. O efeito de solubilização com alimento gorduroso aumenta a velocidade de absorção dos fármacos pouco hidrossolúveis, mas pode não resultar em alteração da biodisponibilidade total para os fármacos absorvidos extensivamente no intestino, tanto no delgado como no grosso. O danazol é um bom exemplo de composto neutro, não ionizável, pouco hidrossolúvel, absorvido principalmente no intestino delgado superior, cuja biodisponibilidade oral é aumentada pelo efeito da solubilização em alimento gorduroso (SINGH; MALHOTRA, 2004).

Os dados da literatura mostram uma menor probabilidade do alimento afetar a extensão de absorção dos fármacos cuja absorção gastrintestinal é rápida e completa, embora a velocidade possa ser afetada, na forma de diminuição da $\mathrm{C}_{\max }$ e aumento do $t_{\max }$, em função do aumento do tempo de esvaziamento gástrico.

O sistema de classificação biofarmacêutica ( $\mathrm{SCB}$ ) desenvolvido por Amidon et al. (1995) classifica os fármacos com base na solubilidade em meio aquoso e na permeabilidade através de membranas (Tabela 2). 
Tabela 2 - Classificação dos fármacos pelo Sistema de Classificação Biofarmacêutica (SCB)

\begin{tabular}{cccl}
\hline Classe & Solubilidade & Permeabilidade & Exemplos* \\
\hline I & Alta & Alta & $\begin{array}{l}\text { Paracetamol, ácido valpróico } \\
\text { (valproato de sódio), cetoprofeno, } \\
\text { disopiramida, verapamil e } \\
\text { metoprolol. }\end{array}$ \\
II & Baixa & Alta & $\begin{array}{l}\text { Griseofulvina, digoxina, fenitoína, } \\
\text { ciclosporina, danazol, } \\
\text { carbamazepina e espironolactona. }\end{array}$ \\
III & Alta & Baixa & Furosemida e bidisomida. \\
IV & Baixa & Baixa & Anfotericina B, colistina. \\
\hline
\end{tabular}

*(FLEISHER et al., 1999)

Os fármacos da classe I (SCB) são bem absorvidos e pouco afetados pelas interações que alteram a absorção. Como o esvaziamento gástrico freqüentemente controla a velocidade de absorção dos fármacos dessa classe, as interações que retardam o esvaziamento gástrico poderão diminuir a velocidade de absorção (Tabela 3). Para os fármacos da classe II (SCB), de baixa solubilidade em meio aquoso, a absorção é limitada pela velocidade de dissolução. Qualquer interação que aumente a solubilidade e a velocidade de dissolução no trato gastrintestinal terá um efeito positivo na absorção dos fármacos dessa classe. Assim, a absorção dos fármacos da classe II é freqüentemente aumentada na proporção do conteúdo gorduroso da refeição coadministrada (Tabela 3). A velocidade de absorção dos fármacos da classe III (SCB), em formulações orais de liberação imediata, freqüentemente é limitada pela velocidade de permeação na membrana intestinal. Muitos fármacos dessa classe também mostram absorção site-dependente, com melhor absorção no intestino delgado superior. Em função disso, qualquer interação que comprometa a absorção no intestino delgado superior pode resultar em uma redução significativa da biodisponibilidade oral. Devido a essas características, muitos 
fármacos da classe III mostram uma intensa diminuição da absorção quando administrados com refeição, independentemente do conteúdo de gorduras (FLEISHER et al., 1999).

Os fármacos da classe IV (SCB), de baixa solubilidade e baixa permeabilidade, possuem baixa biodisponibilidade quando adiministrados oralmente. A absorção desses fármacos geralmente é demorada (prolongado $t_{\max }$ ) e ocorre melhor na região superior do intestino, em função da maior área superficial de mucosa para absorção. Li et al. (1998) verificaram, em estudo com um novo composto antifúngico, diminuição da absorção com refeições gordurosa e protéica e ausência de efeitos com refeição rica em carboidratos. 
Tabela 3 - Interações fármaco-alimento conforme a classificação biofarmacêutica em formulações de liberação imediata.

\begin{tabular}{cll}
\hline $\begin{array}{c}\text { Classe } \\
\text { (SCB) }\end{array}$ & $\begin{array}{l}\text { Efeito do alimento na } \\
\text { absorção }\end{array}$ & Exemplos \\
\hline I & Não alteração & $\begin{array}{l}\text { Oxaprozina, ácido valpróico (valproato de } \\
\text { sódio), disopiramida e verapamil. }\end{array}$ \\
& $\begin{array}{l}\text { Diminuição da } \\
\text { velocidade }\end{array}$ & $\begin{array}{l}\text { Cetoprofeno, midazolam, misoprostol e } \\
\text { teofilina. }\end{array}$ \\
II & $\begin{array}{l}\text { Absorção aumentada } \\
\text { com gorduras }\end{array}$ & $\begin{array}{l}\text { Griseofulvina, fenitoína, ciclosporina e } \\
\text { danazol. }\end{array}$ \\
III & $\begin{array}{l}\text { Diminuição da } \\
\text { absorção }\end{array}$ & $\begin{array}{l}\text { Furosemida, captopril, alendronato e } \\
\text { bidisomida. }\end{array}$ \\
IV & $\begin{array}{l}\text { Baixa absorção, com } \\
\text { ou sem alimento }\end{array}$ & Mebendazol e neomicina. \\
\hline (FLEISHER et al., 1999) &
\end{tabular}

\subsubsection{Mecanismos físico-químicos e fisiológicos}

O alimento influencia a absorção de fármacos através de interações físicoquímicas e fisiológicas. As Tabelas 4 e 5 relacionam alguns desses mecanismos físico-químicos e fisiológicos, respectivamente, com as possíveis conseqüências sobre a absorção dos fármacos. As Tabelas 6 e 7 apresentam as interações fármaco-alimento de natureza físico-química e fisiológica, respectivamente, com exemplos dos efeitos na absorção de fármacos. 
Tabela 4 - Efeitos na absorção do fármaco em função das alterações nas propriedades físico-químicas.

\begin{tabular}{ll}
\hline Propriedade físico-química & Possível efeito na absorção \\
\hline Aumento da velocidade de dissolução & $\begin{array}{l}\text { Aumento da velocidade e extensão de } \\
\text { absorção. }\end{array}$ \\
Aumento da velocidade de degradação & $\begin{array}{l}\text { Diminuição da concentração luminal } \\
\text { do fármaco e da extensão de absorção. }\end{array}$ \\
Diminuição da velocidade de difusão & $\begin{array}{l}\text { Diminuição da velocidade de difusão } \\
\text { radial no lúmen intestinal, causando } \\
\text { diminuição da velocidade e/ou } \\
\text { extensão de absorção. }\end{array}$ \\
\hline
\end{tabular}

(FLEISHER et al., 1999) 
Tabela 5 - Efeitos potenciais na absorção de fármacos em função de alterações na fisiologia gastrintestinal.

\begin{tabular}{|c|c|}
\hline Função fisiológica & Possível efeito na absorção \\
\hline \multicolumn{2}{|l|}{ No lúmen: } \\
\hline $\begin{array}{l}\text { Diminuição da velocidade de } \\
\text { esvaziamento gástrico }\end{array}$ & $\begin{array}{l}\text { Diminuição da absorção para fármacos } \\
\text { instáveis; aumento da absorção para } \\
\text { fármacos de baixa solubilidade. }\end{array}$ \\
\hline Aumento da secreção ácida & $\begin{array}{l}\text { Aumento da absorção para fármacos } \\
\text { básicos instáveis; diminuição da } \\
\text { absorção para fármacos ácidos lábeis. }\end{array}$ \\
\hline Aumento da motilidade intestinal & $\begin{array}{l}\text { Aumento da absorção devido ao } \\
\text { aceleramento da dissolução; } \\
\text { diminuição da absorção devido à } \\
\text { diminuição do tempo de trânsito. }\end{array}$ \\
\hline Aumento da secreção biliar & $\begin{array}{l}\text { Aumento da absorção devido à } \\
\text { solubilização micelar; diminuição da } \\
\text { absorção pela complexação com sais } \\
\text { biliares. }\end{array}$ \\
\hline \multicolumn{2}{|l|}{ Na membrana: } \\
\hline Absorção site-dependente & $\begin{array}{l}\text { Diminuição da absorção se estreita } \\
\text { janela de absorção. }\end{array}$ \\
\hline Processo ativo de absorção & $\begin{array}{l}\text { Diminuição da absorção em caso de } \\
\text { inibição competitiva; aumento da } \\
\text { absorção em caso de trans-estimulação } \\
\text { ou troca. }\end{array}$ \\
\hline Eliminação intestinal & $\begin{array}{l}\text { Diminuição da absorção sistêmica; } \\
\text { aumento da absorção em caso de } \\
\text { inibição competitiva. }\end{array}$ \\
\hline Fluxo sanguíneo esplâncnico & $\begin{array}{l}\text { Aumento da absorção em caso de } \\
\text { aumento da velocidade do fluxo } \\
\text { sanguíneo, com efeitos variáveis sobre } \\
\text { o metabolismo de primeira passagem. }\end{array}$ \\
\hline
\end{tabular}

(FLEISHER et al., 1999) 
Tabela 6 - Interações fármaco-alimento de natureza físico-química e seus efeitos na absorção de fármacos.

\begin{tabular}{ll}
\hline Interação & Exemplos \\
\hline $\begin{array}{l}\text { pH: a elevação do pH causa } \\
\text { diminuição da dissolução para } \\
\text { fármacos básicos. }\end{array}$ & $\begin{array}{l}\text { Diminuição da absorção: indinavir e } \\
\text { isoniazida. }\end{array}$ \\
$\begin{array}{l}\text { Ligação e adsorção: diminuição da } \\
\text { dissolução (alimento com fibras, } \\
\text { cereais e goma guar). }\end{array}$ & $\begin{array}{l}\text { Diminuição da absorção: } \\
\text { fenoximetilpenicilina (penicilina V), } \\
\text { paracetamol, norfloxacino, metformina } \\
\text { e digoxina. }\end{array}$ \\
$\begin{array}{l}\text { Quelação: por íons metálicos do } \\
\text { alimento, especialmente derivados do } \\
\text { leite }\end{array}$ & $\begin{array}{l}\text { Diminuição da absorção: didanosina } \\
\text { (formulada com antiácidos), } \\
\text { tetraciclina e fluorquinolonas } \\
\text { (ciprofloxacino, enoxacino e } \\
\text { ofloxacino). }\end{array}$ \\
$\begin{array}{l}\text { Degradação } \\
\text { Geralmente a estabilidade do fármaco } \\
\text { pode ser melhorada pela formulação } \\
\text { ou modificação da molécula. }\end{array}$ \\
$\begin{array}{l}\text { Velocidade de difusão: aumento da } \\
\text { viscosidade e diminuição da }\end{array}$ & $\begin{array}{l}\text { Diminuição da absorção: bidisomida, } \\
\text { furosemida e clorotiazida; diminuição } \\
\text { da velocidade sem alteração da } \\
\text { extensão da absorção: disopiramida e } \\
\text { sólidos, alto conteúdo de fibras). }\end{array}$ \\
\hline
\end{tabular}

(Adaptado de FLEISHER et al., 1999) 
Tabela 7 - Interações fármaco-alimento de natureza fisiológica e seus efeitos na absorção de fármacos.

\begin{tabular}{ll}
\hline Interação & Exemplos \\
\hline Trânsito gastrintestinal: aumento do & Aumento da absorção: clorotiazida, \\
tempo de esvaziamento gástrico. & rufinamida, fenitoína, propoxifeno, \\
& $\begin{array}{l}\text { espironolactona, hidroclorotiazida, } \\
\text { nitrofurantoína, eritromicina e } \\
\text { riboflavina. }\end{array}$
\end{tabular}

Aumento da secreção ácida: promove hidrólise.

Diminuição da absorção: diclofenaco de sódio, benzilpenicilina (penicilina

G), fenoximetilpenicilina (penicilina

$\mathrm{V})$, estearato de eritromicina, clorpromazina, amoxicilina e ampicilina.

Aumento da secreção biliar: solubilização de fármacos lipofílicos com sais biliares.

Aumento da absorção: fenitoína, carbamazepina, dicumarol, diazepam e griseofulvina.

Aumento de secreção enzimática

Aumento da absorção: estolato de eritromicina.

Processo ativo de absorção elevado:

Diminuição da absorção: levodopa e competição ou inibição dos transportadores comuns. metildopa; Não alteração: baclofeno, gabapentina e cefalosporinas.

Eliminação intestinal elevada: competição ou inibição de enzimas metabolizadoras (exemplo: suco de grapefruit).

Aumento da absorção: felodipina, terfenadina, astemizol, benzodiazepinas, hidralazina, metoprolol e propranolol.

Aumento do fluxo sanguíneo Aumento da absorção: propranolol, esplâncnico: diminuição do labetolol e metoprolol. metabolismo de primeira passagem. (Adaptado de FLEISHER et al., 1999) 


\subsubsection{Influência da formulação}

As investigações do efeito do tipo de formulação na bioequivalência de fármacos, em condições de jejum e alimento, demonstraram que os efeitos do alimento podem variar consideravelmente, dependendo do tipo de formulação. Estudos com isotretinoína mostraram efeito significativo do alimento na formulação padrão, enquanto que na formulação micronizada, o efeito foi mínimo. O reduzido efeito do alimento na formulação micronizada pode ser atribuído principalmente ao fato de que a micronização aumenta a velocidade de dissolução dos fármacos pouco solúveis, em função do aumento da área superficial das partículas (SINGH; MALHOTRA, 2004).

Fármacos de permeabilidade site-dependente têm absorção potencialmente afetada pelas interações com alimento. Uma das mais significativas interações na absorção de fármacos envolve o tempo de residência gastrintestinal e ocorre com formulações orais de liberação controlada. As preocupações com essas formulações devem-se ao efeito de liberação intensa e rápida da dose (dose dumping): Este efeito foi primeiramente observado com uma formulação oral de liberação controlada de teofilina, em que a liberação controlada foi mantida em voluntários no estado de jejum, mas quando esta formulação foi administrada com uma refeição altamente gordurosa, um aumento na velocidade e extensão de absorção resultou em altas concentrações plasmáticas e toxicidade (FLEISHER et al., 1999).

Waldman e Morganroth (1995) compararam as farmacocinéticas entre produtos genérico e referência de verapamil em comprimidos de liberação sustentada, que se apresentaram similares nos estudos de dose única e múltipla, em jejum. No entanto, com alimentação, a formulação genérica exibiu absorção mais rápida.

Holmes e Kutz (1993) compararam as propriedades farmacocinéticas entre formulações de liberação controlada e liberação imediata de isradipina, sob condições de jejum e alimentação. Em condições de jejum, as cápsulas de 
liberação imediata apresentaram ASC similar aos comprimidos de liberação controlada. Com alimentação, a ASC dos comprimidos (liberação controlada) foi 20\% maior em relação às cápsulas (liberação imediata), sendo que as cápsulas apresentaram $\mathrm{t}_{\max }$ menor e $\mathrm{C}_{\max }$ maior, ambos de forma considerável, em relação aos comprimidos. Essas diferenças nos parâmetros farmacocinéticos foram atribuídas, em parte, às diferenças das formulações.

Benziger et al. (1996) não observaram efeito significativo do alimento em comprimidos de liberação controlada de oxicodona, nos parâmetros ASC e $\mathrm{C}_{\max }$ nas condições de jejum e alimentação. Entretanto, os valores de $\mathrm{ASC}$ e $\mathrm{C}_{\max }$ foram alterados significativamente para a forma de liberação imediata (solução), após o consumo de uma refeição altamente gordurosa.

Os dados disponíveis demonstram a importância da realização de estudos de bioequivalência com alimento para formulações de liberação controlada, em função do potencial de interações do alimento com essas formulações.

\subsubsection{Efeitos do alimento no metabolismo de fármacos}

Os efeitos da dieta no metabolismo de fármacos são extensamente descritos na literatura. Certos alimentos podem causar profundos efeitos no metabolismo dos fármacos, levando a alterações na depuração e possíveis efeitos tóxicos. É conhecida a influência: da refeição protéica, de alguns vegetais e de metilxantinas no metabolismo de alguns fármacos. O estado de má nutrição também pode estar associado à: diminuição da biodisponibilidade, reduzida ligação fármaco-proteínas, flutuações no volume de distribuição, alterações de metabolismo hepático e redução de excreção renal de vários fármacos (SINGH, 1999).

As interações metabólicas fármaco-alimento são semelhantes às interações metabólicas fármaco-fármaco, ambas ocorrem quando a administração de um xenobiótico (indutor ou inibidor) modula o metabolismo e a farmacocinética de outro xenobiótico (o fármaco substrato). Essas interações podem resultar em 
intensa variabilidade farmacocinética, havendo relatos de alterações de mais de dez vezes nas concentrações de fármacos. Como a maioria dos xenobióticos que entra no organismo são componentes da dieta, é razoável prever que esses possam modular o metabolismo de fármacos e, assim como as interações fármaco-fármaco, possam resultar em severos efeitos adversos ou falha terapêutica (HARRIS; JANG; TSUNODA, 2003).

A Tabela 8 relaciona os principais sistemas enzimáticos e transportadores envolvidos na disposição de fármacos, com alguns de seus substratos. 
Tabela 8 - Enzimas e transportadores envolvidos na disposição de fármacos em humanos.

\begin{tabular}{ll}
\hline $\begin{array}{l}\text { Enzima ou } \\
\text { transportador }\end{array}$ & Exemplos de substratos \\
\hline CYP1A2 & Cafeína, clozapina, fluvoxamina, imipramina e teofilina. \\
CYP2C9 & Ibuprofeno, diclofenaco, tolbutamida e $S$-varfarina. \\
CYP2C19 & S-mefenitoína, omeprazol e proguanil. \\
CYP2D6 & Carvedilol, desipramina, dextrometorfano e tioridazina. \\
CYP2E1 & Etanol, clorzoxazona, halotano e enflurano. \\
CYP3A4 & $\begin{array}{l}\text { Ciclosporina, terfenadina, midazolam, eritromicina, muitos } \\
\text { inibidores de HIV-protease, antagonistas dos canais de cálcio } \\
\text { e estatinas. }\end{array}$ \\
UGT & Paracetamol, oxazepam, lorazepam, zidovudina e morfina. \\
P-glicoproteína & Ciclosporina, digoxina, fexofenadina e loperamida. \\
OATP & Fexofenadina, digoxina e pravastatina. \\
\hline $\begin{array}{l}\text { CYP: cytochrome P450; OATP: organic anion transporting polypeptide; UGT: } \\
\text { (Adaptado de HARR }\end{array}$
\end{tabular}

A investigação da cinética metabólica no estado alimentado é relevante do ponto de vista da bioequivalência, especialmente quando o(s) metabólito(s) exerce(m) um importante papel na eficácia e segurança do fármaco ou quando o ensaio do composto não transformado é crítico (CHEN; JACKSON, 1995; MARZO, 1999). Os resultados podem fornecer esclarecimentos sobre os mecanismos de indução ou inibição enzimática, quando os fármacos são administrados com alimento. Singh e Malhotra (2004) destacam que, em termos de indução, seria interessante examinar os efeitos de uma refeição altamente protéica sobre o metabolismo, uma vez que o alto teor de proteínas pode causar 
indução enzimática. E para a inibição metabólica, seria interessante examinar o efeito do suco de grapefruit, um conhecido inibidor de citocromo P450 (CYP)3A4 intestinal. Nos casos em que a ingestão concomitante de alimentos diminui a biodisponibilidade de um metabólito, ativo ou não, é possível que o alimento esteja inibindo o metabolismo no trato gastrintestinal ou no fígado. Esses efeitos podem ter sérias implicações terapêuticas, especialmente para prófármacos. Por outro lado, a acelerada formação de metabólitos no estado alimentado é uma indicação de que a administração do pró-fármaco com alimento pode resultar em aumento dos efeitos tóxicos do(s) metabólito(s).

A ingestão crônica de baixo conteúdo energético diminui a atividade dos sistemas enzimáticos de metabolização de fármacos, enquanto a ingestão de alto conteúdo energético e protéico aumenta o metabolismo de fármacos. Por exemplo, as depurações de aminopirina e fenazona mostraram-se significativamente reduzidas em baixa energia. Independentemente do conteúdo energético, a ingesta de alto conteúdo protéico aumenta a atividade das enzimas do metabolismo hepático de fármacos (HARRIS; JANG; TSUNODA, 2003).

Algumas interações fármaco-alimento relacionadas com metabolismo e transporte são apresentadas na Tabela 9. As interações que afetam a disposição dos fármacos administrados oralmente que são substratos de CYP3A4 ou de Pglicoproteína são clinicamente importantes, com potencial necessidade de ajustes de dose. Geralmente as interações envolvendo CYP1A2, CYP2E1, UGT e GST são de menor importância clínica. Em função da variabilidade e complexidade das dietas e da variabilidade inter-individual na atividade dos sistemas enzimáticos, torna-se muito difícil avaliar a freqüência e a relevância clínica dessas interações. 
Tabela 9 - Interações fármaco-alimento envolvendo enzimas e transportadores.

\begin{tabular}{|c|c|c|}
\hline $\begin{array}{l}\text { Enzima ou } \\
\text { transportador }\end{array}$ & $\begin{array}{l}\text { Componente da } \\
\text { dieta }\end{array}$ & Comentários \\
\hline \multirow[t]{5}{*}{ CYP3A4 } & Suco de grapefruit & $\begin{array}{l}\text { Potente inibidor. Aumento da ASC em } \\
\text { até } 300 \% \text { para ciclosporina, } \\
\text { midazolam, terfenadina e felodipino. }\end{array}$ \\
\hline & $\begin{array}{l}\text { Suco de laranja } \\
\text { sevilha }\end{array}$ & $\begin{array}{l}\text { Inibidor. Aumento de } 76 \% \text { da ASC de } \\
\text { felodipino. Outros tipos de suco de } \\
\text { laranja não apresentam efeito. }\end{array}$ \\
\hline & Vinho tinto & $\begin{array}{l}\text { Moderado inibidor/inativador. } \\
\text { Aumento de } 15 \% \text { da ASC de } \\
\text { felodipino. Dependendo do momento } \\
\text { da administração, aumento de } 13 \% \text { ou } \\
\text { diminuição de } 30 \% \text { da ASC de } \\
\text { ciclosporina. }\end{array}$ \\
\hline & Erva de São João & $\begin{array}{l}\text { Potente indutor. Diminuição até } 60 \% \\
\text { da ASC de ciclosporina, indinavir e } \\
\text { alprazolam. }\end{array}$ \\
\hline & Alho & $\begin{array}{l}\text { Indutor. Diminuição de } \\
\text { aproximadamente } 50 \% \text { da ASC de } \\
\text { saquinavir. }\end{array}$ \\
\hline \multirow[t]{3}{*}{ CYP1A2 } & Cafeína & $\begin{array}{l}\text { Moderado indutor. Aumento de } 17 \% \\
\text { da meia-vida da cafeína, após } 21 \text { dias } \\
\text { de abstinência da ingestão intensa de } \\
\text { cafeína. }\end{array}$ \\
\hline & Suco de grapefruit & $\begin{array}{l}\text { Inibidor potencial. Aumento de } 30 \% \\
\text { da ASC de cafeína. Não alteração da } \\
\text { farmacocinética oral para teofilina, } \\
\text { cafeína e clozapina também foi } \\
\text { demonstrado. }\end{array}$ \\
\hline & Suco de uva jufeng & $\begin{array}{l}\text { Ativador potencial. Diminuição de } \\
50 \% \text { da ASC oral de fenacetina. }\end{array}$ \\
\hline
\end{tabular}

(Continua) 
Tabela 9-(Continuação)

\begin{tabular}{|c|c|c|}
\hline $\begin{array}{l}\text { Enzima ou } \\
\text { transportador }\end{array}$ & $\begin{array}{l}\text { Componente da } \\
\text { dieta }\end{array}$ & Comentários \\
\hline & Vegetais crucíferos & $\begin{array}{l}\text { Indutor. Diminuição de } 49 \% \text { da ASC } \\
\text { de fenacetina. }\end{array}$ \\
\hline & Carne assada & $\begin{array}{l}\text { Indutor. Diminuição da ASC oral de } \\
\text { fenacetina, com diminuição de } \\
\text { aproximadamente } 75 \% \text { do } C_{\max } \text {. }\end{array}$ \\
\hline \multirow[t]{2}{*}{ CYP2E1 } & Etanol & $\begin{array}{l}\text { Indutor. ASC de clorzoxazona } \\
\text { aproximadamente } 50 \% \text { menor em } \\
\text { alcoólatras. Aumento de } 30 \% \text { da ASC } \\
\text { oral de etanol, devido ao verapamil. }\end{array}$ \\
\hline & Agrião & $\begin{array}{l}\text { Inibidor. Aumento de } \\
\text { aproximadamente } 50 \% \text { da ASC oral } \\
\text { para clorzoxazona. }\end{array}$ \\
\hline Enzimas de fase II & Vegetais & $\begin{array}{l}\text { Indutores moderados em potencial } \\
\text { para UGT e GST. }\end{array}$ \\
\hline \multirow[t]{2}{*}{ Transportadores } & Sucos de frutas & $\begin{array}{l}\text { Inibição da P-glicoproteína pelo suco } \\
\text { de grapefruit, mas não pelo suco de } \\
\text { laranja. Aumento de aproximadamente } \\
40 \% \text { da ASC de ciclosporina. Diversos } \\
\text { sucos são inibidores potenciais de } \\
\text { OATP no intestino. Diminuição de } 60 \text { - } \\
70 \% \text { da ASC de fexofenadina. }\end{array}$ \\
\hline & Erva de São João & $\begin{array}{l}\text { Indutor da P-glicoproteína. } \\
\text { Diminuição de } 25 \% \text { da ASC de } \\
\text { digoxina. }\end{array}$ \\
\hline $\begin{array}{l}\text { ASC: área sob a } \\
\text { plasmática máxin } \\
\text { polypeptide; UGr } \\
\text { glutathione S-tra }\end{array}$ & $\begin{array}{l}\text { de concentraçã } \\
\text { YP: cytochrome } \\
\text { idine diphosphat } \\
\text { ase. }\end{array}$ & $\begin{array}{l}\text { asmática - tempo; } \mathrm{C}_{\max }: \text { concentração } \\
\text { 150; OATP: organic anion transporting } \\
\text { ucuronosyltransferase; } \mathrm{GST} \text { : }\end{array}$ \\
\hline
\end{tabular}

(Adaptado de HARRIS; JANG; TSUNODA, 2003) 


\subsection{REQUERIMENTOS DOS ESTUDOS DE BIODISPONIBILIDADE SOB EFEITO DO ALIMENTO}

A determinação da biodisponibilidade sistêmica, após administração pela via desejada, é de crucial importância para um fármaco novo, ou seja, uma inovação terapêutica. Quando o fármaco é desenhado para administração sistêmica, sendo a via adequada outra que não a intra-venosa, deve ser determinada a extensão do fármaco perdido durante o processo de absorção ou eliminação pré-sistêmica. No caso da administração oral, os fatores de perda incluem: metabolismo hepático de primeira passagem, metabolismo da parede intestinal, degradação devido ao $\mathrm{pH}$, complexação ou interação com outras substâncias fisiológicas do trato gastrintestinal (MORAIS, 1995).

A biodisponibilidade absoluta pela via oral é determinada comparando-se a área sob a curva de concentração plasmática do fármaco versus tempo (ASC) da administração oral com a ASC da administração intra-venosa (bolus). Na impossibilidade da administração intra-venosa, pode ser empregada uma solução aquosa do fármaco (com adição de agente solubilizante, se necessário) ou suspensão do fármaco micronizado. A escolha de outra via parenteral deve ser amparada por estudos que demonstrem que todo o fármaco (ou uma fração conhecida) alcance a circulação. Geralmente, esses estudos estão associados a outros, desenhados para estudar os perfis farmacocinético e metabólico do fármaco, efeitos de dose-dependência ou efeitos do alimento (MORAIS, 1995).

Em função da típica imprevisibilidade do efeito da presença do alimento no trato gastrintestinal sobre a velocidade e extensão de absorção de um fármaco em uma forma farmacêutica, devem ser estudados os efeitos do alimento para cada nova substância ativa. É importante comentar que podem ser encontradas conclusões conflitantes na literatura a respeito desses efeitos, devido, principalmente, às características intrínsecas do fármaco, da forma farmacêutica e do desenho do estudo: tipo e quantidade da refeição e programa de 
administração com relação ao tempo de ingestão do alimento. Assim, a necessidade de padronização desses estudos tem sido objeto de discussão em vários países.

\subsubsection{Canadá}

Encontra-se em discussão uma proposta emitida pela autoridade reguladora daquele país sobre os requerimentos para os estudos de biodisponibilidade comparativa conduzidos em estado alimentado, com objetivo de demonstração da bioequivalência de duas formulações orais sólidas (CANADA, 2004). Essa proposta (draft guidance) será aplicada para todos os casos em que o estudo de biodisponibilidade comparativa constitui a principal evidência de segurança e eficácia do medicamento, incluindo-se: fármacos não complicados em formulações de liberação imediata; fármacos complicados (estreita faixa terapêutica, alta toxicidade e farmacocinética não-linear) em formulações de liberação imediata e fármacos em formulações de liberação modificada. Podendo ser aplicada, também, para alterações pós-registro em que são requeridos estudos de bioequivalência.

Os tópicos em discussão são:

a) Fármacos não complicados, em formulações de liberação imediata:

Deve ser demonstrada bioequivalência em estudo de dose única sob condições de jejum. Se houver comprovação de riscos sérios sobre a segurança dos voluntários ou de absorção muito baixa ou variável devido à administração do fármaco sem alimento, pode ser aceitável a proposta de um desenho apropriado de estudo de bioequivalência conduzido com uma quantidade de alimento suficiente, apenas, para prevenir os problemas de toxicidade ou absorção. 
b) Fármacos complicados (estreita faixa terapêutica, alta toxicidade e farmacocinética não-linear) em formulações de liberação imediata:

Em geral, deve ser demonstrada bioequivalência sob condições de jejum e alimentação.

c) Fármacos em formulações de liberação modificada:

Deve ser demonstrada bioequivalência sob condições de jejum e alimentação.

Nos casos [b] e [c], se houver comprovação de riscos sérios sobre a segurança dos voluntários devido à administração do fármaco, com ou sem alimento, pode ser aceitável a proposta de um desenho apropriado de estudo de bioequivalência, conduzido sob a condição indicada de uso (alimentação ou jejum).

d) Refeição padrão para o teste:

Deve ser empregada uma refeição representativa que forneça alimento suficiente para permitir uma potencial perturbação da biodisponibilidade sistêmica do fármaco. A refeição escolhida deve ser justificada e relatados os componentes específicos e o tempo da ingestão.

Exemplo de refeição de teste: 2 ovos fritos na manteiga, 2 fatias finas de toucinho (bacon), 2 fatias de torrada com manteiga, $120 \mathrm{mg}$ de batata frita fatiada e $240 \mathrm{~mL}$ de leite integral.

A diretriz em vigor no Canadá sobre a condução de estudos de $\mathrm{BD} / \mathrm{BE}$ para formulações orais de liberação modificada (CANADA, 1996) estabelece os requerimentos de acordo com as circunstâncias em que uma formulação de 
liberação modificada pode ser desenvolvida. Estas circunstâncias classificam-se em três grupos.

Grupo I: formas farmacêuticas de liberação modificada originais, de fármaco ainda não comercializado.

Grupo II: formas farmacêuticas de liberação modificada originais, de fármaco já comercializado em formulação de liberação convencional ou outro tipo de liberação modificada.

Grupo III: segunda ou subseqüentes formas farmacêuticas de liberação modificada, desenvolvidas para serem bioequivalentes à formulação do mercado.

Para os grupos I e II são exigidos estudos clínicos de eficácia e segurança. Para o grupo III é exigida demonstração de bioequivalência com a formulação original ou primeira do mercado.

Para as formulações com revestimento gastro-resistente (delayed-release), com fármaco não complicado, geralmente pode ser requerida biodisponibilidadde comparativa com base na $\mathrm{ASC}$ e $\mathrm{C}_{\max }$, desde que a única diferença entre a formulação gastro-resistente e a correspondente de liberação imediata seja uma mudança no tempo da curva de concentração plasmática do fármaco vesus tempo. Esses estudos devem ser realizados em condições de jejum e alimentação. A formulação gastro-resistente referência para o grupo III é o produto inovador ou, na ausência deste, o líder no mercado. 
Critérios para biodisponibilidade comparativa (produtos do grupo II):

I. Estudos de dose única:

Deve comparar a formulação de liberação modificada com a formulação convencional inovadora, com objetivo de avaliar a biodisponibilidade comparativa sob condições de jejum. Todavia, por segurança dos voluntários pode ser requerido estudo com alimento, conforme consulta prévia à autoridade reguladora. Um segundo objetivo é comparar a biodisponibilidade da formulação teste nas condições de jejum e alimentação.

Os desenhos aplicáveis são:

a) um estudo cruzado de quatro períodos, quatro seqüências e quatro tratamentos (produtos teste e referência em ambas as condições: jejum e alimentação);

b) um estudo cruzado de três períodos, três seqüências e três tratamentos (produtos teste e referencia em jejum e, adicionalmente, produto teste com alimentação);

c) dois estudos cruzados, ambos de dois períodos e duas sequencias de administração: um estudo deve comparar as formulações teste e referência em jejum, o outro estudo deve avaliar a formulação teste nas condições de jejum e alimentação.

A relação das médias das ASC da formulação de liberação modificada em relação à formulação convencional deve estar entre $80 \%$ e $125 \%$ na condição de jejum. A relação das médias das $\mathrm{C}_{\max }$ da dose única da formulação de liberação modificada em relação à formulação convencional não deve exceder $125 \%$ na condição de jejum. 
II. Estudos de estado estacionário:

Adicionalmente aos estudos de dose única, deve ser feita uma comparação entre a primeira formulação de liberação modificada a entrar no mercado e a formulação de liberação convencional, com doses equivalentes no intervalo de doses da formulação de liberação modificada, no estado de equilíbrio. Geralmente, esses estudos devem ser realizados sob condições de jejum, todavia, por segurança dos voluntários pode ser requerido estudo com alimento, conforme consulta prévia à autoridade reguladora.

\subsubsection{Estados Unidos}

\subsubsection{FDA}

Um guia específico da FDA (UNITED STATES, 2002) fornece recomendações para o planejamento e condução dos estudos de biodisponibilidade e bioequivalência em presença de alimento, apresentando também informações sobre quando esses estudos deverão ser realizados.

São recomendados estudos de biodisponibilidade sob efeito do alimento para toda nova entidade química durante o período de investigação como fármaco novo. Para novos medicamentos em formulações de liberação modificada são recomendados estudos de biodisponibilidade e bioequivalência sob efeito de alimento. 


\subsubsection{Farmacopéia dos Estados Unidos}

A Farmacopéia Americana (UNITED STATES, 2005), em seu Capítulo Geral <1088>, apresenta diretrizes para avaliação in vivo das formas farmacêuticas.

\section{Avaliação in vivo de formas farmacêuticas de liberação modificada:}

Para garantir a eficácia e segurança das formulações de liberação modificada é fundamental a realização de estudos apropriados. Estudos in vitro fornecem informações sobre as características de liberação do fármaco, a partir da forma farmacêutica, e são úteis para monitorização da estabilidade do produto e para controle do processo de fabricação. A avaliação da segurança e eficácia é melhor atingida através dos estudos in vivo de farmacodinâmica $\mathrm{e}$ farmacocinética. Quando está bem definida uma correlação entre as concentrações plasmáticas do fármaco ou metabólito ativo e a resposta clínica (terapêutica ou adversa) é possível empregar somente os dados de concentração plasmática como base para aprovação de uma formulação de liberação modificada desenhada para substituir uma formulação de liberação imediata.

Caracterização das propriedades farmacocinéticas do fármaco:

É recomendada a caracterização do perfil de absorção do fármaco empregando uma preparação de rápida disponibilidade (solução intravenosa ou solução oral) que servirá, por sua vez, de referência para avaliação do perfil de absorção da forma farmacêutica de liberação modificada. Assim, alterações na biodisponibilidade podem ser observadas, por exemplo, se o fármaco exibe metabolismo hepático saturável de primeira passagem, uma redução da biodisponibilidade sistêmica pode ser observada após a administração oral. No desenvolvimento de uma formulação de liberação modificada, pode ser 
necessário determinar a absorção do fármaco em vários segmentos do trato gastrintestinal. Os efeitos do alimento também podem ser importantes e devem ser investigados.

Caracterização das propriedades farmacocinéticas da forma farmacêutica:

Para caracterização do produto são requeridos, no mínimo: (1) um estudo cruzado de dose única para cada concentração de uma formulação de liberação modificada e (2) um estudo de dose múltipla, de estado estacionário, empregando a maior concentração da forma farmacêutica de liberação modificada. Para cápsulas de liberação modificada, cujas concentrações do fármaco são definidas pelo volume do conteúdo, um estudo de dose única e um de estado estacionário empregando apenas a maior concentração são suficientes, sendo as outras concentrações caracterizadas através dos dados de dissolução in vitro.

Tipos de estudos geralmente realizados:

I. Caso A: forma farmacêutica oral, de liberação modificada, original, de um fármaco já no mercado numa forma de liberação imediata, para o qual existem dados de farmacocinética e farmacodinâmica.

1. Estudo de dose única, cruzado:

Tratamentos: formulação de liberação modificada, administrada em jejum; formulação de liberação rápida, administrada em jejum; e a formulação de liberação modificada, administrada com uma refeição altamente gordurosa (ou outro tipo de refeição com potencial de desafiar, ao máximo, a formulação).

O estudo de efeito do alimento deve incluir o controle da ingestão de líquidos (exemplo: $240 \mathrm{~mL}$ ) e da temperatura (exemplo: ambiente) no momento 
da administração do medicamento, que deve ser dentro de 5 minutos após completar a refeição.

Não havendo diferenças significativas na velocidade e extensão da biodisponibilidade ( $\mathrm{ASC}, \mathrm{C}_{\max } \mathrm{e} \mathrm{T}_{\max }$ ) em função da refeição, não serão necessários estudos adicionais sob efeito de alimento. Caso haja diferenças significativas, será necessário definir como o alimento afeta a formulação, assim como qual é a relação do efeito do alimento com o tempo. Esses estudos têm dois propósitos: determinar se haverá necessidade de instruções na bula sobre condições especiais de administração em relação à refeição e fornecer informações sobre o padrão de absorção da formulação de liberação modificada, em comparação com a formulação de liberação imediata.

Diretrizes para avaliação do efeito do alimento:

a) Determinar se o efeito é resultante da interação com a formulação (exemplo: alteração na liberação do fármaco) ou se não está relacionado com a formulação (exemplo: alteração na absorção do fármaco a partir do trato gastrintestinal ou alteração na fase de distribuição ou eliminação, independentemente da absorção): deve ser realizado estudo de dose única, cruzado, comparando a solução (ou formulação de liberação imediata) sob condições de alimento e jejum. Se não for detectado efeito do alimento, podese concluir que existem problemas com a formulação; caso seja detectado efeito, pode-se concluir que o efeito não está relacionado com a formulação.

b) A influência do tempo na interação fármaco-alimento é testada através de um estudo cruzado de quatro braços, com administração da formulação de liberação modificada nas seguintes condições: jejum; com uma refeição altamente gordurosa; uma hora antes de uma refeição altamente gordurosa; duas horas após uma refeição altamente gordurosa. 
c) Caso o efeito do alimento tenha sido determinado em uma formulação de liberação imediata como resultante de alterações na absorção do fármaco dissolvido a partir do trato gastrintestinal ou de alterações na disposição, devem ser desenhados estudos para definir a relação apropriada entre dose e alimentação.

d) Podem ser conduzidos estudos com refeição de composição alternativa, quando o produto for indicado para ser administrado com refeição não gordurosa.

e) Deve ser monitorado o perfil completo de absorção da liberação modificada em dose única.

f) Para formulações de liberação retardada (gastro-resistente), devem ser realizados estudos de biodisponibilidade para caracterizar adequadamente os efeitos do alimento e embasar a posologia.

2. Estudos de doses múltiplas (estado estacionário):

Quando o fármaco, existente na forma de liberação imediata, apresenta farmacocinética linear, um estudo de estado estacionário deve ser conduzido com a formulação de liberação modificada em uma dosagem, preferencialmente a maior da faixa usual, empregando uma formulação de liberação imediata como controle. Quando não é conhecida a comparação das propriedades farmacocinéticas entre as diferentes dosagens do fármaco existente na forma de liberação imediata, ou os dados mostram não-linearidade farmacocinética, devem ser conduzidos estudos de estado estacionário, cruzados, comparando os efeitos da forma de liberação modificada com os da forma de liberação imediata, em duas diferentes dosagens: um estudo com a menor e outro com a maior dosagem 
da faixa recomendada. Também podem ser necessários estudos na população alvo, em grupos de pacientes ou estudos de interação com outros fármacos, dependendo da finalidade terapêutica que a formulação de liberação modificada terá.

II. Caso B: forma farmacêutica não-oral, de liberação modificada.

III. Caso C: genérico de uma forma farmacêutica de liberação modificada: deve ser bioequivalente com o produto referência de liberação modificada quanto à velocidade e extensão de biodisponibilidade (ASC, $\mathrm{C}_{\max }, \mathrm{C}_{\min }$ e grau de flutuação) em estudos cruzados de dose única e de equilíbrio estacionário. Para formulação oral de liberação modificada, devem ser realizados os estudos com alimento descritos no Caso A. 


\subsection{REQUERIMENTO DE ESTUDOS DE BIOEQUIVALÊNCIA COM} ALIMENTAÇÃO E/OU JEJUM EM DIVERSOS PAÍSES

A Tabela 10 apresenta um resumo do estudo comparativo sobre requerimento de estudos de bioequivalência para medicamento genérico em diversos países, quanto à condição em jejum ou sob efeito de alimento.

Tabela 10 - Estudo comparativo sobre requerimento para estudos de bioequivalência sob efeito de alimento e/ou jejum, para medicamento genérico em diversos países.

\section{Formulações de Liberação $\quad$ Formulações de Liberação Imediata Modificada}

BRASIL ${ }^{(1)} \quad$ Exige estudo em jejum. Exige estudo com alimento quando o fármaco possui interação com alimento e há recomendação de administração com alimento

(consultar Lista-1 da ANVISA).

Exige estudo com alimentação (adicionalmente ao estudo em jejum). Se formulação gastro-resistente: consultar Lista-1 da ANVISA.

$\begin{array}{ll}\text { CANADÁ }^{(2 ; 3 ; 4)} & \begin{array}{l}\text { Para fármaco não complicado } \\ \text { (fármacos complicados são os de }\end{array} \\ & \text { estreita faixa terapêutica, alta } \\ & \text { toxicidade ou farmacocinética não- } \\ & \text { linear) exige estudo em jejum. } \\ & \text { Deve-se incluir estudo com } \\ & \text { alimentação para medicamentos que } \\ & \text { são administrados com alimento } \\ & \text { para reduzir efeitos colaterais } \\ & \text { gastrintestinais. }\end{array}$

Na proposta em discussão_(Draft Guidance. May /2004): exigência de estudo dose única em jejum. Em casos comprovados de risco para os voluntários, é aceito estudo com alimentação suficiente para prevenir toxicidade ou problemas de absorção. Para complicated Drugs (Estreita faixa terapêutica, alta toxicidade e farmacocinética nãolinear): exigência de estudo de bioequivalência sob condições de jejum e alimentação.
Exige estudo dose única, jejum e alimentação: a) um estudo de 4 períodos ou; b) 2 estudos ( $1^{\circ}$ estudo: jejum, 2 períodos; $2^{\circ}$ estudo: jejum e alimentação, 3 períodos ou; c) 2 estudos (um jejum, um alimentação), ambos 2 períodos (opção menos informativa).

Preconiza também estudo de dose múltipla, geralmente após jejum, adicional ao estudo dose única,.

Na proposta em discussão (Draft Guidance, May/2004): exigência de estudo de bioequivalência sob condições de jejum e alimentação. Em caso de risco para os voluntários, pode ser aceito estudo na condição indicada (jejum ou alimentado). 


\section{Formulações de Liberação} Imediata
Formulações de Liberação Modificada
EMEA $^{(5 ; 6)} \quad$ O estudo deve ser, preferivelmente, em jejum. Se o produto referência contém recomendações específicas em relação à ingestão de alimento e sobre efeitos da interação com alimento, o estudo deve ser desenhado de acordo.

\section{ESTADOS UNIDOS $^{(7)}$}

$\operatorname{JAP}^{\mathbf{A} O^{(8)}}$
Exige estudo em jejum. Também recomenda estudo com alimentação, exceto se: teste e referência de rápida dissolução com fármaco Classe I (SCB) ou; bula do referência determina administração com estômago vazio ou; bula do referência não faz declaração sobre efeito de alimento.

Formulação de liberação imediata ou com revestimento gastroresistente: exige normalmente, estudo em jejum, dose única. Exige estudo com alimentação (low fat) se: há especificação de administração com alimentação; a biodisponibilidade é muito baixa em jejum; há incidência de efeitos adversos.
Formulação de liberação prolongada: preconiza estudo dose única em jejum; estudo dose única com alimentação e; estudo dose múltipla. Os estudos são para cada concentração (só para maior concentração se farmacocinética linear). A exigência dos estudos são de acordo com critérios, que estão em aberto.

Formulação com revestimento gastroresistente: os mesmos critérios para liberação imediata, além de estudo de bioequivalência com alimentação.

Exige: estudo em jejum e; estudo com alimentação.

Exige estudo dose única em jejum e; estudo dose única com alimentação (high fat).

1. BRASIL. Resolução - RE no 397, de 12/1 1/2004 (ANVISA/MS).

2. HEALTH CANADA. Guidance for Industry. Conduct and Analysis of Bioavailability and Bioequivalence Studies - Part A: Oral Dosage Formulations Used for Systemic Effects. 1992.

3. HEALTH CANADA. Guidance for Industry. Conduct and Analysis of Bioavailability and Bioequivalence Studies - Part B: Oral Modified Release Formulations. 1996.

4. HEALTH CANADA. Draft Guidance for Industry. Bioequivalence Requirements: Comparative Bioavailability Studies Conducted in the Fed State. 05/05/2004.

5. EMEA. CPMP/EWP/QWP/1401/98. Note for Guidance on The Investigation of Bioavailability and Bioequivalence. London, 26 July 2001.

6. EMEA. CPMP/EWP/280/96. Note for Guidance on Modified Release Oral and Transdermal Dosage Forms: Section II (Pharmacokinetic and Clinical Evaluation). London, 28 July 1999.

7. U.S. Department of Health and Human Services. FDA. CDER. Guidance for Industry. Food-Effect Bioavailability and Fed Bioequivalence Studies. December 2002.

8. JAPAN. Guideline for Bioequivalence Studies of Generic Products. December 22, 1997. 


\section{RESULTADOS E DISCUSSÃO}

A revisão e análise realizada neste trabalho englobaram a avaliação, em uma primeira etapa, dos eventos que se manifestam no ambiente gastrintestinal, constituintes do processo de absorção de fármacos, considerando as variáveis atribuídas às condições de jejum e alimentação. Em uma segunda etapa, foram analisados os critérios e recomendações para condução dos estudos de determinação da biodisponibilidade de um fármaco na presença de alimento e também sobre o requerimento dos estudos de bioequivalência com alimentação definido em alguns países (Tabela 10).

Durante o desenvolvimento de um medicamento, o fármaco é caracterizado através de numerosos estudos relacionados com suas propriedades farmacocinéticas. Os resultados dos estudos clínicos permitem um julgamento sobre a eficácia e segurança do novo fármaco. Com base nos dados de farmacocinética, é tomada a decisão sobre a dose e as recomendações para o adequado esquema terapêutico.

O efeito do alimento na biodisponibilidade de um fármaco atualmente é investigado, sistematicamente, o mais cedo possível em sua fase de desenvolvimento. A investigação inicial sobre a influência do alimento pode ser recomendada para fármacos lipofílicos. Como exemplo, rufinamida, um antiepilético de baixa hidrossolubilidade, apresentou absorção mais lenta enquanto aumentou-se a dose administrada oralmente para voluntários sadios. A investigação inicial foi realizada em 12 voluntários sadios e o alimento produziu um aumento de $44 \%$ na média de $\mathrm{ASC}$ e duas vezes no $\mathrm{C}_{\max }$. Esta investigação inicial possibilitou a recomendação, antes do primeiro estudo em pacientes, para administração de rufinamida após refeição (GODBILLON et al., 1996).

Deve ser considerada a variabilidade de condições em que, normalmente, os medicamentos são administrados. Pode ser que o estômago esteja vazio ou com algum conteúdo alimentar, ou mesmo cheio, no caso de administração com refeição. Também há inúmeras outras variáveis provenientes de doença, raça, 
gênero, idade etc. Mesmo em indivíduos saudáveis, é de difícil definição a variabilidade referente à fisiologia gastrintestinal, em função da ingestão de alimentos, bebidas, suplementos alimentares, além dos fatores sócio-econômicos, ambientais, culturais, hábitos e costumes. São variáveis individuais que influenciam o comportamento do fármaco ou da formulação, com possível significância nos resultados clínicos.

O estudo da interação fármaco-alimento inclui a avaliação de efeitos farmacocinéticos e farmacodinâmicos. Constituintes do alimento podem interferir na absorção, no metabolismo e excreção, como também na interação com receptores.

A absorção do fármaco pode ser afetada pela interação dos compontentes do alimento com o fármaco ou com a formulação. O estudo dessas interações envolve conhecimento das características do fármaco, da formulação e da refeição, para compreensão dos efeitos sobre a fisiologia gastrintestinal.

O efeito do alimento na absorção do fármaco é o resultado de diversos eventos, de natureza físico-química e fisiológica. Assim, a absorção de alguns fármacos pode ser pouco ou não ser afetada pelo alimento. É o caso de fármacos de boa hidrossolubilidade em formulações de liberação imediata, características que diminuem a susceptibilidade de interação com constituintes do alimento, uma vez que o fármaco pode ter boa difusão para o sítio de absorção. Fármacos lipossolúveis podem interagir com as gorduras do alimento, sendo que esta interação geralmente promove a absorção do fármaco.

A refeição altamente gordurosa tem maior potencial de alteração da fisiologia gastrintestinal, especialmente quanto ao prolongamento do tempo de esvaziamento gástrico, aumento do fluxo sanguíneo e secreção biliar. Esses efeitos podem afetar significativamente a absorção de fármacos, sendo especialmente críticos para as formulações de liberação modificada. Uma formulação com revestimento gastro-resistente foi planejada para manter-se íntegra no ambiente ácido do estômato e liberar o fármaco somente após chegar no intestino. Um maior tempo de permanência no estômago representa um 
desafio para a formulação, uma vez que a liberação do fármaco no estômago pode comprometer a eficácia devido à degradação ácida, ou produzir efeitos colaterais por irritação da mucosa gástrica. Este desafio torna-se importante no aspecto crítico de segurança para as formulações de liberação estendida ou controlada. Este tipo de formulação contém uma elevada quantidade do fármaco e foi desenvolvida para manter os níveis terapêuticos do fármaco pelo funcionamento de um sistema de liberação controlada. Para tanto, torna-se crucial avaliar seu desempenho sob os extremos de condições possíveis de ocorrer no ambiente gastrintestinal, quando da sua administração aos pacientes. Uma falha no sistema de liberação pode causar a liberação rápida de elevada quantidade do fármaco (dose dumping) e serem atingidos níveis plasmáticos tóxicos.

A avaliação de formulações através de estudos in vivo de biequivalência é bem aceita tanto pelo segmento industrial quanto pelas universidades, em função da experiência de casos com baixa previsibilidade dos estudos in vitro. As propriedades individuais da formulação determinam a dissolução in vivo, o trânsito no trato gastrintestinal, influenciando o perfil de concentração plasmática. Estes são processos multifatoriais, incluindo o efeito causado pela composição do alimento na passagem pelo estômago, tamanho da formulação e motilidade pilórica, trânsito através do jejuno e íleo e o tempo de residência no cólon. As mudanças físico-químicas durante o trânsito são amplas, com mudanças de $\mathrm{pH}$ e de composição dos líquidos, interação com outras partículas (alimento, microrganismos no cólon, adsorção e componentes não digeriveis) e mudanças de viscosidade. Todas estas variabilidades são avaliadas por meio do ensaio clínico formal. A soma das influências individuais dos processos multifatoriais sobre o teste de bioequivalência in vivo, refletida no intervalo de confiança, dificilmente pode ser estimada baseada nos dados in vitro (AHR; VOITH; KUHLMANN, 2000).

O objetivo dos estudos de bioequivalência, no sentido mais estrito, é provar que as biodisponibilidades de dois produtos farmacêuticos distintos, que 
contêm a mesma quantidade, da mesma substância ativa, na mesma forma de dosagem, são equivalentes. Conseqüentemente, o objetivo final, é demonstrar que não existe inconveniência terapêutica na intercambialidade destes produtos.

Em alguns casos, a influência do alimento deve ser estudada para vários tipos de refeição, dependendo dos hábitos do país. O efeito do alimento na biodisponibilidade do cloridrato de benazepril foi investigado em 2 estudos com 12 voluntários cada, com ingestão de desjejum continental (leve) e americano, antes da administração do fármaco. $O$ desjejum americano aumentou $t_{\max }$ de 1 hora (jejum) para 4 horas, $\mathrm{C}_{\max }$ aumentou significativamente; o desjejum continental aumentou $t_{\max }$ de 1 para 2 horas e não afetou $C_{\max }$; a ASC não foi afetada por ambas as refeições (GODBILLON et al., 1996).

\subsection{DECISÃO PARA ESTUDO EM JEJUM E/OU ALIMENTO}

Vimos que para um fármaco novo são realizados os estudos de biodisponibilidade sob efeito do alimento, necessários para definir as condições adequadas de administração com relação à alimentação. $O$ mesmo deve ser realizado para uma nova formulação, visto que a formulação é um dos elementos das interações. Portanto, são necessários estudos comparativos das condições de jejum e alimentação, podendo-se empregar refeições de constituições variadas. Do ponto de vista de bioequivalência, em que, a princípio, já foram definidas as interações com alimento pela empresa inovadora, a formulação genérica precisa demonstrar sua bioequivalência com a referência. Para isto, o estudo deve ser conduzido nas condições de administração definidas para a referência. Mesmo assim, devem ser considerados os aspectos de relevância clínica, especialmente em relação às formulações de liberação modificada.

Diferentes formulações de liberação modificada do mesmo fármaco podem diferir quanto à interação com alimento. Assim, os estudos de biodisponibilidade e bioequivalência com alimentação tornam-se imprescindíveis para estas formulações. As condições experimentais ideais para produzir o efeito 
do alimento incluem a ingestão de uma refeição altamente gordurosa prédefinida, imediatamente antes à administração dos medicamentos.

Os estudos de avaliação da bioequivalência para formulações de liberação modificada são desenhados para demonstrar, entre outros pontos, que:

a) a formulação teste exibe o perfil de liberação característico da referência;

b) o fármaco não é liberado abruptamente da formulação teste (dose dumping);

c) o desempenho das formulações teste e referência sejam equivalentes nas condições variadas do teste (jejum e alimento).

É uma unanimidade, ao analisar a legislação em vários países, a exigência de ambos os estudos, em estado de jejum e em condições de alimentação, para as formulações de liberação modificada. Para as formulações de liberação imediata e as de revestimento gastro-resistente, encontram-se algumas variantes quanto ao tipo de estudo requerido e quanto aos critérios de decisão para exigência dos estudos.

A Figura 1 contém esquema sobre o que determina a norma em vigor da ANVISA, Resolução RE no 397 (BRASIL, 2004), sobre requerimento de estudos com alimentação e/ou jejum. Para as formulações com sistema de liberação modificada a situação está bem definida, ou seja, estudos em jejum e com alimento. Para as formulações com revestimento gastro-resistente, a condição de administração (jejum e/ou alimento) será informada pela ANVISA (Lista 1 ou consulta). Para as formulações de liberação convencional, o texto da RE 397 deixa sub-entendido que o jejum é a condição padrão do estudo, requerendo estudo com alimento nos casos de conjunção de duas características: a absorção do fármaco seja influenciada significativamente pelo alimento e indicação de administração com alimento. Assim, para as formulações de liberação imediata, a decisão do tipo de estudo depende das informações disponiveis e confiáveis sobre o fármaco, que possam fornecer uma conclusão sobre os efeitos da interação com alimento. Para definir a padronização, a RE 397 estabeleceu a 
Lista 1, a qual contém relação dos fármacos e tipo de estudo (jejum e/ou alimento), disponível no endereço eletrônico da ANVISA (http://www.anvisa.gov.br/medicamentos/listas/index.htm).

A Figura 2 apresenta um fluxograma de tomada de decisão para definição da condição de administração para estudo de bioequivalência de formulações de liberação imediata. A Tabela 11 contém resumo da pesquisa sobre interação com alimento e indicação de administração das formas farmacêuticas orais para alguns fármacos, relacionando também a condição de administração sugerida para estudo de bioequivalência, com base nas informações de interação com alimento e indicação de administração e aplicação do fluxograma da Figura 2. Esse fluxograma contempla uma situação de relevância clínica em que a absorção do fármaco é influenciada pelo alimento de forma variável ou não claramente definida, resultando na necessidade de administração consistente em relação ao alimento, como nos casos de ciclosporina e tacrolimo (Tabela 11). Nestes casos, a eficácia do produto depende da manutenção da condição de administração com relação ao tipo e quantidade da refeição e ao tempo entre a ingestão de alimento e administração do produto, necessitando, portanto, de comprovação de bioequivalência com o referência, nas condições de jejum e alimentação.

Os critérios sugeridos para requerimento e condução dos estudos de Biodisponibilidade e Bioequivalência sob efeito de alimento constituem o item 5.2. Vale ressaltar a possibilidade de realização de estudo sob a condição indicada de administração (jejum ou alimentação), independentemente da interação com o alimento, quando justificáveis em função da exposição potencial dos voluntários a efeitos adversos ou toxicidade. 


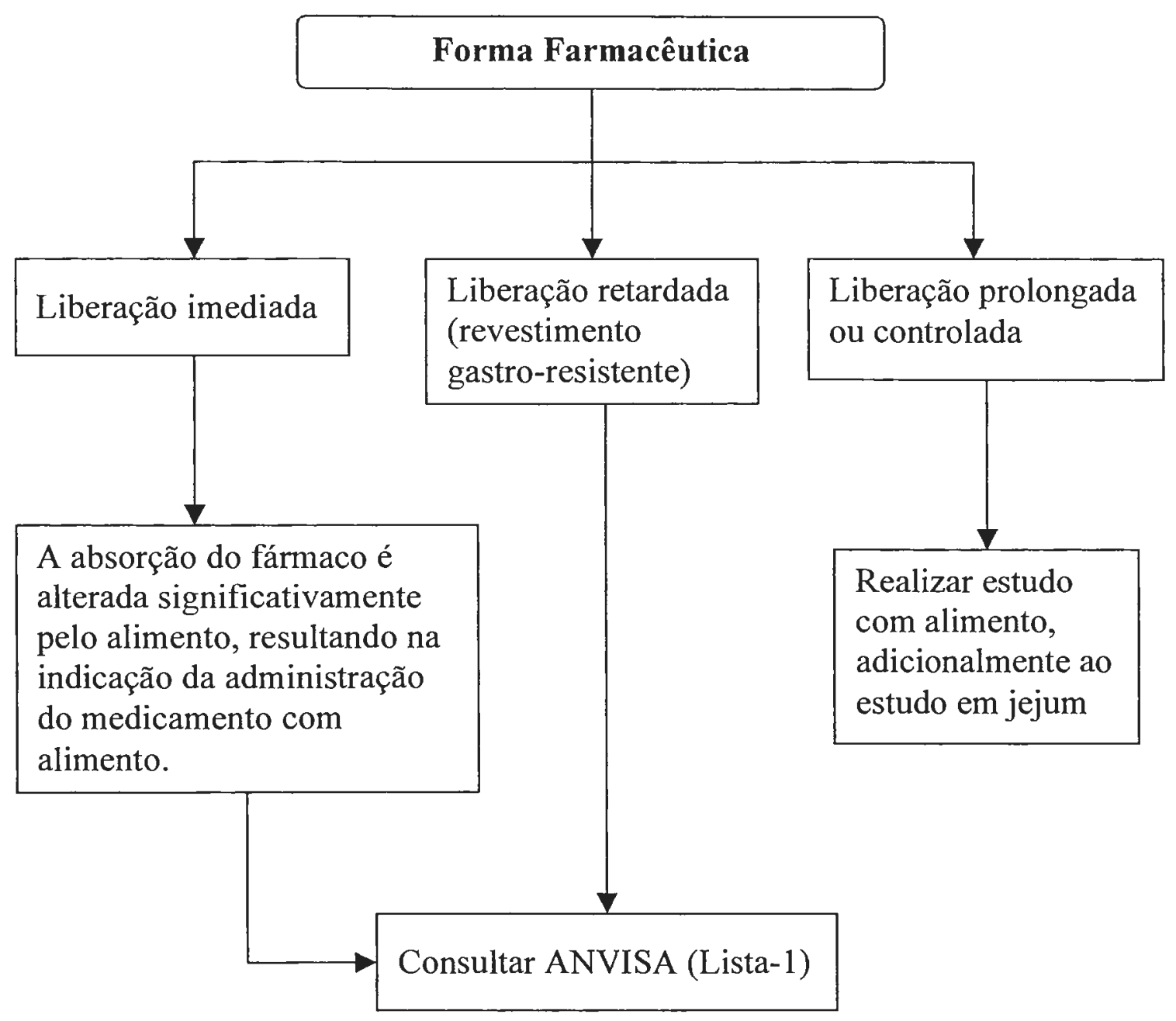

Figura 1 - Exigência de estudo de bioequivalência com alimentação, segundo norma da ANVISA (BRASIL, 2004). 


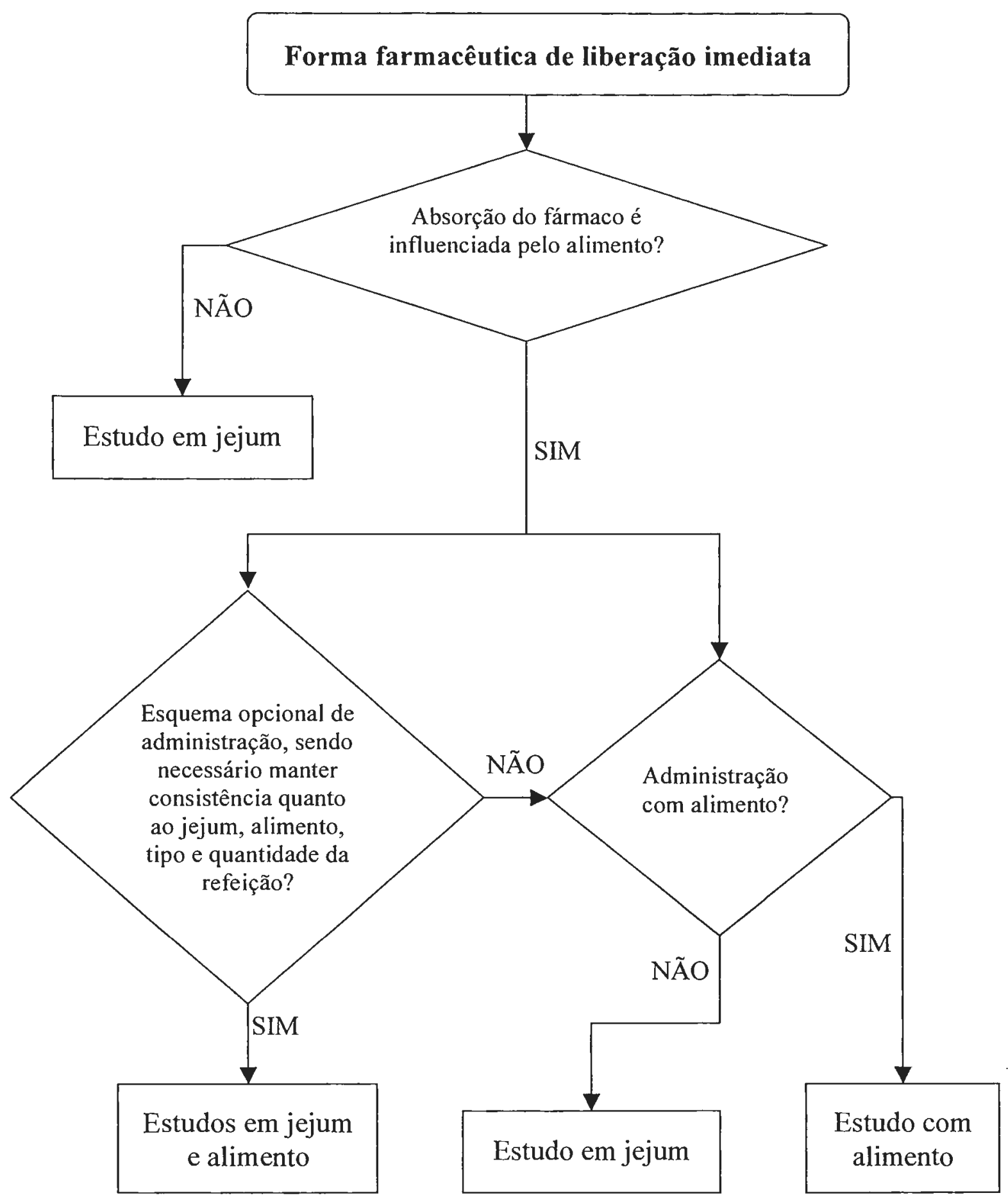

Figura 2 - Decisão para exigência de estudo de bioequivalência em jejum e/ou com alimentação, para composição da Lista-1 da ANVISA com formulações de liberação imediata. 
$\infty$

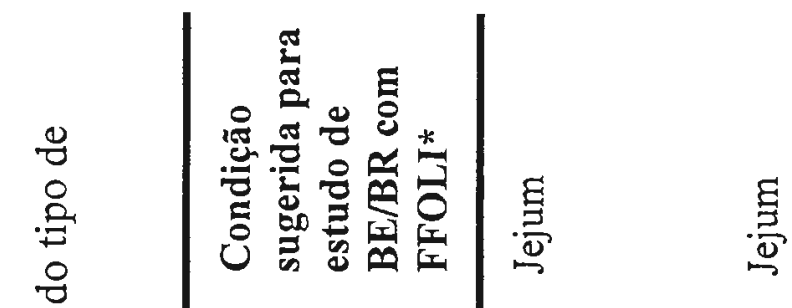

용

䆓

कี

.

离

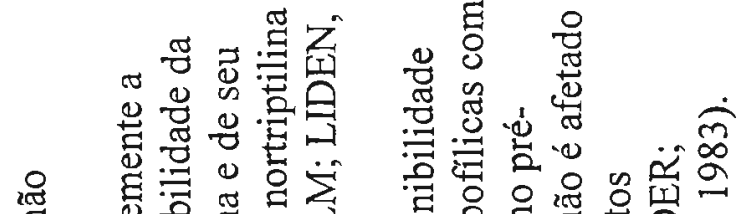

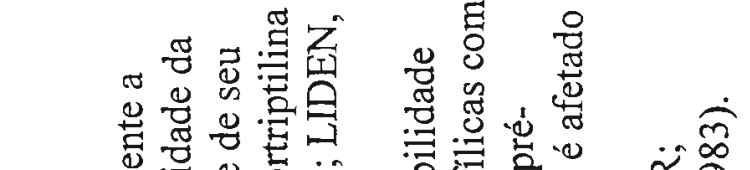

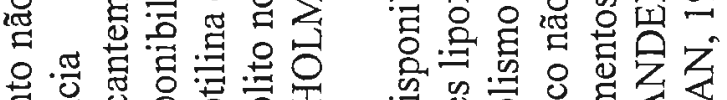

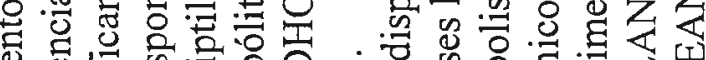

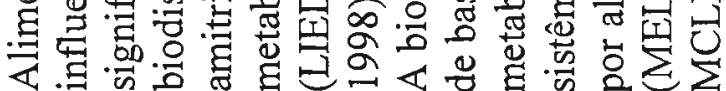

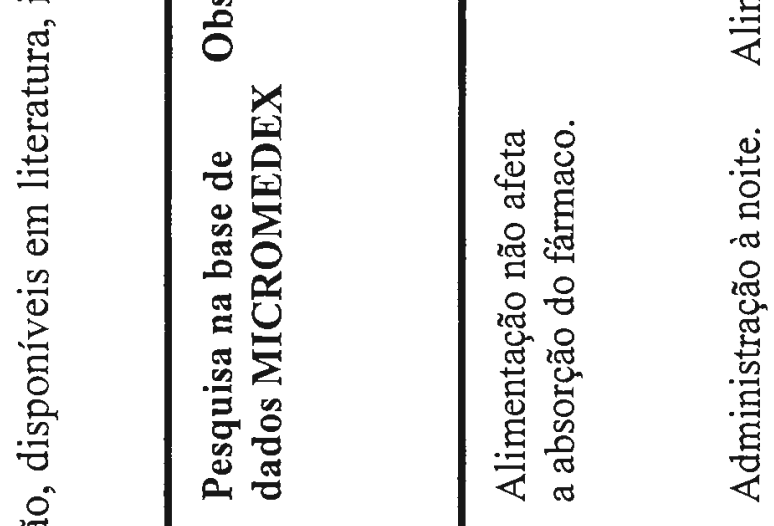

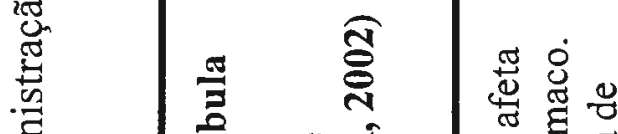

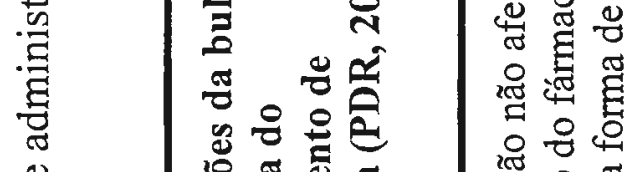

क

हี

0

음 윰

寻

1 嵌

0

苗 $\cdot \frac{\pi}{0}$

要

政

苞龸

․․요

\%

is

苋焉

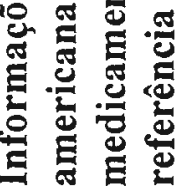

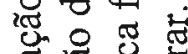

苞总语

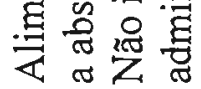

올

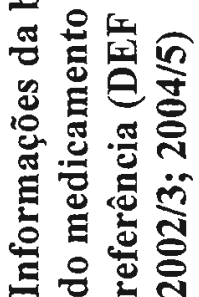

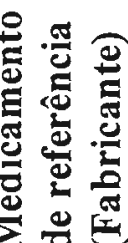

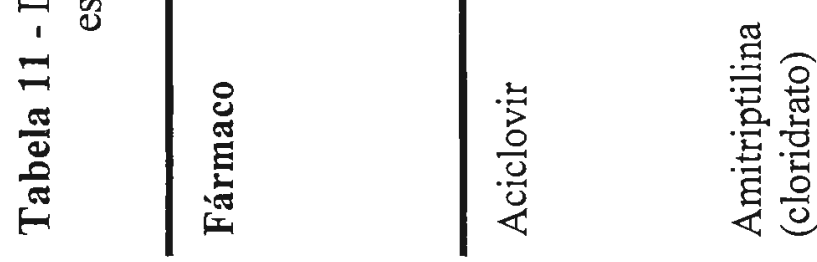




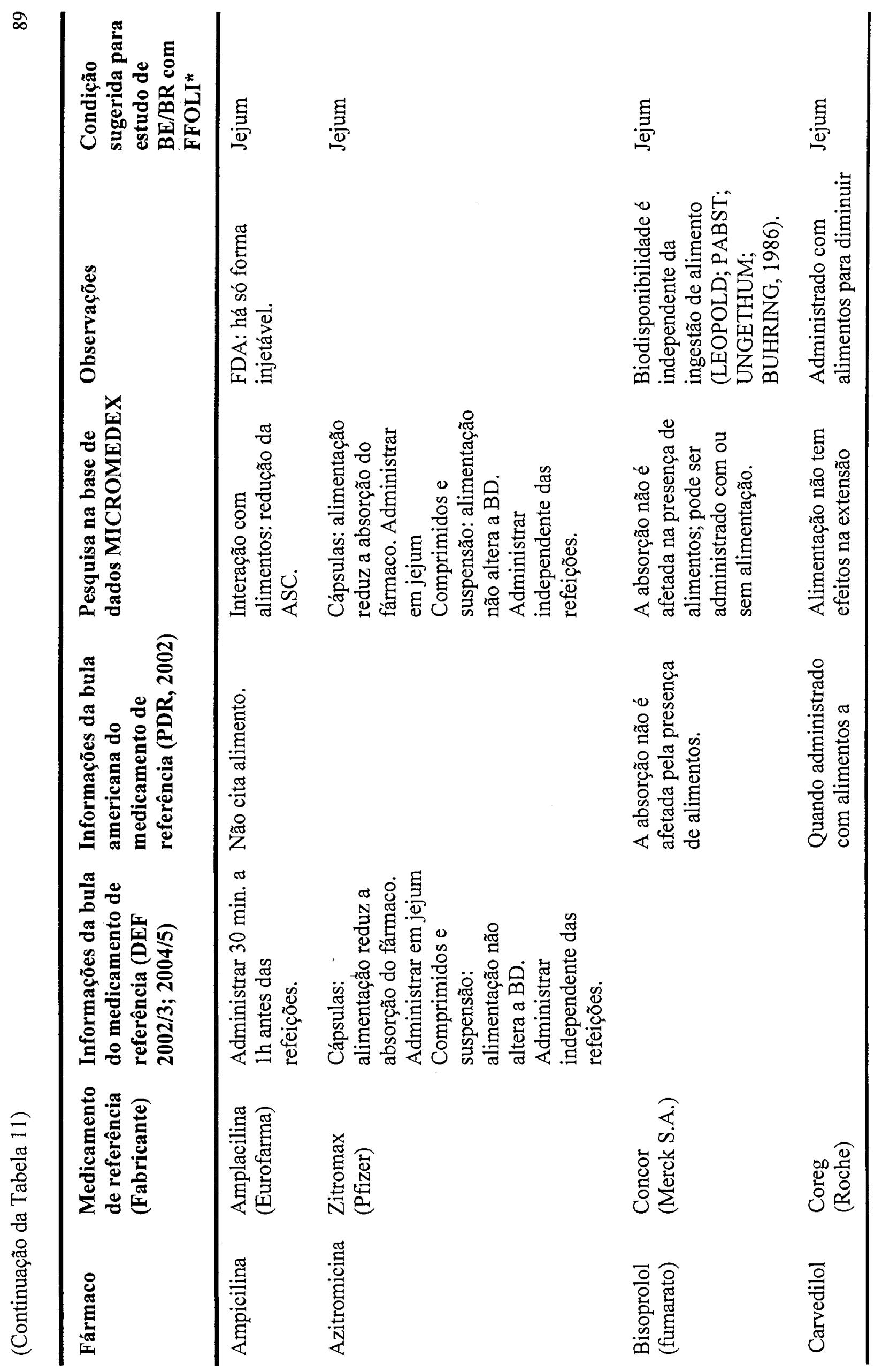




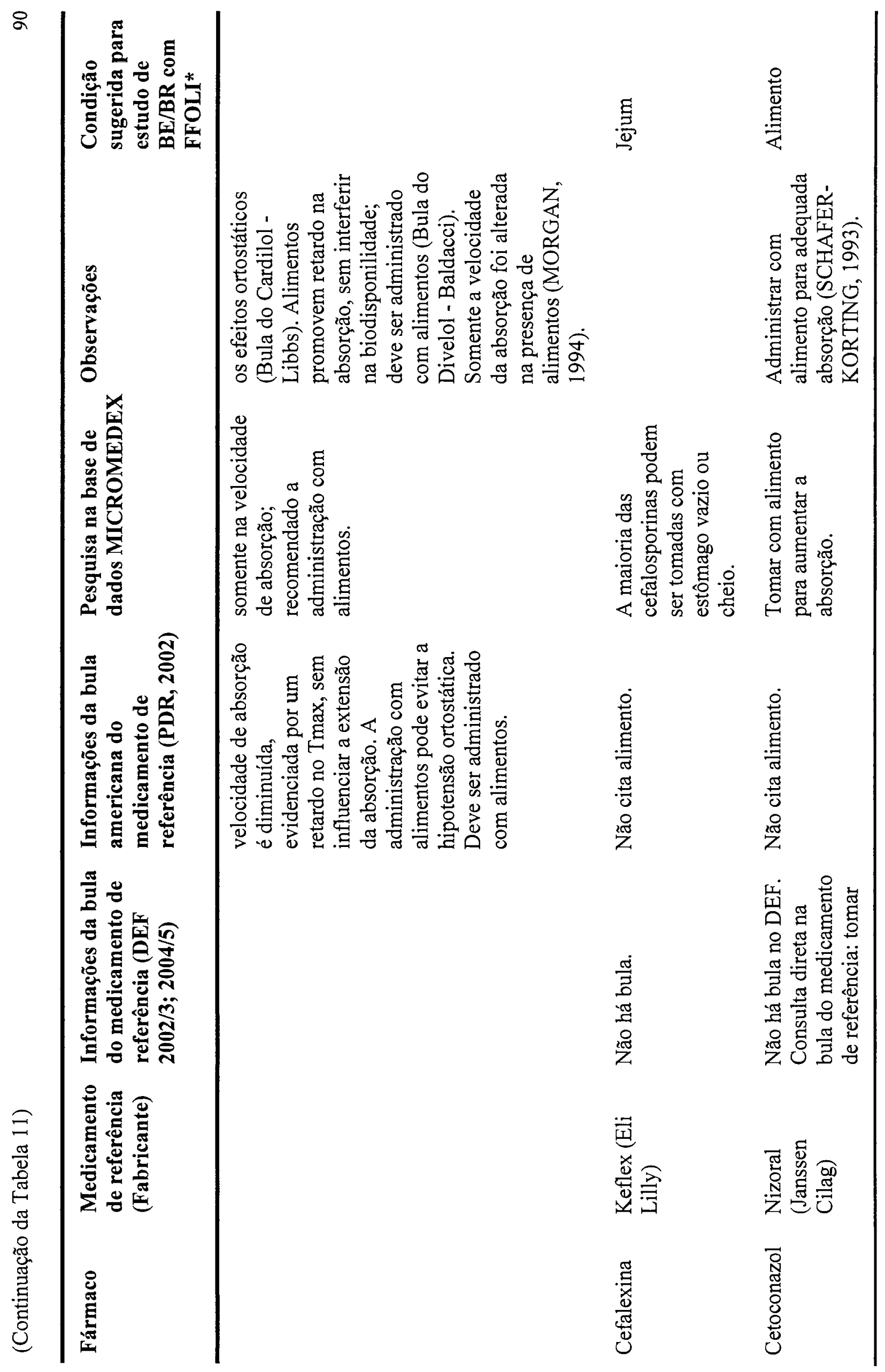




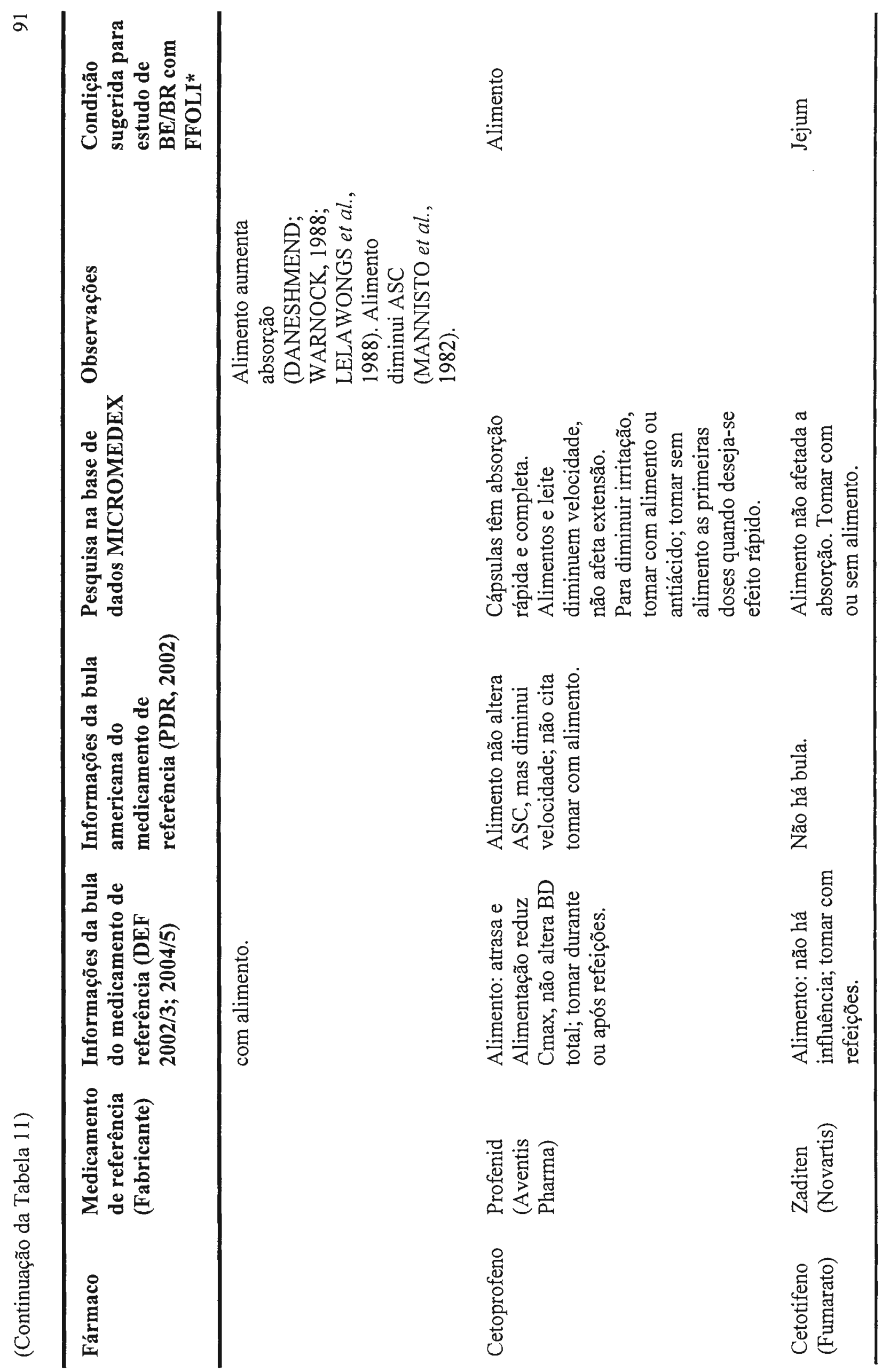




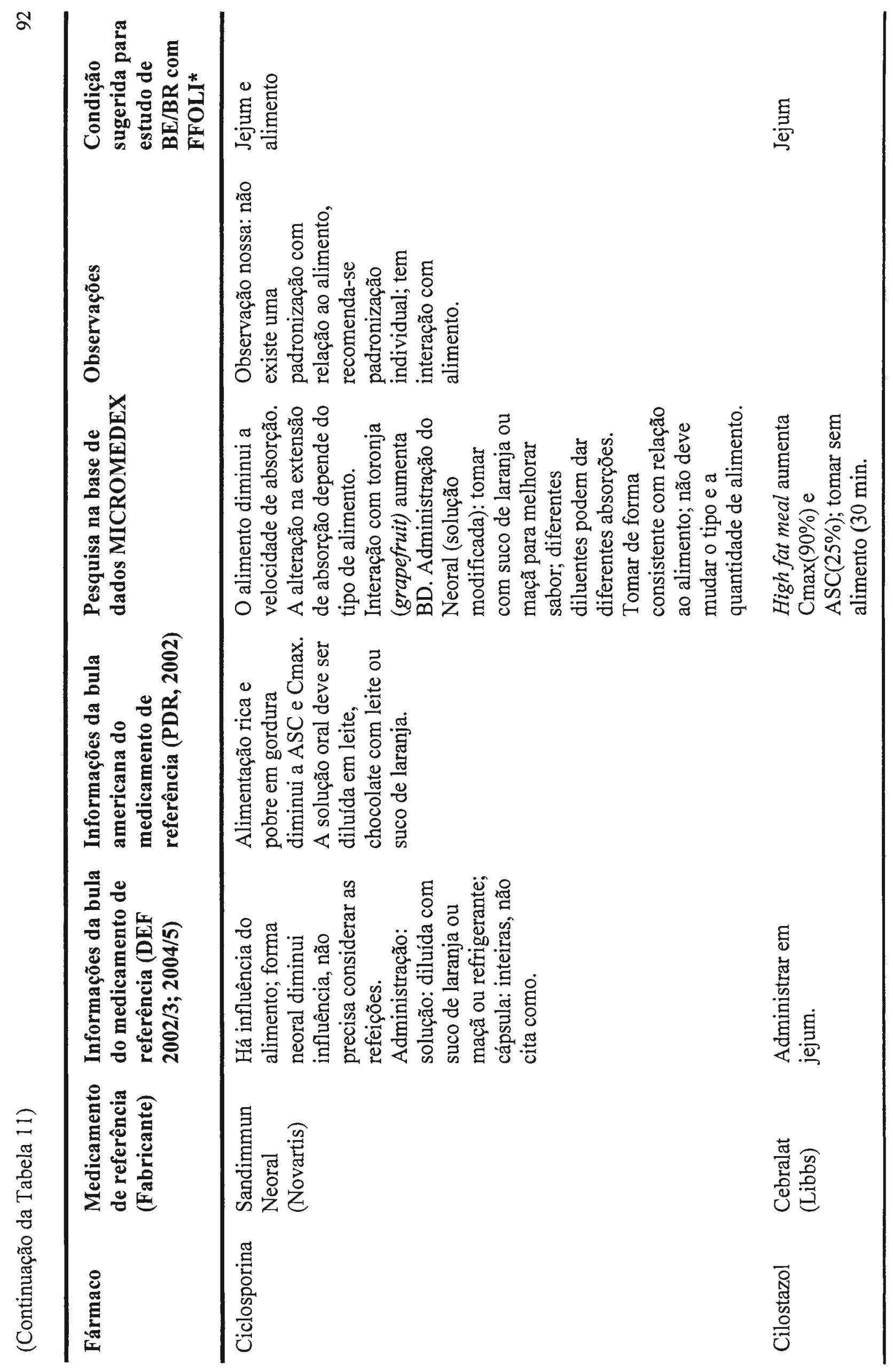




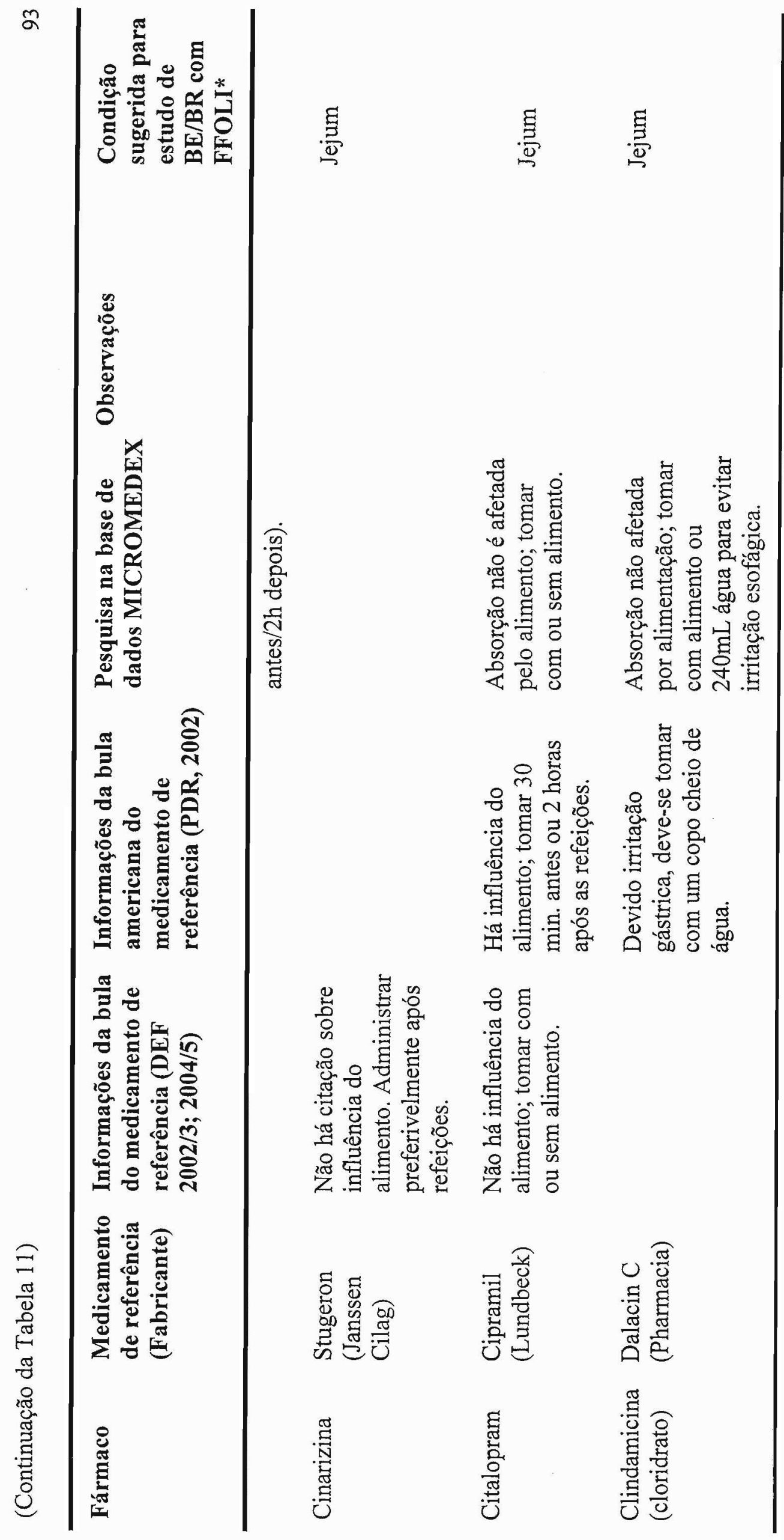




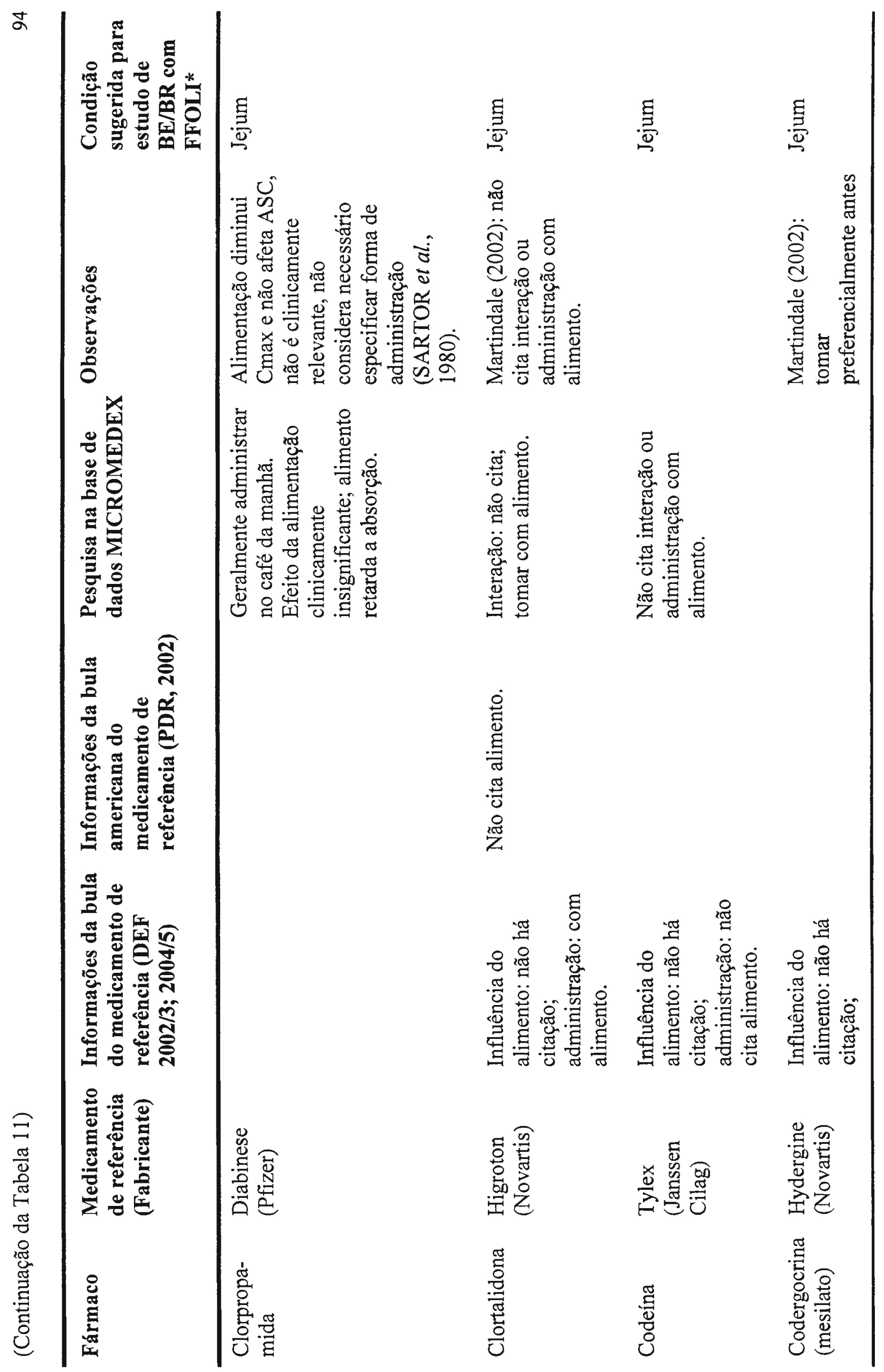




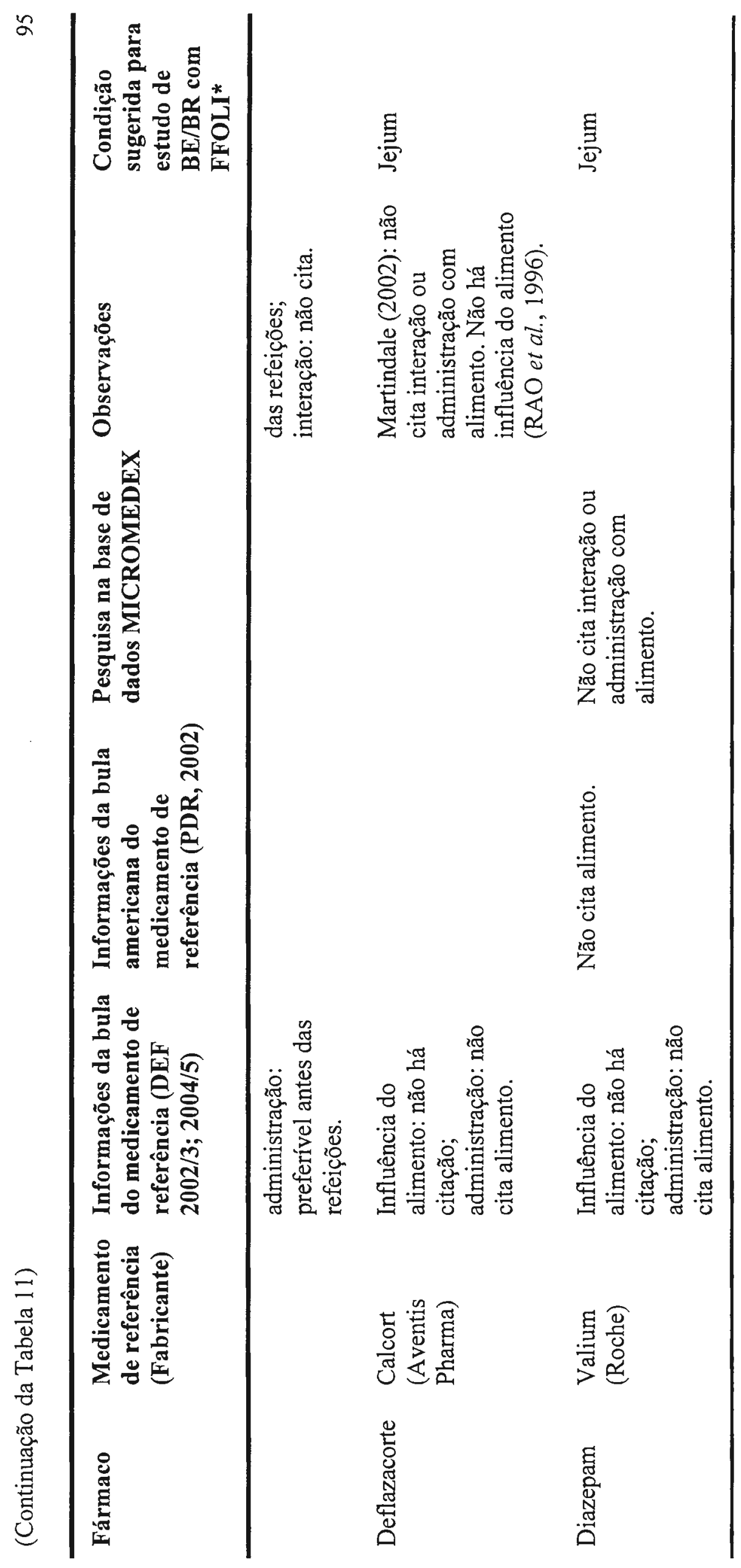




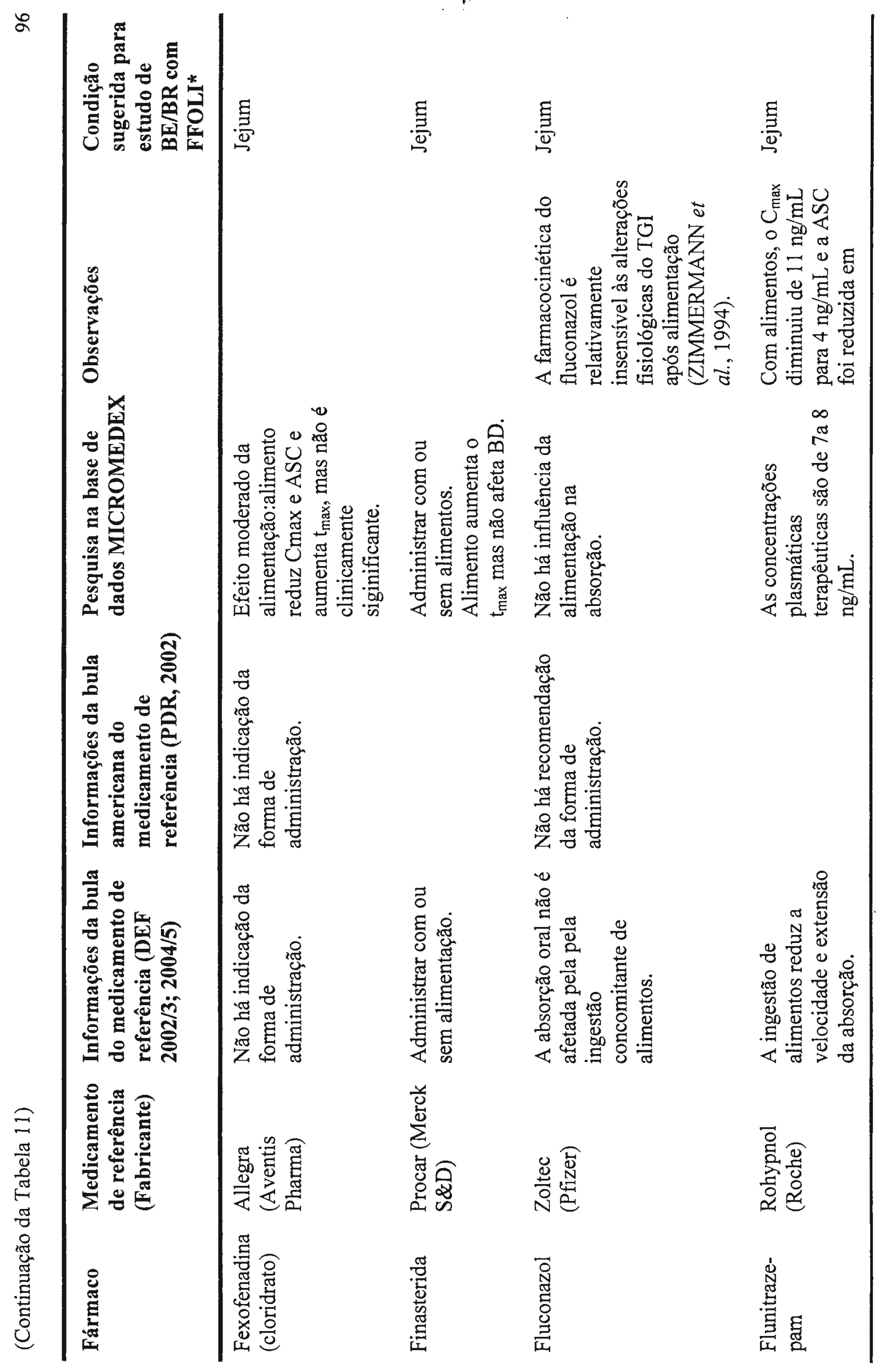




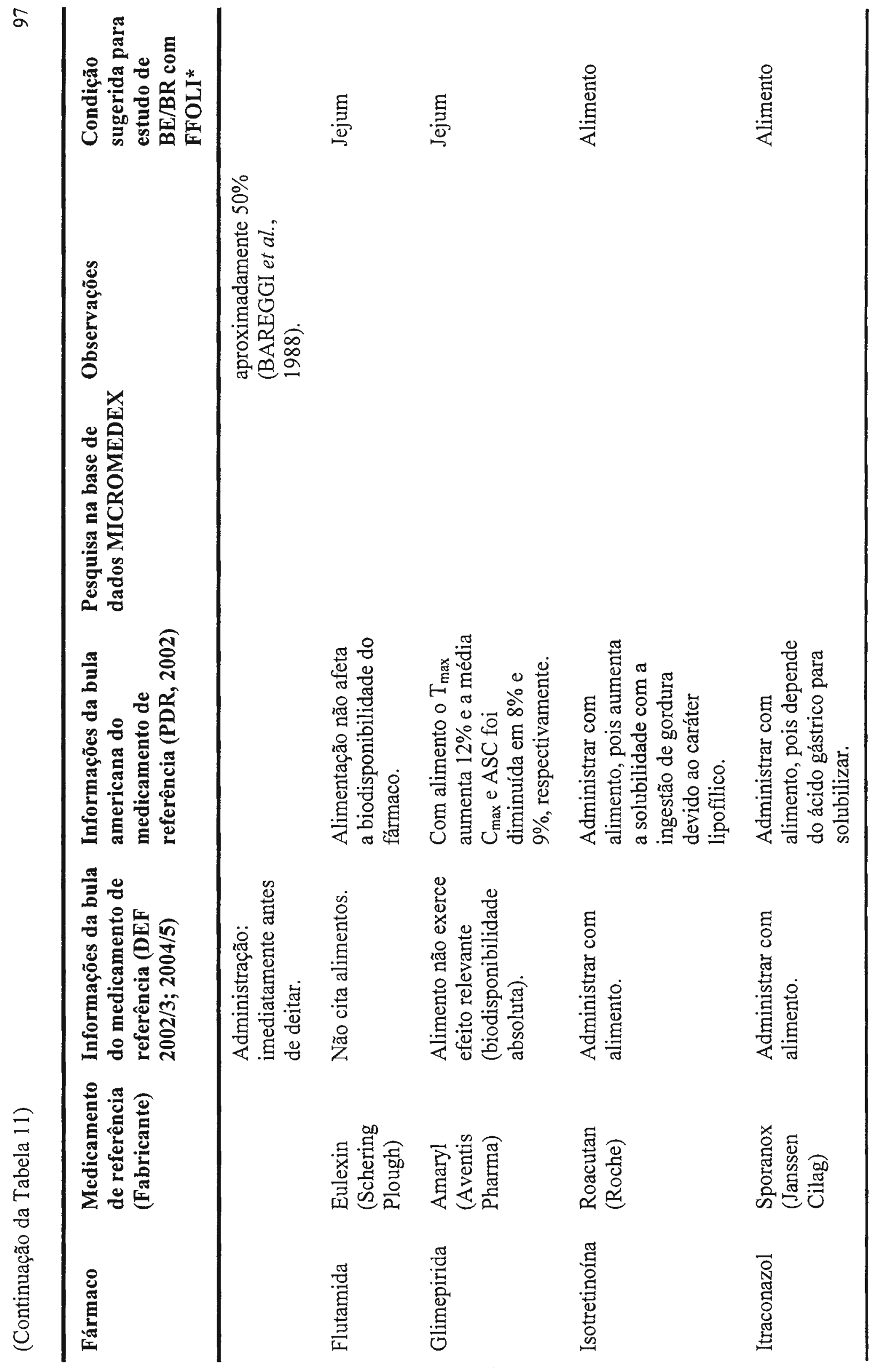




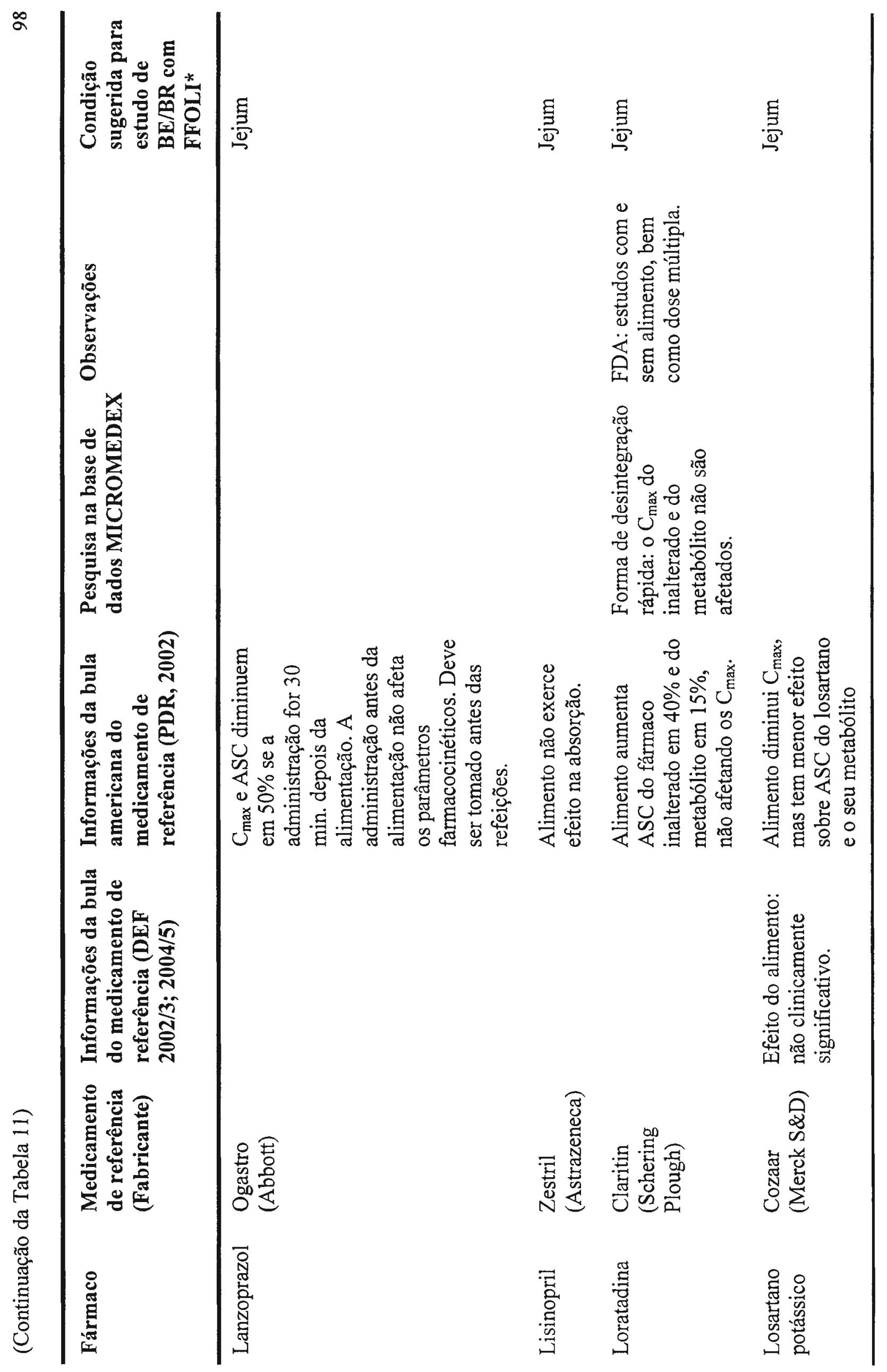




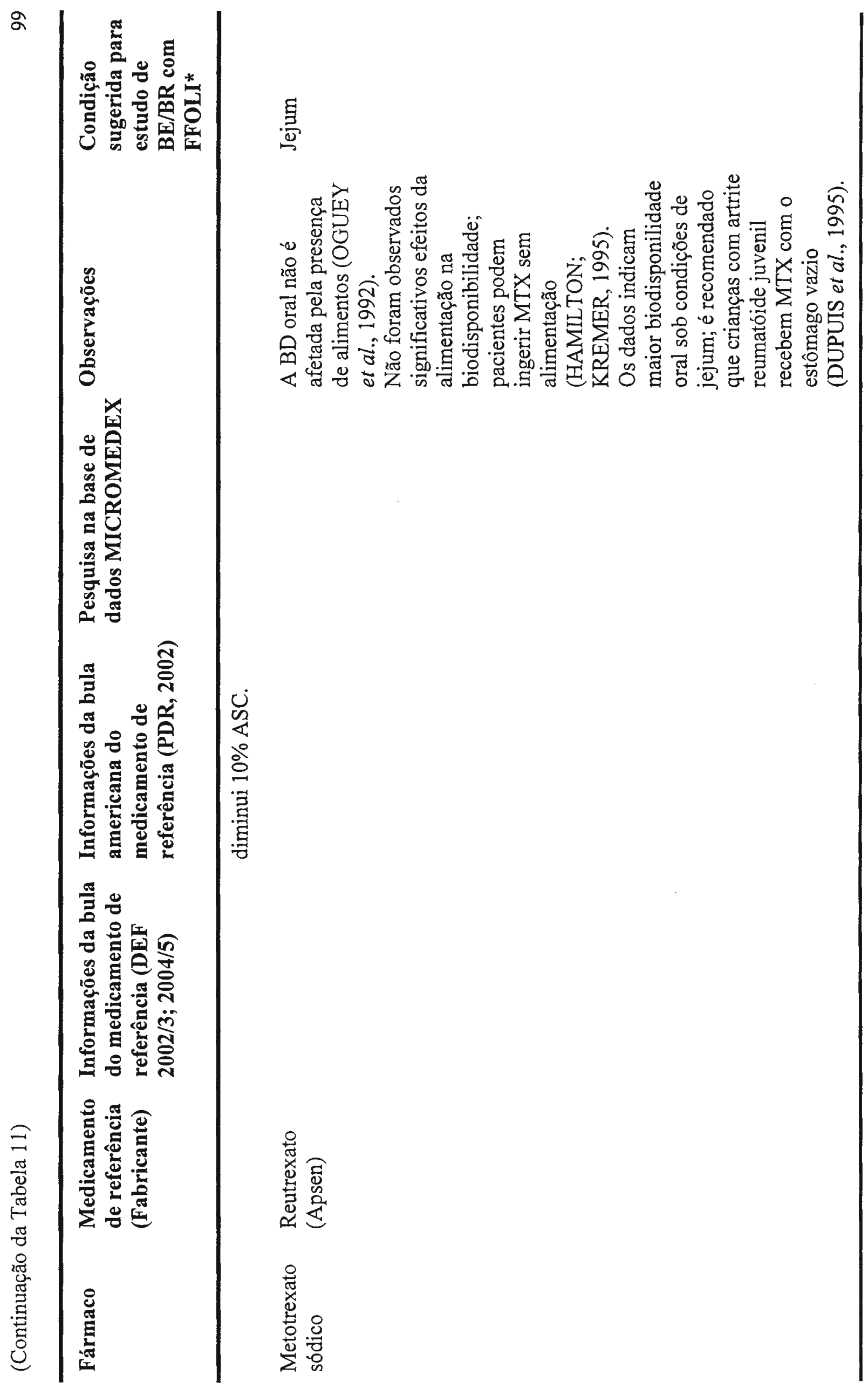


- BIBLIOTECA

Faculdade de Cièncias Fainiaceutlicás

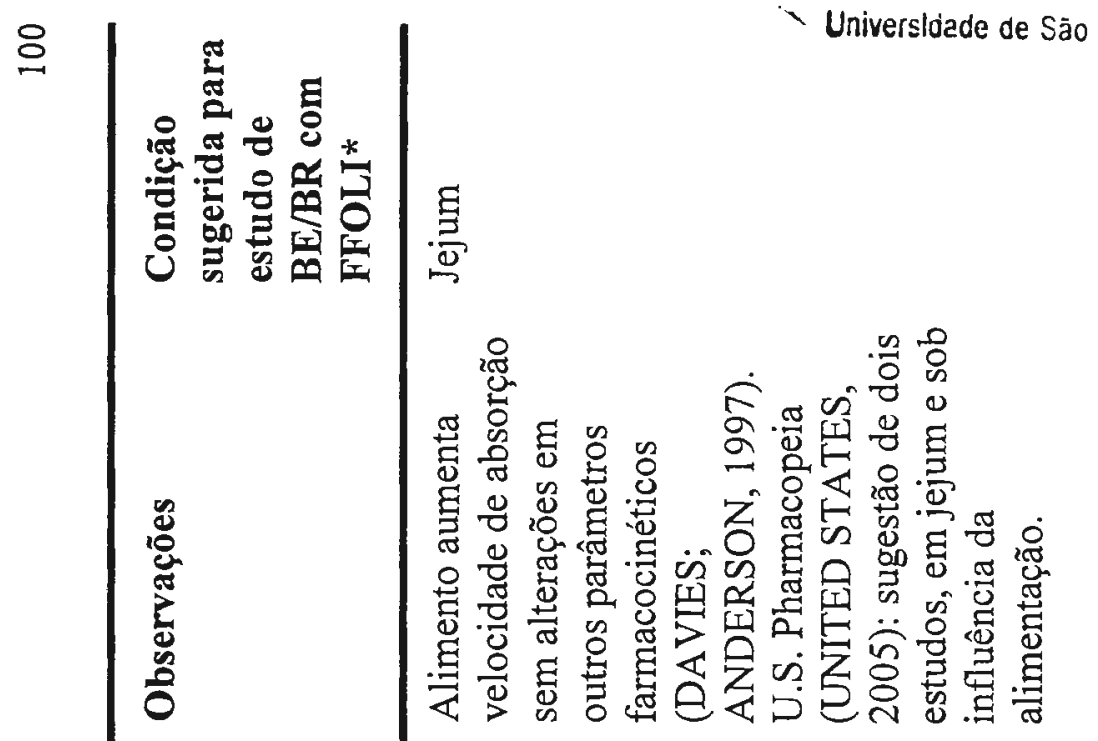

急

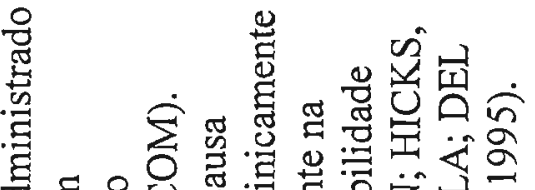

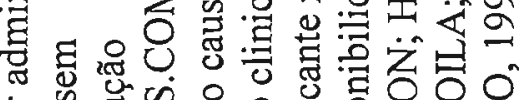

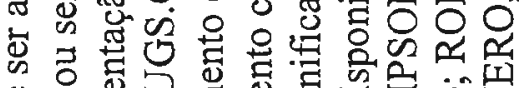

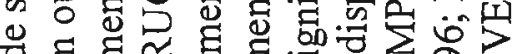

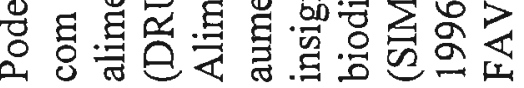

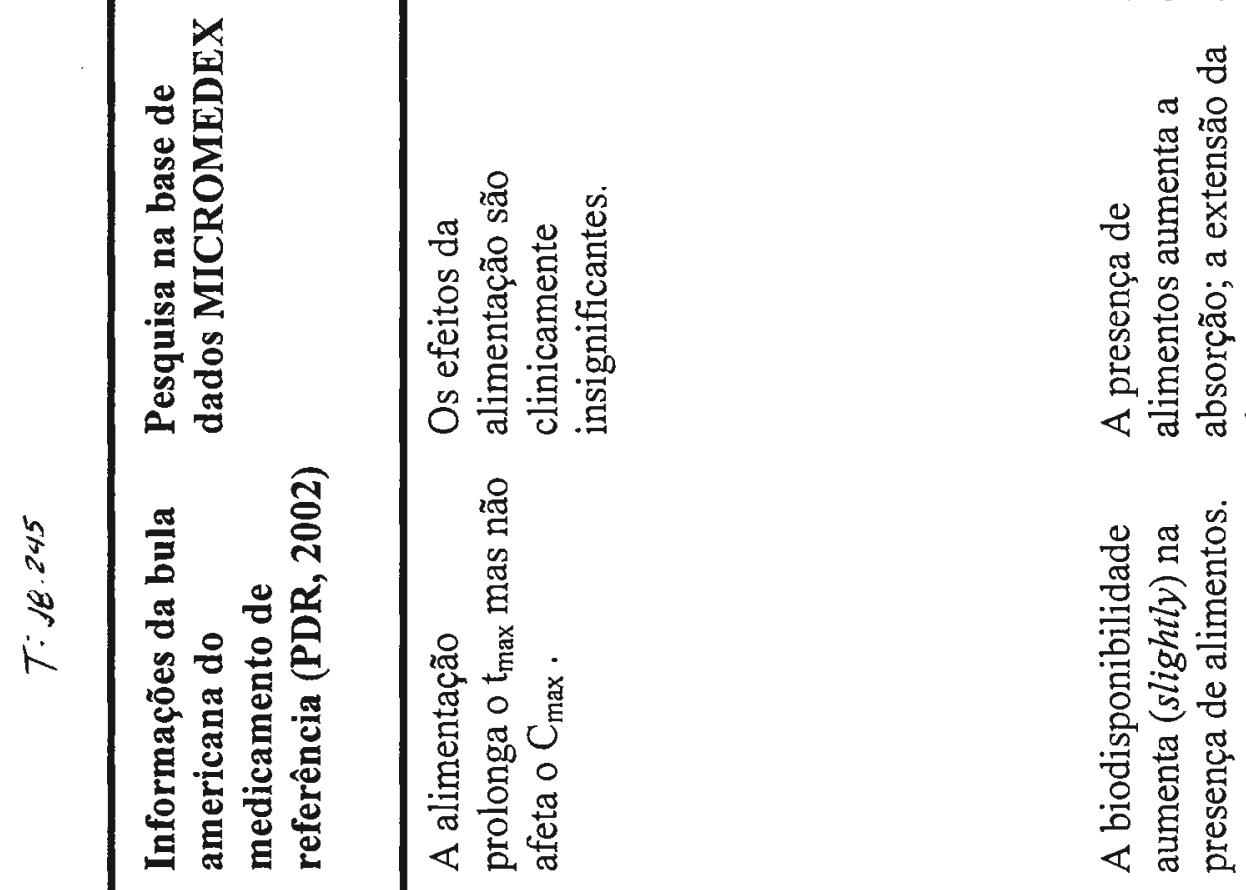
要

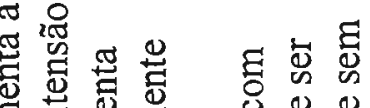

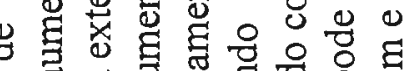
刃 웅

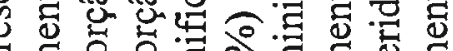

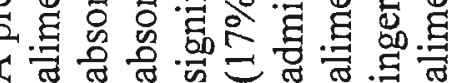

폴 웅

농 量 \&

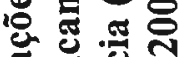
污

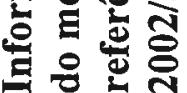

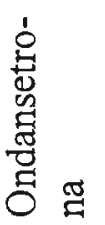




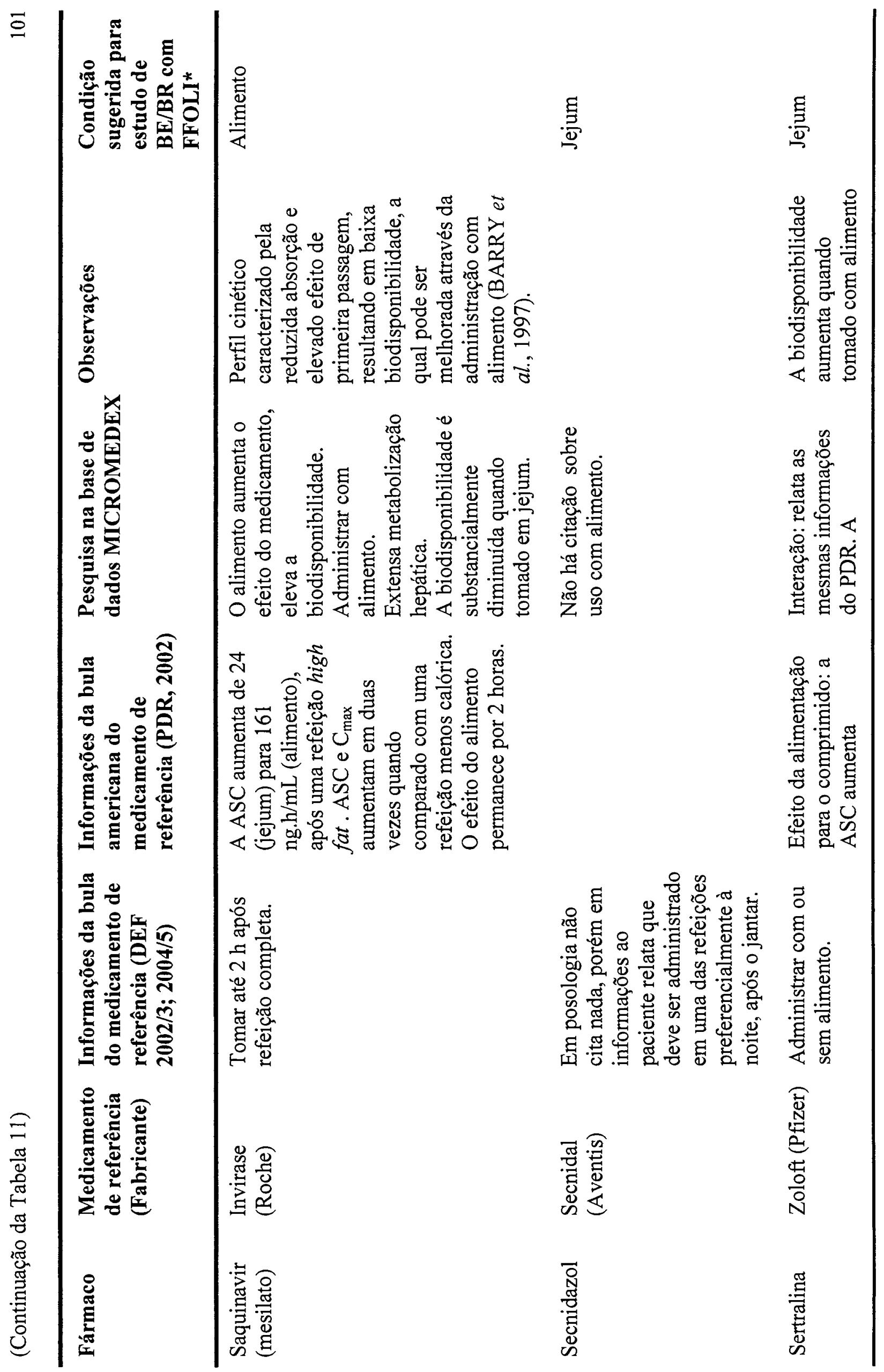




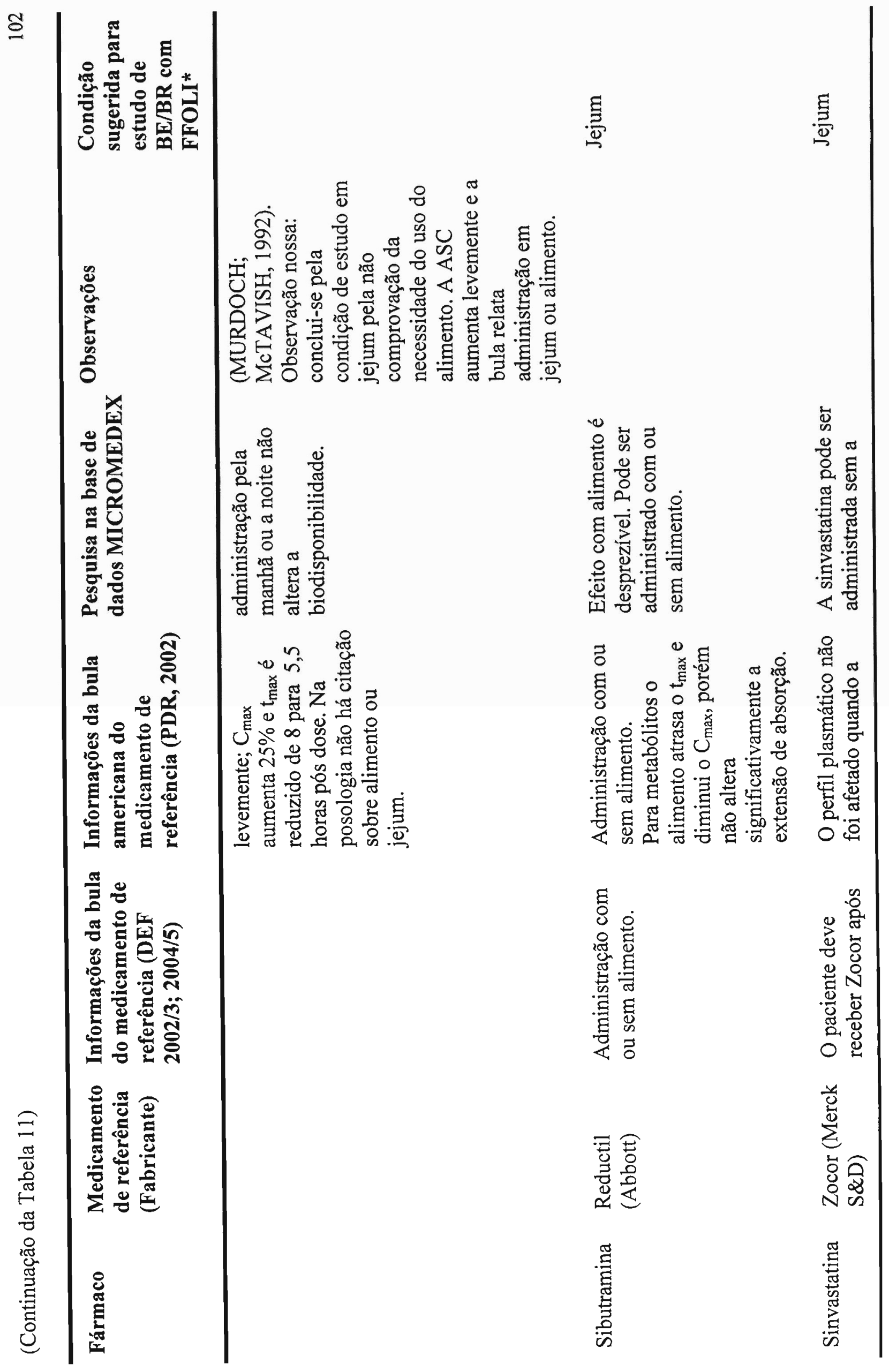




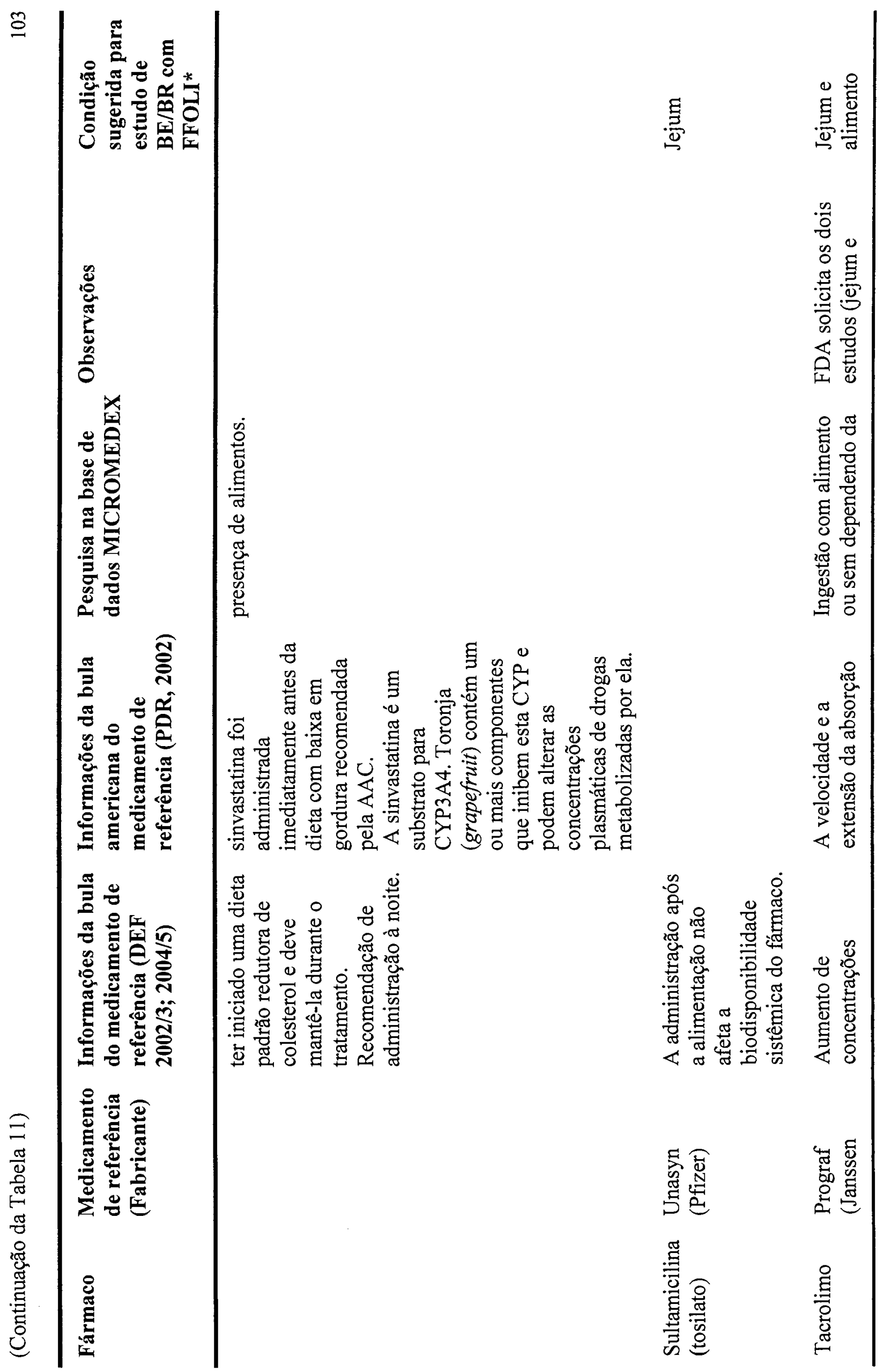




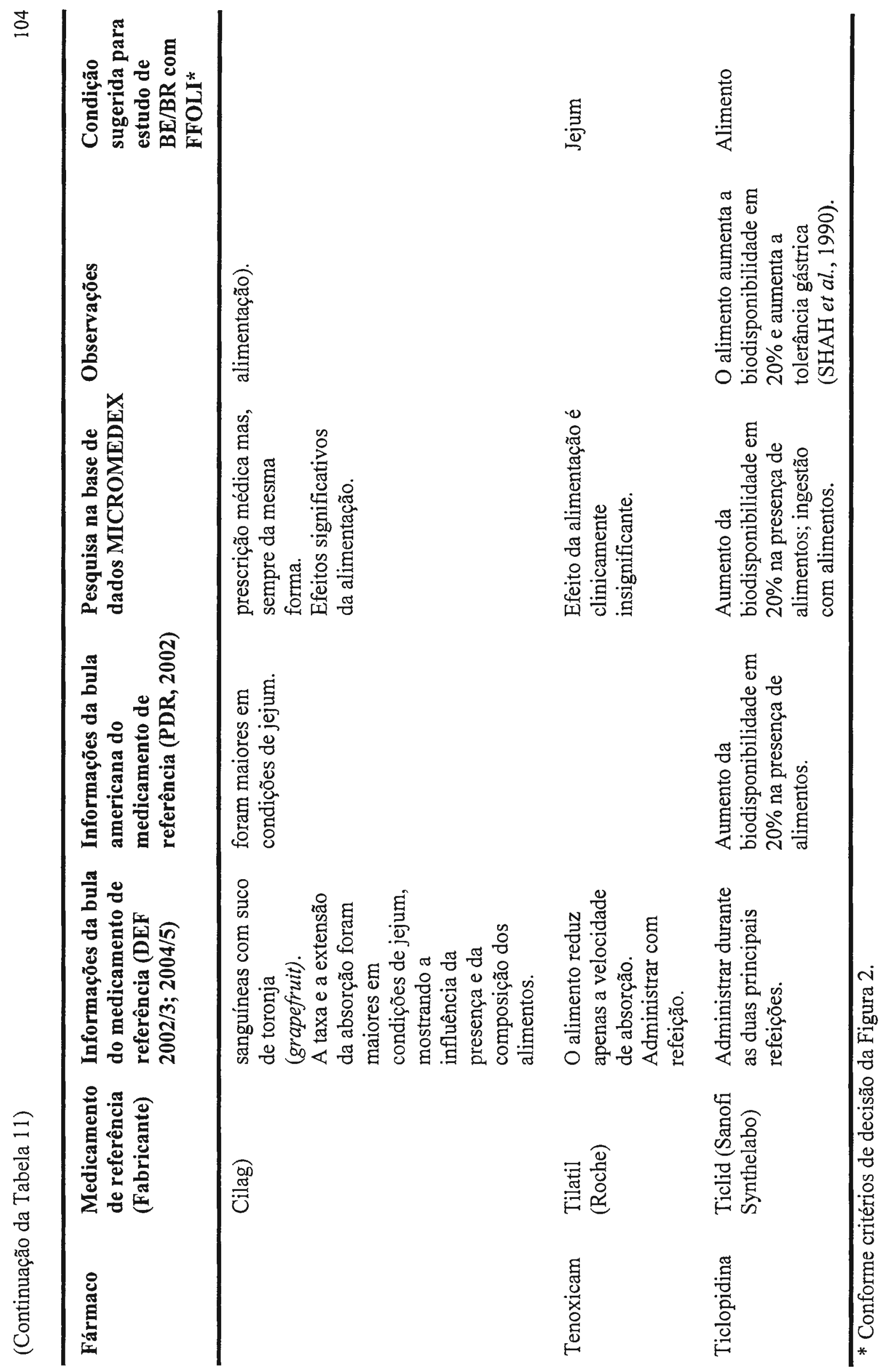




\subsection{PROPOSTA DE GUIA PARA ESTUDOS DE BIODISPONIBILIDADE E BIOEQUIVALÊNCIA COM ALIMENTAÇÃO}

\subsubsection{Introdução}

Este guia contém recomendações para o planejamento e condução dos estudos de biodisponibilidade (BD) e bioequivalência (BE) sob efeito de alimento. Estes estudos são aplicados às formas farmacêuticas de administração oral, com liberação imediata ou modificada, na etapa de desenvolvimento e para $o$ atendimento às exigências legais no processo de autorização de comercialização.

Os estudos de biodisponibilidade sob efeito do alimento geralmente são conduzidos no período de investigação de novos fármacos $\mathrm{e}$ novos medicamentos, para avaliar os efeitos do alimento na velocidade e extensão da absorção de um fármaco quando o medicamento é administrado imediatamente após uma refeição, em comparação com a administração sob condições de jejum. Os estudos de bioequivalência com alimentação, por sua vez, são conduzidos para demonstrar a bioequivalência de um medicamento genérico com o medicamento referência, sob condições de alimentação.

$\mathrm{O}$ alimento pode alterar a biodisponibilidade de um fármaco e influenciar na bioequivalência entre os produtos teste e referência, podendo ter conseqüências clinicamente significativas. Os efeitos do alimento na biodisponibilidade são, geralmente, máximos quando o medicamento é administrado imediatamente após a ingestão da refeição. Em geral, refeições com altos índices de calorias totais e de gorduras são mais prováveis de afetar a fisiologia gastrintestinal e promover um maior efeito na biodisponibilidade do fármaco.

Recomenda-se o emprego de refeições altamente calóricas e altamente gordurosas nos estudos de BD/BE sob efeito de alimento, como forma de desafiar, ao máximo, o produto. 
A administração de um medicamento com alimento pode alterar a biodisponibilidade por afetar o fármaco ou a formulação. $\mathrm{Na}$ prática, é difícil determinar o exato mecanismo pelo qual o alimento altera a biodisponibilidade do fármaco sem realizar estudos específicos. Em alguns casos, as interações dos excipientes e as modificações induzidas pelo alimento na fisiologia intestinal podem contribuir com os efeitos do alimento e influenciar na demonstração da bioequivalência.

Para muitas formulações de liberação imediata e para as formulações de liberação modificada, os efeitos do alimento são, muito provavelmente, o resultado de uma complexa combinação de fatores que influenciam a dissolução in vivo da formulação e/ou a absorção do fármaco. Nesses casos, o modo e a magnitude dos efeitos do alimento sobre a biodisponibilidade da formulação, bem como no que afeta a demonstração da bioequivalência, são difíceis, senão impossíveis de prever, sem a realização de um estudo de bioequivalência com alimentação.

\subsubsection{Recomendações dos estudos de biodisponibilidade e bioequivalência sob efeito de alimento}

Recomenda-se a realização de estudos de biodisponibilidade e bioequivalência sob efeito de alimento para todas as formas farmacêuticas orais de liberação modificada.

Para alterações pós-registro de medicamentos com formulação de liberação imediata ou modificada, em que se exige uma nova comprovação de bioequivalência em jejum, geralmente não são necessários estudos de bioequivalência com alimentação. 


\subsubsection{Para medicamento novo}

\subsection{Formas farmacêuticas orais de liberação imediata}

Recomenda-se a realização de estudo de biodisponibilidade sob efeito de alimento no período de investigação de um novo fármaco. São recomendados estudos de biodisponibilidade sob efeito de alimento no início do processo de desenvolvimento para orientar a seleção das formulações. Dados de biodisponibilidade sob efeito de alimento devem estar disponíveis para desenhar os estudos de eficácia e segurança clínica e prover informação para os itens "farmacologia clínica e/ou dosagem e administração" da bula do produto. Quando são realizadas alterações (na fórmula e/ou no método de fabricação) na formulação do ensaio clínico, antes do registro, deve ser demonstrada bioequivalência entre esta e a formulação a ser comercializada, seguindo os critérios preconizados em Resoluções e Recomendações da ANVISA para alterações pós-registro de medicamentos, quanto à necessidade ou não de estudo de bioequivalência. Nesse caso, se indicado, esse estudo de bioequivalência deve ser realizado, geralmente, em condições de jejum.

\subsection{Formas farmacêuticas orais de liberação modificada}

Recomenda-se estudo comparativo da biodisponibilidade em condições de jejum e alimentação. Quando são realizadas alterações (na fórmula e/ou no método de fabricação) na formulação do ensaio clínico antes do registro, deve ser demonstrada bioequivalência entre esta e a formulação a ser comercializada, seguindo os critérios preconizados em Resoluções e Recomendações da ANVISA para alterações pós-registro de medicamentos, quanto à necessidade ou não de estudo de bioequivalência. Nesse caso, se indicado, esse estudo de bioequivalência deve ser realizado, geralmente, em condições de jejum. 
5.2.2.2 Para medicamento genérico ou similar

5.2.2.2.1 Formas farmacêuticas orais de liberação imediata

a) deve ser realizado estudo de bioequivalência em jejum;

b) deve ser realizado estudo de bioequivalência com alimentação, alternativamente ao estudo em jejum, quando a bula do medicamento referência recomenda administração com alimentação, em função do efeito do alimento na absorção do fármaco;

c) adicionalmente ao estudo de bioequivalência em jejum, deve ser realizado estudo de bioequivalência com alimentação para medicamentos contendo fármaco da lista de Fármacos Críticos (estreita faixa terapêutica, alta toxicidade, farmacocinética não linear, absorção influenciada pelo alimento etc.) divulgada pela ANVISA. Uma condição alternativa (só em jejum, ou só com alimento, ou com refeição diferenciada) pode ser aceita, mediante justificativa documentada e previamente aprovada pela ANVISA, nos casos em que a administração do medicamento em estado de jejum ou com alimentação representa riscos potenciais aos voluntários.

\subsection{Formas farmacêuticas orais de liberação modificada}

Adicionalmente ao estudo de bioequivalência em jejum, deve ser realizado estudo de bioequivalência com alimentação. Uma condição alternativa (só em jejum, ou só com alimento, ou com refeição diferenciada) pode ser aceita, mediante justificativa documentada e previamente aprovada pela ANVISA, nos casos em que a administração do medicamento em estado de jejum ou com alimentação representa riscos potenciais aos voluntários. 


\subsubsection{Condução dos estudos}

\subsubsection{Desenho do estudo}

Recomenda-se desenho cruzado, randomizado, balanceado, dose única, dois tratamentos (jejum $\mathrm{x}$ alimento) separados por um adequado período de washout, dois períodos e duas seqüências para estudos de biodisponibilidade sob efeito de alimento, aplicados às formulações de liberação imediata ou modificada. Para estudos de bioequivalência com alimentação recomenda-se o mesmo desenho, exceto para os tratamentos em que os produtos teste e referência são administrados após uma refeição padrão.

\subsubsection{Dose}

Geralmente, emprega-se a maior concentração do produto nos estudos de biodisponibilidade e bioequivalência sob efeito de alimento, exceto nos casos de risco de toxicidade.

\subsubsection{Refeição padrão}

Recomenda-se o emprego de refeição que promova máxima alteração na fisiologia gastrintestinal e, assim, possa afetar a biodisponibilidade sistêmica do fármaco. Uma refeição altamente gordurosa (aproximadamente 50\% do conteúdo calórico total) e altamente calórica ( 800 a 1000 calorias) é recomendável. A escolha da refeição deve ser justificada, relatando-se a composição, o conteúdo calórico (vide tabela modelo) e o tempo de ingestão. Adicionalmente às características descritas aqui, refeições com variadas composições de carboidrato, 
gorduras e proteínas podem ser empregadas nos estudos de biodisponibilidade sob efeito de alimento na etapa de desenvolvimento de novos medicamentos.

Tabela 12 - Modelo para informação do conteúdo calórico da refeição padronizada no estudo.

\begin{tabular}{|l|c|c|c|}
\hline & Calorias recomendadas & Calorias & Calorias (\%) \\
\hline Gorduras & $500 \mathrm{a} 600$ & & \\
\hline Carboidratos & 250 & & \\
\hline Proteínas & 150 & & \\
\hline TOTAL & $800 \mathrm{a} 1000$ & & 100 \\
\hline
\end{tabular}

\subsubsection{Tratamentos}

a) Em jejum

O medicamento deve ser administrado aos voluntários com $240 \mathrm{~mL}$ de água, após jejum de, no mínimo, 10 horas. Não deve ser permitido alimento por, no mínimo, 4 horas após a administração. Pode ser permitida água à vontade, exceto por 1 hora antes e 1 hora após a administração. Os voluntários devem receber refeições padronizadas e programadas para o mesmo horário em cada período do estudo.

\section{b) Com alimento}

Após jejum de, no mínimo, 10 horas, os voluntários devem iniciar a refeição padrão 30 minutos antes da administração do medicamento. Os voluntários devem ingerir a refeição em, no máximo, 30 minutos, sendo o medicamento administrado 30 minutos após o início da refeição, com $240 \mathrm{~mL}$ de 
água. Não deve ser permitido alimento por, no mínimo, 4 horas após a administração. Pode ser permitida água à vontade, exceto por 1 hora antes e 1 hora após a administração. Os voluntários devem receber refeições padronizadas e programadas para o mesmo horário em cada período do estudo.

\subsubsection{Coleta das amostras}

São coletadas amostras de fluido biológico (geralmente plasma) seguindo um cronograma que permita a completa caracterização do perfil plasmático concentração do fármaco versus tempo do medicamento. Deve-se considerar a possibilidade de alteração do perfil plasmático concentração-tempo em função da administração com alimento para adequar os tempos de coleta.

\subsubsection{Quantificação do fármaco}

O método bioanalítico empregado deve ser bem caracterizado, completamente validado e documentado. Devem ser seguidos os princípios de boas práticas analíticas e cumpridos todos os requisitos estabelecidos no guia específico da ANVISA sobre validação do método bioanalítico.

\subsubsection{Análise dos dados}

Devem ser obtidos os seguintes parâmetros farmacocinéticos a partir das curvas de concentração-tempo resultantes para os produtos teste e referência nos estudos de biodisponibilidade e bioequivalência com alimento: $\mathrm{ASC}_{0 \text {-t }}, \mathrm{ASC}_{0 \text {-inf, }}$ $\mathrm{C}_{\max }, \mathrm{t}_{\max }, \mathrm{t}_{\text {lag }}$ (se presente, no caso de FFOLM), $t_{1 / 2}$ e outros parâmetros farmacocinéticos julgados relevantes conforme o caso.

A análise estatística e apresentação dos resultados devem ser de acordo com o "guia para planejamento e realização da etapa estatística de estudos de biodisponibilidade relativa/bioequivalência", da ANVISA. Deve ser determinado 
o intervalo de confiança (IC) de $90 \%$ para a razão das médias geométricas entre os produtos teste e referência para $\mathrm{ASC}_{0-\mathrm{t}}, \mathrm{ASC}_{0 \text {-inf }}$ e $\mathrm{C}_{\max }$. Para os estudos de biodisponibilidade sob efeito de alimento (medicamentos novos), o tratamento em jejum serve como referência. Para os estudos de bioequivalência com alimentação (medicamentos genéricos), o tratamento de referência é o produto referência definido pela ANVISA administrado com alimento.

A ausência do efeito do alimento na biodisponibilidade não é estabelecida se o IC $90 \%$ para a razão das médias geométricas entre os tratamentos com alimento e jejum, baseado nos dados log-transformados, não está contido nos limites de $80-125 \%$ para $\mathrm{ASC}_{0 \text {-inf }}\left(\mathrm{ASC}_{0-\mathrm{t}}\right.$ quando apropriado) ou $\mathrm{C}_{\max }$ Neste caso, devem ser fornecidas recomendações específicas sobre a significância clínica do efeito do alimento.

A ausência do efeito do alimento na biodisponibilidade é indicada quando o IC $90 \%$ para a razão das médias geométricas entre os tratamentos com alimento e jejum, baseado nos dados log-transformados, está contido nos limites de 80$125 \%$ para $\mathrm{ASC}_{0 \text {-inf }}\left(\mathrm{ASC}_{0-\mathrm{t}}\right.$ quando apropriado) e $\mathrm{C}_{\max }$.

A bioequivalência do produto teste com o referência sob condições de alimentação é concluída quando o IC $90 \%$ para a razão das médias geométricas entre os produtos teste e referência, baseado nos dados log-transformados, está contido nos limites de $80-125 \%$ para ASC e $\mathrm{C}_{\max }$. Os valores de $\mathrm{t}_{\max }$ dos produtos teste e referência devem ser comparáveis com base em relevância clínica. 


\section{CONCLUSÕES}

Os resultados obtidos no presente trabalho, que incluiu a avaliação da literatura científica e a análise da regulamentação técnica nacional e internacional, conduziram às seguintes conclusões:

1. No caso de registro de medicamentos novos no Brasil, é indispensável a realização de estudos de efeito de alimento na biodisponibilidade de fármacos, cujos resultados servirão de base às recomendações de administração adequada do medicamento em relação às dietas.

2. Para registro de medicamentos genéricos e similares na forma farmacêutica oral de liberação modificada (FFOLM) é fundamental realizar dois estudos de bioequivalência (em jejum e com alimento).

3. No caso de alterações pós-registro de medicamentos genéricos e similares na forma farmacêutica oral de liberação modificada, recomenda-se a realização de estudo de bioequivalência, geralmente, em jejum.

4. Para o registro de medicamentos genéricos e similares na forma farmacêutica de liberação convencional deve-se realizar estudo de bioequivalência em jejum ou, alternativamente, estudo com alimentação nos casos em que a absorção do fármaco seja influenciada significativamente pelo alimento e a indicação de administração seja com alimento.

5. A proposta apresentada como parte integrante da presente dissertação, para o "guia para requerimento e condução de estudos de biodisponibilidade e bioequivalência de medicamentos sob efeito de alimento" reúne as informações necessárias à execução desses estudos, podendo este ser submetido à consulta pública e posterior publicação pela ANVISA. 
6. Necessidade de definição pela ANVISA da lista de fármacos críticos (estreita faixa terapêutica, alta toxicidade, farmacocinética nãolinear, variabilidade na absorção) para condução dos estudos de biodisponibilidade e bioequivalência sob condições diferenciadas em relação ao jejum e alimentação.

7. Recomenda-se a realização de estudo de bioequivalência com refeição diferenciada, em substituição ao estudo em jejum, quando este é solicitado, para casos justificáveis que representam riscos aos voluntários. 


\section{REFERÊNCIAS BIBLIOGRÁFICAS}

AHR, G.; VOITH, B.; KUHLMANN, J. Guidances related to bioavailability and bioequivalence: European industry perspective. Eur. J. Drug. Metab. Pharmacokinet., v.25, n.1, p.25-27, 2000.

AMIDON, G.L.; LENNERNAS, H.; SHAH, V.P.; CRISON, J.R. A theoretical basis for a biopharmaceutic drug classification: the correlation of in vitro drug product dissolution and in vivo bioavailability. Pharm. Res., v.12, n.3, p.413-420, 1995.

ANDERSON, J.D. Current issues in bioequivalence determination. Appl. Clin. Trials, v.1, p.44-49, 1992.

BAREGGI, S.R.; PIROLA, R.; TRUCI, G.; LEVA, S.; SMIRNE, S. Effect of after-dinner administration on the pharmacokinetics of oral flunitrazepam and loprazolam. J. Clin. Pharmacol., v.28, n.4, p.371-375, 1988.

BARRY, M.; GIBBONS, S.; BACK, D.; MULCAHY, F. Protease inhibitors in patients with HIV disease. Clinically important pharmacokinetic considerations. Clin. Pharmacokinet., v.32, n.3, p.194-209, 1997.

BENINI, L.; BRIGHENTI, F.; CASTELLANI, G.; BRENTEGANI, M.T.; CASIRAGHI, M.C.; RUZZENENTE, O. et al. Gastric-emptying of solids is markedly delayed when meals are fried. Dig. Dis. Sci., v.39, p.2288-2294, 1994.

BENSON, M.D. Therapeutic equivalents in clinical practice. Int. J. Fertil. Womens Med., v.46, n.2, p.89-94, 2001.

BENZIGER, D.P.; KAIKO, R.F.; MIOTTO, J.B.; FITZMARTIN, R.D.; REDER, R.F.; CHASIN, M. Differential effects of food on the bioavailability of controlled-release oxycodone tablets and immediate release oxycodone solution. J. Pharm. Sci., v.85, n.4, p.407-410, 1996.

BRASIL. Ministério da Saúde. Agência Nacional de Vigilância Sanitária. Legislação. VisaLegis. Lei n.5991, de 17 de dezembro de 1973. Dispõe sobre o controle sanitário do comércio de drogas, medicamentos, insumos farmacêuticos e correlatos, e dá outras providências. Disponível em: http://elegis.bvs.br/leisref/public/showAct.php?id=16614\&word $=$. Acesso em: 17 jun. 2005.

BRASIL. Ministério da Saúde. Agência Nacional de Vigilância Sanitária. Legislação. VisaLegis. Lei n.9787, de 10 de fevereiro de 1999. Altera a Lei no 6.360, de 23 de setembro de 1976, que dispõe sobre a vigilância sanitária, estabelece o medicamento genérico, dispõe sobre a utilização de nomes 
genéricos em produtos farmacêuticos e dá outras providências. Disponível em: http://e-legis.bvs.br/leisref/public/showAct.php?id=245. Acesso em: 17 jun. 2005.

BRASIL. Ministério da Saúde. Agência Nacional de Vigilância Sanitária. Legislação. VisaLegis. Resolução RDC n.133, de 29 de maio de $2003 a$. Dispõe sobre o registro de medicamento similar e dá outras providências. Disponível em: http://e-legis.bvs.br/leisref/public/showAct.php?id=7901. Acesso em: 17 jun. 2005.

BRASIL. Ministério da Saúde. Agência Nacional de Vigilância Sanitária. Legislação. VisaLegis. Resolução RDC n.135, de 29 de maio de $2003 b$. Aprova o regulamento técnico para medicamentos genéricos. Disponível em: http://e-legis.bvs.br/leisref/public/showAct.php?id=7909. Acesso em: 17 jun. 2005.

BRASIL. Ministério da Saúde. Agência Nacional de Vigilância Sanitária. Legislação. VisaLegis. Resolução RE n.397, de 12 de novembro de 2004. Guia para provas de biodisponibilidade relativa/bioequivalência. Disponível em: http://e-legis.bvs.br/leisref/public/showAct.php?id=13226. Acesso em: 17 jun. 2005.

BRASIL. Ministério da Saúde. Agência Nacional de Vigilância Sanitária. Legislação. VisaLegis. Resolução RE n.896, de 29 de maio de 2003c. Guia para provas de biodisponibilidade relativa/bioequivalência. Disponível em: http://e-legis.bvs.br/leisref/public/showAct.php?id=3690. Acesso em: $17 \mathrm{jun}$. 2005.

BRASIL. Ministério da Saúde. Agência Nacional de Vigilância Sanitária. Legislação. VisaLegis. Resolução RE n.898, de 29 de maio de 2003d. Guia para planejamento e realização da etapa estatística de estudos de biodisponiblidade relativa/bioequivalência. Disponível em: http://elegis.bvs.br/leisref/public/showAct.php?id=2489. Acesso em: 17 jun. 2005.

BRASIL. Ministério da Saúde. Agência Nacional de Vigilância Sanitária. Legislação. VisaLegis. Resolução RE n.899, de 29 de maio de 2003e. Guia para validação de métodos analíticos e bioanalíticos. Disponível em: http://elegis.bvs.br/leisref/public/show Act.php?id=5745. Acesso em: 17 jun. 2005.

BUMM, R.; BLUM, A.L. Lessons from prolonged gastric $\mathrm{pH}$ monitoring. Aliment. Pharmacol. Therap., v.1, p.518S-526S, 1987.

CALVERT, R.T. Bioequivalence and generic prescribing: a pharmacy view. $J$. Pharm. pharmacol., v.48, p.9-10, 1996. 
CANADA. Health Canada. Draft guidance for industry: bioequivalence requirements: comparative bioavailability studies conducted in the fed state. Ottawa, 2004. 6p.

CANADA. Health Canadá. Guidance for industry: conduct and analysis of bioavailability and bioequivalence studies - part A: oral dosage formulations used for systemic effects. Ottawa, 1992. 54p.

CANADA. Health Canadá. Guidance for industry: conduct and analysis of bioavailability and bioequivalence studies - part B: oral modified release formulations. Ottawa, 1996.136p.

CARDONA PERA, D. Interacción fármacos-alimentos. Nutr. Hosp., v.14, suppl.2, p.129S-140S, 1999.

CARRIZO, F.E.E. Estudios de bioequivalencia: enfoque metodológico y aplicaciones prácticas en la evaluación de medicamentos genéricos. Rev. Med. Uruguay, v.16, n.2, p.133-143, 2000.

CHAN, L.N. Drug-nutrient interaction in clinical nutrition. Curr. Opin. Clin. Nutr. Metab. Care, v.5, n.3, p.327-332, 2002.

CHARMAN, W.N.; PORTER, C.J.; MITHANI, S.; DRESSMAN, J.B. Physiochemical and physiological mechanisms for the effects of food on drug absorption: the role of lipids and pH. J. Pharm. Sci., v.86, n.3, p.269-282, 1997.

CHEN, M.L.; JACKSON, A.J. The role of metabolites in bioequivalency assessment. II. drugs with linear pharmacokinetics and first-pass affect. Pharm. Res., v.12, p.700-708, 1995.

CHEN, M.L.; SHAH, V.; PATNAIK, R.; ADAMS, W.; HUSSAIN, A.; CONNER, D.; MEHTA, M.; MALINOWSKI, H.; LAZOR, J.; HUANG, S.M.; HARE, D.; LESKO, L.; SPORN, D.; WILLIAMS, R. Bioavailability and bioequivalence: an FDA regulatory overview. Pharm. Res., v.18, n.12, p.1645-1650, 2001.

DAKOVIC-SVAJCER, K. Food and drugs. Med. Pregl., v.55, n.1/2, p.5-12, 2002.

DANESHMEND, T.K.; WARNOCK, D.W. Clinical pharmacokinetics of ketoconazole. Clin. Pharmacokinet., v.14, n.1, p.13-34, 1988.

DAVIES, N.M.; ANDERSON, K.E. Clinical pharmacokinetics of naproxen. Clin. Pharmacokinet., v.32, n.4, p.268-293, 1997.

DENNIS, M.J. Absorption processes. In: HANSCH, C. Comprehensive medicinal chemistry. Oxford: Pergamon Press, 1990. v.5, p.1-43. 
DICIONÁRIO DE ESPECIALIDADES FARMACÊUTICAS: DEF 2002/2003. 31. ed. Rio de Janeiro: Publicações Científicas, 2002. 1234p.

DICIONÁRIO DE ESPECIALIDADES FARMACÊUTICAS: DEF 2004/2005. 33. ed. Rio de Janeiro: Publicações Científicas, 2004. 930p.

DRESSER, G.K.; BAILEY, D.G. The effects of fruit juices on drug disposition: a new model for drug interactions. Eur. J. Clin. Invest., v.33, suppl.2, p.10$16,2003$.

DRUGS.COM Drug Information Online. Prescription Drug information for consumers \& professionals. Disponivel em: http://www.drugs.com. Acesso em: 15 jul. 2005.

DUPUIS, L.L.; KOREN, G.; SILVERMAN, E.D.; LAXER, R.M. Influence of food on the bioavailability of oral methotrexate in children. J. Rheumatol., v.22, n.8, p.1570-1573, 1995.

EUROPEAN AGENCY FOR THE EVALUATION OF MEDICINAL PRODUCTS. Evaluation of Medicines for Human Use. CPMP/EWP/280/96. Note for guidance on modified release oral and transdermal dosage forms: section II - pharmaceutical and clinical evaluation. London, 1999. 11 p.

EUROPEAN AGENCY FOR THE EVALUATION OF MEDICINAL PRODUCTS. Evaluation of Medicines for Human Use. (CPMP/EWP/QWP/1401/98). Note for guidance on the investigation of bioavailability and bioequivalence. London, 2001. 18p.

FLEISHER, D.; LI, C.; ZHOU, Y.; PAO, L.H.; KARIM, A. Drug, meal and formulation interactions influencing drug absorption after oral administration: clinical implications. Clin. Pharmacokinet., v.36, n.3, p.233254, 1999.

FUHR, U. Drug interactions with grapefruit juice: extent, probable mechanism and clinical relevance. Drug Saf., v.18, n.4, p.251-272, 1998.

GLEITER, C.H,; GUNDERT-REMY,U. Bioequivalence and drug toxicity. Drug Saf., v.11, p.1-6, 1994.

GLEITER, C.H.; KLOTZ, U.; KUHLMANN, J.; BLUME, H.; STANISLAUS, F.; HARDER, S.; PAULUS, H.; POETHKO-MÜLLER, C.; HOLZSLOMCZYK, M. When are bioavailability studies required?: a German proposal. J. Clin. Pharmacol., v.38, p.904-911, 1998.

GODBILLON, J.; CARDOT, J.M.; LECAILLON, J.B.; LEFEVRE, G.; SIOUFI, A. Bioequivalence assessment: a pharmaceutical industry perspective. Eur. $J$. Drug Metab. Pharmacokinet., v.21, n.2, p.153-158, 1996. 
GRAHAM, D.Y.; SMITH, J.L.; BOUVET, A.A.What happens to tablets and capsules in the stomach - endoscopic comparison of disintegration and dispersion characteristics of two microencapsulated potassium formulations. J. Pharmaceut. Sci., v.79, p.420-424, 1990.

HAMILTON, R.A.; KREMER, J.M. The effects of food on methotrexate absorption. J. Rheumatol., v.22, n.4, p.630-632, 1995.

HANSCH, C. Comprehensive medicinal chemistry. Oxford: Pergamon Press, 1990. v.5, p.165-179.

HARDY, J.G.; EVANS, D.F.; ZAKI, I.; CLARK, A.G.; TONNESEN, H.H.; GAMST, O.N. Evaluation of an enteric coated naproxen tablet using gamma scintigraphy and pH monitoring. Int. J. Pharmaceut., v.37, p.245-250, 1987.

HARRIS, R.Z.; JANG, G.R.; TSUNODA, S. Dietary effects on drug metabolism and transport. Clin. Pharmacokinet., v.42, n.13, p.1071-1088, 2003.

HAUSKEN, T.; ODEGAARD, S.; BERSTAD, A. Antroduodenal motility studied by real time ultrasonography. Gastroenterol., v.100, p.59-63, 1991.

HOLMES, D.G.; KUTZ, K. Bioequivalence of a slow-release and a non-retard formulation of isradipine. Am. J. Hypertens., suppl.6, p.70-73, 1993.

HUANG, S.M.; LESKO, L.J. Drug-drug, drug-dietary supplement, and drugcitrus fruit and other food interactions: what have we learned? J. Clin. Pharmacol., v.44, p.559-569, 2004.

HUNTER, E.; GELL, J.T.; SHARMA, H.; McNEILLY, A.M. The in vivo behaviour of hard gelatin capsules filled with thixotropic liquids. Part 2: Quantitative aspects. Pharmazeutische Industrie, v.45, p.433-434, 1983.

INVESTIGATION of bioavailability and bioequivalence. The rules governing medicinal products in the European Community. EudraLex, v.3, addendum 2, p.149-169, 1991.

JACKSON, A.J. Generics and bioequivalence. Kockville: CRC Press, 1994. $203 p$.

JAPAN. Ministry of Health and Welfare. Guideline for bioequivalence studies of generic products. Tokyo: National Institute of Health Sciences, 1997. 23p.

JOHNSON, B.F.; FOWLE, A.S.; LADER, S.; FOX, J.; MUNRO-FAURE, A.D. Biological availability of digoxin from Lanoxin produced in the United Kingdom. Br. Med. J., v.4, p.323-326, 1973.

KING, P.M.; ADAM, R.D.; PRYDE, A.; McDICKEN, W.N.; HEADING, R.C. Relationships of human antroduodenal motility and transpyloric fluid 
movement: non-invasive observations with real-time ultrasound. Gut, v.25, p.1384-1391, 1984.

KOCH-WESER, J. Drug therapy: bioavailability of drugs. N. Engl. J. Med., v.291, p.233-237, 1974.

KONTUREK, J.W.; THOR, P.; DOMSCHKE, W.; KONTUREK, S.J. Role of $\mathrm{CCK}$ in the control of gastric emptying and gastric secretory response to fatty meal in humans. Biomed. Res., v.16, suppl.2, p.141-146, 1995.

KUHN, M.A. Drug interactions with medications and food. Nurs. Spectr., v.8, n.11, p.12-14, 1998.

LEIBOVITCH, E.R.; DEAMER, R.L.; SANDERSON, L.A. Food-drug interactions: careful drug selection and patient counseling can reduce the risk in older patients. Geriatrics, v.59, n.3, p.19-22, 32-33, 2004.

LELAWONGS, P.; BARONE, J.A.; COLAIZZI, J.L.; HSUAN, A.T.; MECHLINSKI, W.; LEGENDRE, R.; GUARNIERI, J. Effect of food and gastric acidity on absorption of orally administered ketoconazole. Clin. Pharm., v.7, n.3, p.228-235, 1988.

LEOPOLD, G.; PABST, J.; UNGETHUM, W.; BUHRING, K.U. Basic pharmacokinetics of bisoprolol, a new highly beta 1-selective adrenoceptor antagonist. J. Clin. Pharmacol., v.26, n.8, p.616-621, 1986.

LI, C.; PAO, L.H.; LI, L. et al. Regional intestinal absorption and meal effects on LY303366 in a canine model. Pharm. Sci., v.1, suppl.1, p.S10, 1998.

LIEDHOLM, H.; LIDEN, A. Food intake and the presystemic metabolism of single doses of amitriptyline and nortriptyline. Fundam. Clin. Pharmacol., v.12, n.6, p.636-642, 1998.

LINDENBAUM, J.; MELLOW, M.H.; BLACKSTONE, M.O.; BUTLER, V.P. Variation in biologic availability of digoxin from four preparations. N. Engl. J. Med., v.285, p.1344-1347, 1971.

MAKA, D.A.; MURPHY, L.K. Drug-nutrients interactions: a review. $A A C N$ Clin. Issues, v.11, n.4, p.580-589, 2000.

MANNISTO, P.T.; MANTYLA, R.; NYKANEN, S.; LAMMINSIYU, U.; OTTOILA, P. Impairing effect of food on ketoconazole absorption. Antimicrob. Agents Chemother., v.21, n.5, p.730-733, 1982.

MARTINDALE - the complete drug reference. 33rd ed. London; Chicago: Pharmaceutical Press, 2002. 2483 p. 
MARZO, A. Open questions on bioequivalence: some problems and some solutions. Pharmacol. Res., v.40, n.4, p.357-368, 1999.

McARTHUR, K.; HOGAN, D.; ISENBERG, J.I. Relative stimulatory effects of commonly ingested beverages on acid secretion in humans. Gastroenterol., v.83, p.199-204, 1982.

McGILVERAY, I.J. Bioequivalence: a Canadian regulatory perspective. In: WELLING, P.G.; TSE, F.L.S.; DIGHE, S.V., eds. Pharmaceutical bioequivalence. New York: Marcel Dekker, 1991.p.381.

McGILVERAY, I.J. Progress in harmonization of bioavailability and bioequivalence standards. In: JACKSON, A.J. Generics and bioequivalence. Kockville: CRC Press, 1994. p.187-191.

McLAUGHLAN, G.; FULLARTON, G.M.; CREAN, G.P.; McCOLL, K.E.L. Comparison of gastric body and antral $\mathrm{pH}$ : a 24 hour ambulatory study in healthy volunteers. Gut., v.30, p.573-578, 1989.

MCLEAN, A.; BROWNE, S.; ZHANG, Y.; SLAUGHTER, E.; HALSTENSON, C.; COUCH, R. The influence of food on the bioavailability of a twice-daily controlled release carbamazepine formulation. J. Clin. Pharmacol., v.41, n.2, p.183-186, 2001.

MELANDER, A.; McLEAN, A. Influence of food intake on presystemic clearance of drugs. Clin. Pharmacokinet., v.8, n.4, p.286-296, 1983.

MORAIS, J.A.G. Regulatory requirements for bioavailability studies of new active substances I. In: BLUME, H.H.; MIDHA, K.K. Bio-International 2: bioavailability, bioequivalence and pharmacokinetic studies; international conference of F.I.P. Stuttgart: Medpharm Scientific Publishers, 1995. p.171179.

MORGAN, T. Clinical pharmacokinetics and pharmacodynamics of carvedilol. Clin. Pharmacokinet., v.26, n.5, p.335-346, 1994.

MURDOCH, D.; McTAVISH, D. Sertraline. A review of its pharmacodynamic and pharmacokinetic properties, and therapeutic potential in depression and obsessive-compulsive disorder. Drugs, v.44, n.4, p.604-624, 1992.

NAKAI, K.; FUJITA, M.; OGATA, H. International harmonization of bioequivalence studies and issues shared in common. J. Pharm. Soc. Jpn., v.120, n.11, p.1193-1200, 2000.

OGUEY, D.; KOLLIKER, F.; GERBER, N.J.; REICHEN, J. Effect of food on the bioavailability of low-dose methotrexate in patients with rheumatoid arthritis. Arthritis Rheum., v.35, n.6, p.611-614, 1992. 
OSER, B.L.; MELNICK, P.; HOCHBERG, M. Physiological availability of the vitamins: study of methods for determining availability in pharmaceutical products. Ind. Eng. Chem. Anal. Educ., v.17, p.401-411, 1945.

PHYSICIANS' DESK REFERENCE. 56th ed. Montvale: Medical Economics, 2002. 3635p.

PORTA, V. Avaliação da bioequivalência de formulações do mercado nacional contendo fluconazol. São Paulo, 1999. 129p. Tese de Doutorado - Faculdade de Ciências Farmacêuticas - Universidade de São Paulo.

PUSZTAI, A. Transport of proteins through the membranes of the adult gastrointestinal tract - A potencial for drug delivery? Adv. Drug Deliv. Rev., v.3, p.215-228, 1989.

RAO, N.; ELLER, M.; ARUMUGHAM, T.; WEIR, S. The effect of food on the relative bioavailability of deflazacort. Eur. J. Drug Metab. Pharmacokinet., v.21, n.3, p.241-245, 1996.

RICHARDSON, C.T.; WALSH, J.H.; HICKS, M.I.; FORDTRAN, J.S. Studies on the mechanisms of food-stimulated gastric acid secretion in normal human subjects. J. Clin. Invest., v.58, p.623-681, 1976.

ROILA, F.; DEL FAVERO, A. Ondansetron clinical pharmacokinetics. Clin. Pharmacokinet., v.29, n.2, p.95-109, 1995.

SARTOR, G.; MELANDER, A.; SCHERSTEN, B.; WAHLIN-BOLL, E. Influence of food and age on the single-dose kinetics and effects of tolbutamide and chlorpropamide. Eur. J. Clin. Pharmacol, v.17, n.4, p.285293, 1980.

SASAKI, M.; MAEDA, A.; SAKAMOTO, K.; FUJIMURA, A. Effect of bile acids on absorption of nitrendipine in healthy subjects. Br. J. Clin. Pharmacol., v.52, n.6, p.699-701, 2001.

SCHAFER-KORTING, M. Pharmacokinetic optimisation of oral antifungal therapy. Clin. Pharmacokinet., v.25, n.4, p.329-341, 1993.

SCHMIDT, L.E.; DALHOFF, K. Food-drug interactions. Drugs, v.62, n.10, p.1481-1502, 2002.

SCHUG, B.S.; BRENDEL, E., CHANTRAINE, E., WOLF, D., MARTIN, W., SCHALL, R., BLUME, H.H. The effect of food on the pharmacokinetics of nifedipine in two slow release formulations: pronounced lag-time after a high fat breakfast. Br. J. Clin. Pharmacol., v.53, p.582-588, 2002.

SEPPLE, C.P.; READ, N.W. Effect of prefeeding lipid on food intake and satiety in man. Gut, v.31, p.158-161, 1990. 
SHAH, A.; LIU, M.C.; VAUGHAN, D.; HELLER, A.H. Oral bioequivalence of three ciprofloxacin formulations following single-dose administration: 500 $\mathrm{mg}$ tablet compared with $500 \mathrm{mg} / 10 \mathrm{~mL}$ or $500 \mathrm{mg} / 5 \mathrm{~mL}$ suspension and the effect of food on the absorption of ciprofloxacin oral suspension. $J$. Antimicrob. Chemother., v.43, suppl.A, p.49-54, 1999.

SHAH, J.; FRATIS, A.; ELLIS, D.; MURAKAMI, S.; TEITELBAUM, P. Effect of food and antacid on absorption of orally administered ticlopidine hydrochloride. J. Clin. Pharmacol., v.30, n.8, p.733-736, 1990.

SHOIE, P.A.; BRODIE, B.B.; HOGBEN, C.A.M. The gastric secretion of drugs: a pH partition hypothesis. J. Pharmcacol. Exp. Ther., v.119, p.361-369, 1957.

SIMPSON, K.H.; HICKS, F.M. Clinical pharmacokinetics of ondansetron. $J$. Pharm. Pharmacol., v.48, n.8, p.774-781, 1996.

SINGH, B.N. Effects of Food on Clinical Pharmacokinetics. Clin. Pharmacokinet., v.37, n.3, p.213-255, 1999.

SINGH, B.N.; MALHOTRA, B.K. Effects of food on the clinical pharmacokinetics of anticancer agents: underlying mechanisms and implications for oral chemotherapy. Clin. Pharmacokinet., v.43, n.15, p.1127-1156, 2004.

SORENSEN, J.M. Herb-drug, food-drug, nutrient-drug, and drug-drug interactions: mechanisms involved and their medical implications. J. Altern. Complement. Med., v.8, n.3, p.293-308, 2002.

STORPIRTIS, S. Biofarmacotécnica: fundamentos de biodisponibilidade, bioequivalência: dissolução e intercambialidade de medicamentos genéricos. São Paulo, 1999. 78p.

STORPIRTIS, S.; CONSIGLIERI, V.O. Bioequivalência de medicamentos: objetivos, parâmetros farmacocinéticos, delineamento experimental e critérios de avaliação. Rev. Bras. Cienc. Farm., São Paulo, v.36, n.1, p.13-21, 2000 .

TSCHANZ, C.; STARGEL, W.W.; THOMAS, J.A. Interactions between drugs and nutrients. Adv. Pharmacol., v.35, p.1-26, 1996.

TYRER, J.H.; EADIE, M.J.; SUTHERLAND, J.M.; HOOPER, W.D. Outbreak of anticonvulsant intoxication in an Australian city. Br. Med. J., v.4, p.271273,1970 .

UNITED STATES Pharmacopeia: USP28: The National Formulary: NF19. Rockville: The United States Pharmacopeial Convention, 2005. 3187p. 
UNITED STATES. Department of Healthy and Human Services. Food and Drug Administration. Center for Drug Evaluation and Research. Guidance for industry: SUPAC-MR: modified release solid oral dosage forms. Rockville, 1997. 52p.

UNITED STATES. Department of Healthy and Human Services. Food and Drug Administration. Center for Drug Evaluation and Research. Guidance for industry: food-effect bioavailability and fed bioequivalence studies. Rockville, 2002. 12p.

UNITED STATES. Department of Healthy and Human Services. Food and Drug Administration. Center for Drug Evaluation and Research. Guidance for industry: bioavailability and bioequivalence studies for orally administered drug productos - general considerations. Rockville, 2002. 26p.

UNITED STATES. Department of Healthy and Human Services. Food and Drug Administration. Center for Drug Evaluation and Research. Approved drug products with therapeutic equivalence evaluations. Rockville, 2005. Disponível em: http:/www.fda.gov/cder/orange/default.htm. Acesso em: 15 jul. 2005.

UNITED STATES. Food and Drug Administration. Bioequivalence requirements and in vivo bioavailability procedures. Fed. Reg., v.42, p.1624-1653, 1977.

VUELTA, M.; BARROSO, E.; SORA, M. Interacciones alimentosmedicamentos. Enferm. Intensiva, v.8, n.1, p.54-58, 1997.

WAGNER, J.G. Biopharmaceutics and relevant pharmacokinetics. Hamilton: Drug Intelligence Publications, 1971.p.12.

WALDMAN, S.A.; MORGANROTH, J. Effects of food on the bioequivalence of different verapamil sustained-release formulations. J. Clin. Pharmacol., v.35, n.2, p.163-169, 1995.

WALLACE, A.W.; AMSDEN, G.W. Is it really ok to take this with food? Old interactions with a new twist. J. Clin. Pharmacol., v.42, p.437-443, 2002.

WALTER-SACK, I.; KLOTZ, U. Influence of diet and nutritional status on drug metabolism. Clin. Pharmacokinet., v.31, n.1, p.47-64, 1996.

WASHINGTON, N.; WASHINGTON, C.; WILSON, C.G. Physiological pharmaceutics, barriers to drug absorption. 2.ed. London: Taylor and Francis, 2001. 312p.

WELAGE, L.S.; KIRKING, D.M; ASCIONE, F.J.; GAITHER, C.A. Understanding the scientific issues embedded in the generic drug approval process. J. Am. Pharm. Assoc., v.41, n.6, p.856-867, 2001. 
WELLING, P.G. Effects of food on drug absorption. Annu. Rev. Nutr., v.16, p.383-415, 1996.

WELLING, P.G. Influence of food and diet on gastrointestinal drug absorption: a review. J. Pharmacokinet. Biopharmacol., v.5, p.291-334, 1977.

WELLING, P.G.; TSE, F.L.S.; DIGHE, S.V. Pharmaceutical bioequivalence. New York: Marcel Dekker, 1991. 467p.

ZIMMERMANN, T.; YEATES, R.A.; LAUFEN, H.; PFAFF, G.; WILDFEUER, A. Influence of concomitant food intake on the oral absorption of two triazole antifungal agents, itraconazole and fluconazole. Eur. J. Clin. Pharmacol., v.46, n.2, p.147-150, 1994. 